Florida International University FIU Digital Commons

\title{
Parental Attitudes, Beliefs and Behaviors about Caries Prevention among Black Preschool Children
}

Rachel Clarke

Florida International University, rachelclarke22@gmail.com

DOI: 10.25148 /etd.FIDC001749

Follow this and additional works at: https://digitalcommons.fiu.edu/etd

Part of the Public Health Education and Promotion Commons, and the Social and Behavioral Sciences Commons

\section{Recommended Citation}

Clarke, Rachel, "Parental Attitudes, Beliefs and Behaviors about Caries Prevention among Black Preschool Children" (2017). FIU Electronic Theses and Dissertations. 3223.

https://digitalcommons.fiu.edu/etd/3223 


\title{
FLORIDA INTERNATIONAL UNIVERSITY
}

Miami, Florida

\section{PARENTAL ATTITUDES, BELIEFS AND BEHAVIORS ABOUT CARIES PREVENTION AMONG THEIR BLACK PRESCHOOL CHILDREN}

\author{
A dissertation submitted in partial fulfillment \\ of the requirements for the degree of \\ DOCTOR OF PHILOSOPHY \\ in \\ PUBLIC HEALTH \\ by \\ Rachel D. Clarke
}

2017 
To: $\quad$ Dean Tomás R. Guilarte, Ph.D

Robert Stempel College of Public Health and Social Work

This dissertation, written by Rachel D. Clarke, entitled Parental Attitudes, Beliefs and Behaviors about Caries Prevention among Their Black Preschool Children having been approved in respect to style and intellectual content, is referred to you for judgment.

We have read this dissertation and recommend that it be approved.

Elena Bastida

Florence George

Kathryn Hartlieb

H. Virginia McCoy

Mary Shaw, Major Professor

Date of Defense: March 23, 2017

The dissertation of Rachel D. Clarke is approved

Dean Tomás R. Guilarte Robert Stempel College of Public Health and Social Work

Andrés G. Gil Vice President for Research and Economic Development and Dean of the University Graduate School

Florida International University, 2017 
(C) Copyright 2017 by Rachel D. Clarke

All rights reserved. 


\section{DEDICATION}

I am dedicating this dissertation to my mother and to the memory of my father. They have influenced my interest in health and health care. Without my mother I would not be here today. 


\section{AKNOWLEDGMENTS}

I would like to acknowledge Dr. Mary Shaw, Dr. Elena Bastida, Dr. Virginia

McCoy, Dr. Florence George, and Dr. Kathryn Hartlieb. The aforementioned members of my committee have provided guidance, and advice during the dissertation process, and have been patient throughout. I would also like to thank members of the Public Health faculty for their guidance and advice, special mention is extended to Dr. Rashida Biggs and Dr. Kristopher Fennie.

I would like to specially acknowledge the Department of Health Promotion and Disease Prevention for providing me with a Graduate Assistantship. This assistantship provided financial support, which allowed me to focus on my studies and to gain professional experience in my field. Finally, I would like to acknowledge my fellow graduate students who have assisted me in various ways, including data collection, data analysis, and providing moral support. 


\title{
ABSTRACT OF THE DISSERTATION \\ PARENTAL ATTITUDES, BELIEFS AND BEHAVIORS ABOUT CARIES \\ PREVENTION AMONG BLACK PRESCHOOL CHILDREN
}

\author{
by \\ Rachel D. Clarke \\ Florida International University, 2017 \\ Miami, Florida \\ Professor Mary Shaw, Major Professor
}

Tooth decay is one of the most common chronic conditions that affect children in the U.S. Non-Hispanic Blacks are among the children facing the greatest racial and ethnic disparities in caries experience and treatment. Parents play a significant role in ensuring the success of preventative measures aimed at reducing prevalence of early childhood caries. It is therefore important for public health professionals to understand the oral health, attitudes, beliefs, and behaviors of Black parents in order to effectively design and tailor interventions for caries prevention among preschool children.

The twofold purpose of this study was to: (a) determine whether attitudes, beliefs of Black parents predict behaviors about preventative measures against caries for their preschool children, and (b) determine whether the attitudes and beliefs about caries preventive behaviors vary between different ethnic groups of Blacks in Miami-Dade County.

The cross sectional study utilized an oral health survey comprised of a modified version of the CDHQ, and the Nutrition Questionnaire for Children to examine attitudes, 
beliefs and behaviors of Black parents. The study sample included 192 African

American, Haitian, and Afro-Caribbean parents of 3-5 year-old children in Miami-Dade County.

Logistic regression and Chi Square analysis were used to answer the research questions and hypotheses. Perceived seriousness of decay, parental efficacy to brush child's teeth, and chance control are significant predictors of children using toothpaste and parents brushing children's teeth twice a day $(p<0.05)$. Chance control, parental efficacy to control sugar snacking, attitude towards prevention and intention to control sugar snacking were all significant predictors of sugar snacking behaviors $(p<0.05)$. Between group differences were observed for 4 of the oral health attitudes examined.

Health educators can play a major role in designing and delivering quality oral health and disease prevention interventions for parents of preschoolers. Clearly there are opportunities to complement school-based oral health education for preschool children with a culturally appropriate parental component. The between group differences indicate that interventions need to be more specifically tailored to the racial/ethnic group intended to receive the intervention in order to have greater effectiveness. 


\section{TABLE OF CONTENTS}

CHAPTER

PAGE

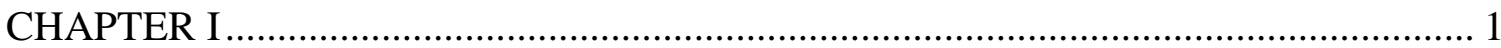

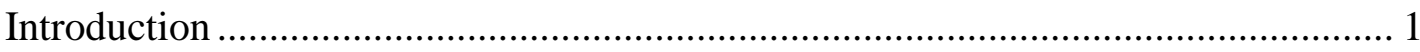

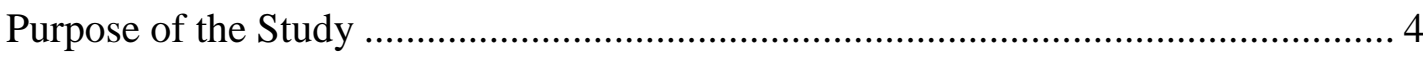

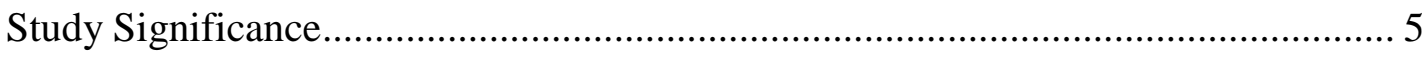

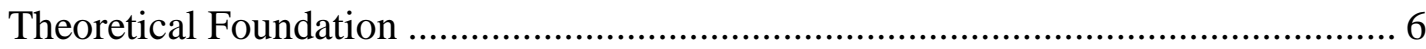

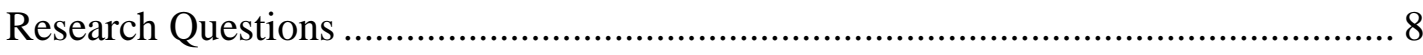

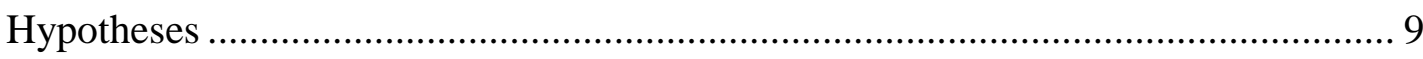

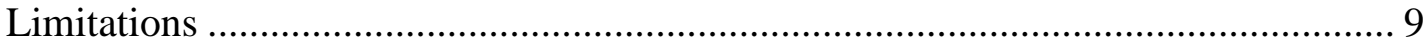

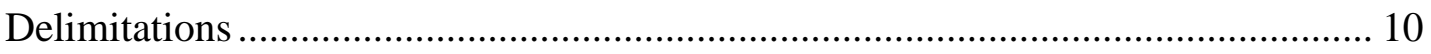

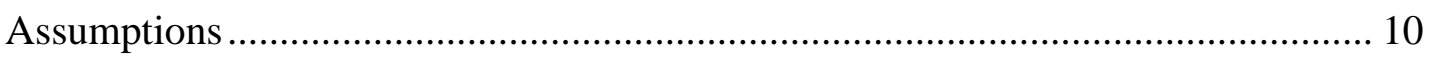

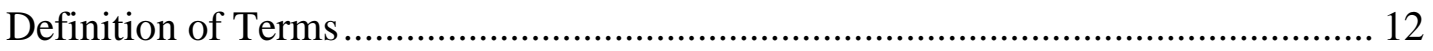

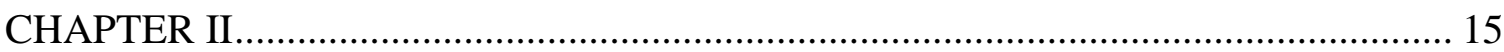

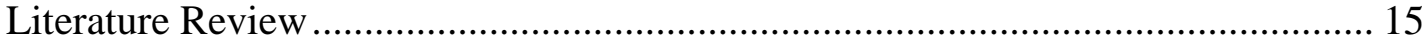

Literature Review Methodology ............................................................... 15

Caries Prevalence in the United States ......................................................... 16

Oral Health Promotion and Disease Prevention Perspectives ........................ 17

Oral Health Disparities ............................................................................... 18

Oral Health, General Health, and Quality of Life......................................... 20

Oral diseases, poor oral health, and chronic diseases ................................... 22

Parental Factors Influencing Children's Oral Health .................................... 26

Childhood oral health interventions................................................................ 30

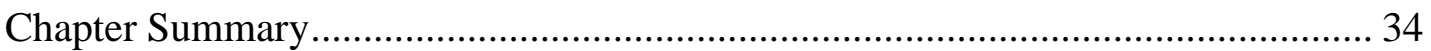

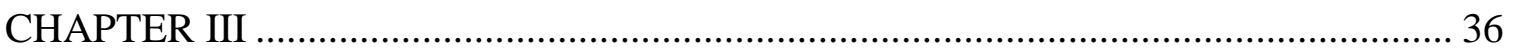

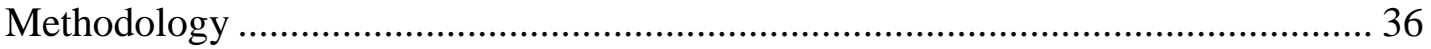

Population and Sample .............................................................................. 36

Protection of Human Participants .............................................................. 37

Data Collection Procedures ............................................................................. 38

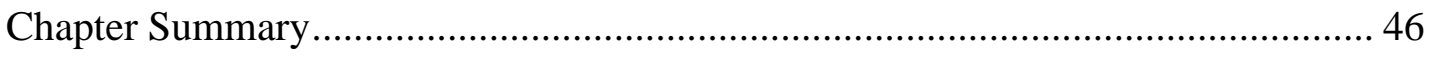

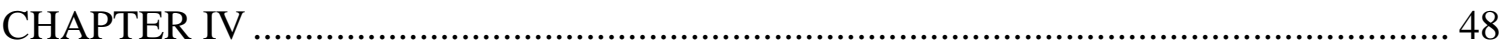

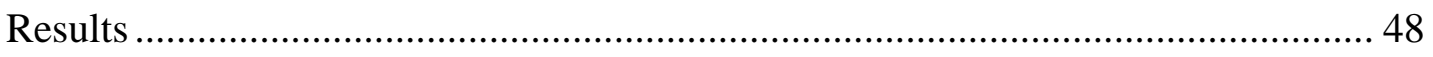

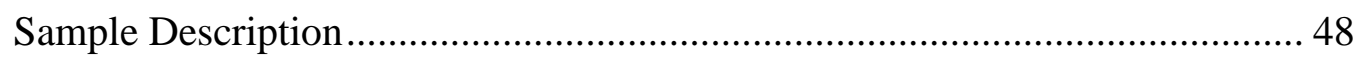

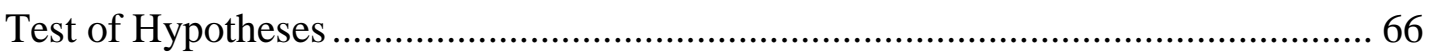




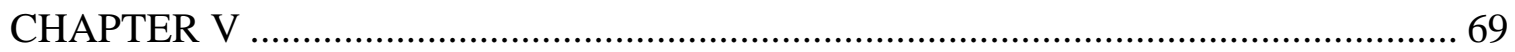

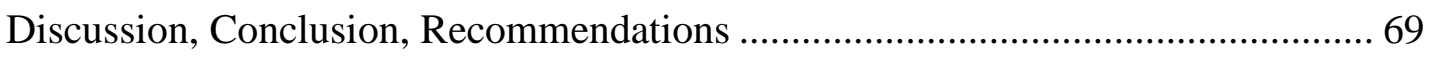

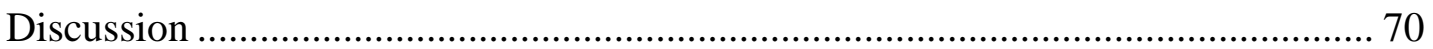

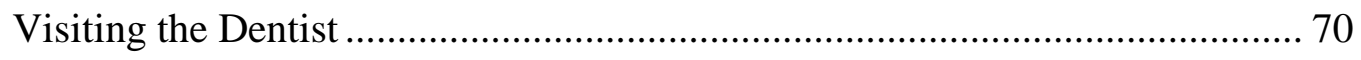

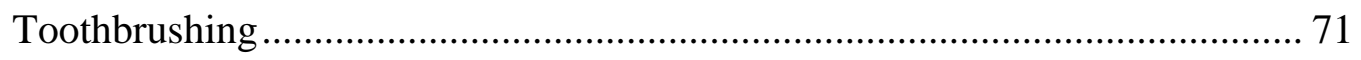

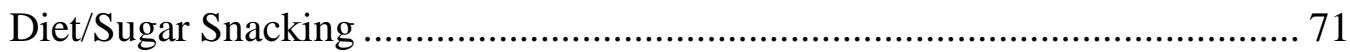

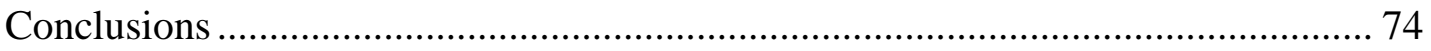

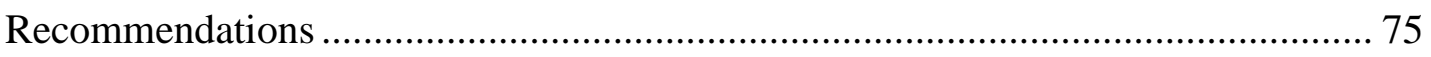

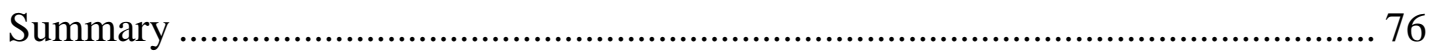

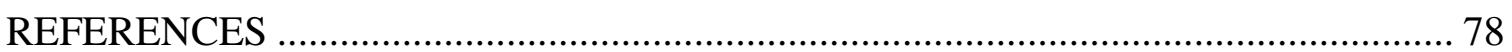

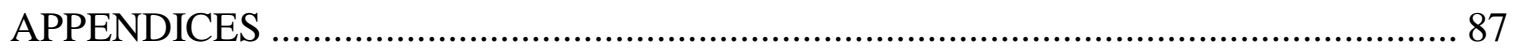

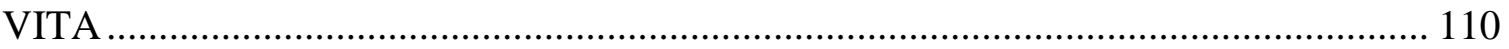




\section{LIST OF TABLES}

TABLE

PAGE

1. Table showing relationship between theory of planned behavior and study variables

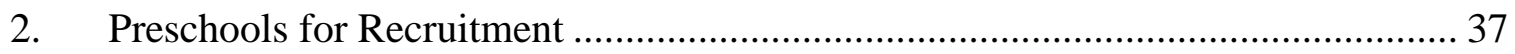

3. Detailed Demographics of Sample Population..................................................... 49

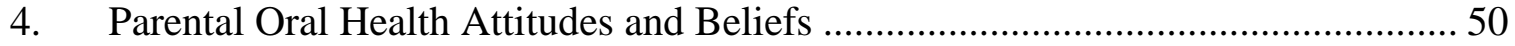



6. Logistic regression examining relationships between oral health attitudes and

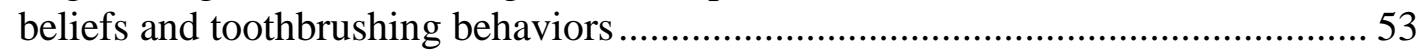

7. Logistic regression examining the relationship between oral health attitudes and beliefs and toothbrushing behaviors, controlling for gender, ethnicity and age.

8. Logistic regression examining the relationship between oral health attitudes and beliefs and toothbrushing behaviors, controlling for income, mother's education level, father's education level

9. Logistic regression examining the relationship between oral health attitudes and beliefs and toothbrushing behaviors, controlling for gender, ethnicity, age, income, mother's education level, father's education level........................... 56

10. Table showing logistic regression for oral health attitudes and beliefs and predicting sugar snacking/diet behaviors

11. Table showing logistic regression for oral health attitudes and beliefs and predicting sugar snacking/diet behaviors, controlling for gender and ethnicity and age

12. Table showing logistic regression for oral health attitudes and beliefs predicting sugar snacking/diet behaviors, controlling for gender and ethnicity and age and income and mother and father education level....

13. Table showing logistic regression for oral health attitudes and beliefs predicting sugar snacking/diet behaviors, controlling for income and mother and father education level

14. Chi Square showing between group differences in attitudes.

15. Chi Square Post Hoc Analyses for between group differences 66 


\section{ABBREVIATIONS AND ACRONYMNS}

\begin{tabular}{ll} 
AAPD & American Academy of Pediatric Dentistry \\
ADA & American Dental Association \\
AND & The Academy of Dietetics and Nutrition \\
AIDS & Acquired immune deficiency syndrome \\
ASTDD & Association of State and Territorial Dental Directors \\
CDC & Center for Disease Control and Prevention \\
CDHQ & International Collaborative Study on Child Dental Health Questionnaire \\
CNQ & The Child Nutrition Questionnaire \\
ECC & Early Childhood Caries \\
ECP & Extended Care Permit \\
ECOHIS & The early childhood health impact scale \\
HIV & Human immunodeficiency virus \\
IOM & Institute of Medicine \\
MSFW & Migrant and seasonal farm workers \\
NIDCR & National Institute of Dental and Craniofacial Research \\
OHRC & National Maternal and Child Health Resource Center \\
SES & Socioeconomic status \\
TPB & Theory of Planned Behavior \\
U.S. & United States \\
USDHHS & United States Department of Health and Human Services \\
WHO & World Health Organization \\
\hline
\end{tabular}




\section{CHAPTER I}

\section{Introduction}

Oral diseases qualify as major public health problems due to their high prevalence and incidence in all regions of the world (Petersen, 2003). Dental caries, a common oral disease, affects 60 - 90\% of school-aged children globally (Petersen, Bourgeois, Ogawa, Estupinan-Day, \& Ndiaye, 2005; World Health Organization [WHO], 2012). It is one of the most common chronic conditions that affect children in the United States (U.S.), although it is largely preventable (Centers for Disease Control and Prevention [CDC], 2014).

Dental caries and other oral diseases are linked to non-communicable diseases, e.g. obesity \& diabetes, mainly because of similarity in risk factors (Petersen et al., 2005). The mouth and facial area, free of pain and oral diseases or disorder, usually indicate good oral health, which is important to general health and quality of life (WHO, 2012; WHO, 2017). Due to the separation of medicine and dentistry, the significant implications of untreated oral diseases in children may often be overlooked (Mouradian, Wehr, \& Crall, 2000).

Oral health promotion and disease prevention measures may support the population in maintaining good oral health and by extension good health overall. For children aged $3-6$ years these measures include: limiting foods and drinks high in sugar, maintaining a balanced diet, brushing twice a day with a child size toothbrush and a pea sized amount of fluoride toothpaste, flossing if two teeth are touching, fluoride treatment, 
and visiting the dentist (American Academy of Pediatric Dentistry [AAPD], 2013; Mouth Healthy, 2017).

Early oral health care is important since the foundation for a lifetime of preventative education and dental care is laid in early childhood (Bahuguna, Jain, \& Khan, 2011). Research has also shown that the oral health of pre-school children is dependent upon the attitudes and behaviors of their parents towards oral health (Chhabra \& Chhabra, 2012; Saied-Moallemi, Virtanen, Ghofranipour, \& Murtomaa, 2008) with parents playing a significant role in ensuring the success of preventative measures and the prevention of early childhood caries (Chu, 2006). Specifically, children are more likely to have better dental health behaviors and outcomes if their mothers have positive attitudes toward oral health (Saied-Moallemi et al., 2008).

Despite reported improvements in oral health in recent years, many disparities exist, especially for groups with lower socioeconomic status (SES) in both developing and developed countries (Petersen et al., 2005). Oral disease in children and adults is greater among lower socioeconomic groups, new immigrants, and children (Bagramian, Garcia-Godoy, \& Volpe, 2009; WHO, 2012).

In the U. S., non-Hispanic Black children are among those who carry a disproportionate burden of oral health disparities when compared to other racial/ethnic groups (CDC, 2015). Despite the ethnic diversity among Blacks residing in the U.S., research addressing their health outcomes has not yet considered their ethnic differences (Agyemang, Bhopal, \& Bruijnzeels, 2005). According to Agyemang et al. (2005), ethnic populations within the Black race are often not clearly defined and the fundamental 
concepts underlying ethnic classifications are poorly understood (Agyemang et al., 2005). Black populations may include people from the West Indies, Haiti, and various parts of Africa (Agyemang et al., 2005).

These different groups of Blacks have distinct beliefs, behaviors, risk factors, disease experience and access and utilization of health services (Agyemang et al., 2005). The varying utilization of health services by Blacks cannot be properly addressed if all Black populations are considered as a single homogenous group (Agyemang et al., 2005). In many instances, immigrants from the Caribbean and other parts of the world may be grouped with African Americans and Africans under the category "Black" (Agyemang et al., 2005). This, however, prevents an understanding of the ethnic differences, which in turn, affects health outcomes, particularly oral health disparities affecting Black children (Agyemang et al., 2005).

Immigration may lead to even more complexities, as it leads to a larger number of ethnic groups, and recent immigrants also have to deal with the complexities of adjusting to the culture and norms in their new home (Schwartz, Unger, Zamboanga, \& Szapocznik, 2010). According to the U.S. Census Bureau 2014 American Community Survey (ACS), there were about 4 million Caribbean immigrants living in the U.S. in 2014 and approximately 40\% (1.6 million) of them reside in Florida (Zong \& Batalova, 2016). New immigrants may experience cultural barriers, lack of financial resources, and inabilities to successfully navigate the unfamiliar health care system, which can hinder access to appropriate dental care (Rowan-Legg, 2013). 
Improving the oral health of Black children aligns with two of the oral health goals of Healthy People 2020 (Healthy People 2020, 2017), a national health promotion and disease prevention initiative. These are: a) to reduce the proportion of young children aged $3-5$ with dental caries experience in their primary teeth; and b) to reduce the proportion of young children aged $3-5$ with untreated tooth decay in their primary teeth (Healthy People 2020, 2017). Since the oral health of pre-school children is dependent upon the attitudes and behaviors of their parents towards oral health (Chhabra \& Chhabra, 2012), it is important to understand what characterizes the attitudes, beliefs, and behaviors about caries prevention among ethnically diverse Black parents of preschool children $(3-5$ years $)$.

The existing literature does not adequately explain attitudes, beliefs, and behaviors about caries preventative behaviors of Black parents of preschool children (35 years). Specifically, the literature does not differentiate between different Black ethnic groups. This study provides new knowledge that can be put into action by public health agencies and health educators to improve the oral health and well-being of preschool children. The knowledge gained may also be utilized to augment evidence-based interventions such as those for childhood obesity prevention since oral health and nutrition are intimately linked.

\section{Purpose of the Study}

The purpose of this exploratory study was to (a) examine the attitudes, beliefs, and behaviors of Black parents about preventative measures against caries for their preschool children (3-5 years) and (b) determine whether the attitudes and beliefs about 
caries preventive behaviors vary between different ethnic groups of Blacks in MiamiDade.

\section{Study Significance}

Dental caries, affects 60-90\% of school-aged children globally (Petersen et al., 2005; WHO, 2012). In the U.S., 33\% of children ages 5 - 19 have untreated caries on at least 1 tooth $(\mathrm{CDC}, 2014)$. In addition to the high prevalence of oral diseases, they are very expensive to treat, making them a significant public health problem (Sheiham, 2005). According to the Surgeon General report, the impact of oral diseases is even more significant among poorer children, who experience higher rates of caries and are unable to afford treatment (United States Department of Health and Human Services [USDHHS], 2000). Furthermore, tooth decay, which is among the leading chronic diseases in children (CDC, 2014), is linked to chronic diseases including obesity and diabetes; while other chronic diseases such as cardiovascular disease may present with oral symptoms (USDHHS, 2000). Since poor oral health has the ability to cause pain, affect one's self-esteem, and have a negative impact on an overall quality of life (Association of State and Territorial Dental Directors [ASTDD], 2011); maintaining optimal oral health throughout the life course is an important public health issue.

The results of this study provide essential knowledge that can be employed by public health dentists and dental health promotion professionals to effectively tailor oral health interventions, and ultimately eliminate the existing oral health disparities among Black children. Moreover, public health agencies and health educators can use this information to integrate oral health disease promotion and disease program with obesity 
prevention initiatives to improve overall health of poor and medically underserved, ethnically diverse Black children.

\section{Theoretical Foundation}

The study was guided by the Theory of Planned Behavior (TPB) (Ajzen, 1991). TPB examines the relationship between an individual's beliefs, attitudes, intentions, perceived control over the behavior, actual control over the behavior and the behavior. In this study, the TPB was used to analyze attitudinal, belief, parental efficacy and intention items associated with caries prevention behaviors.

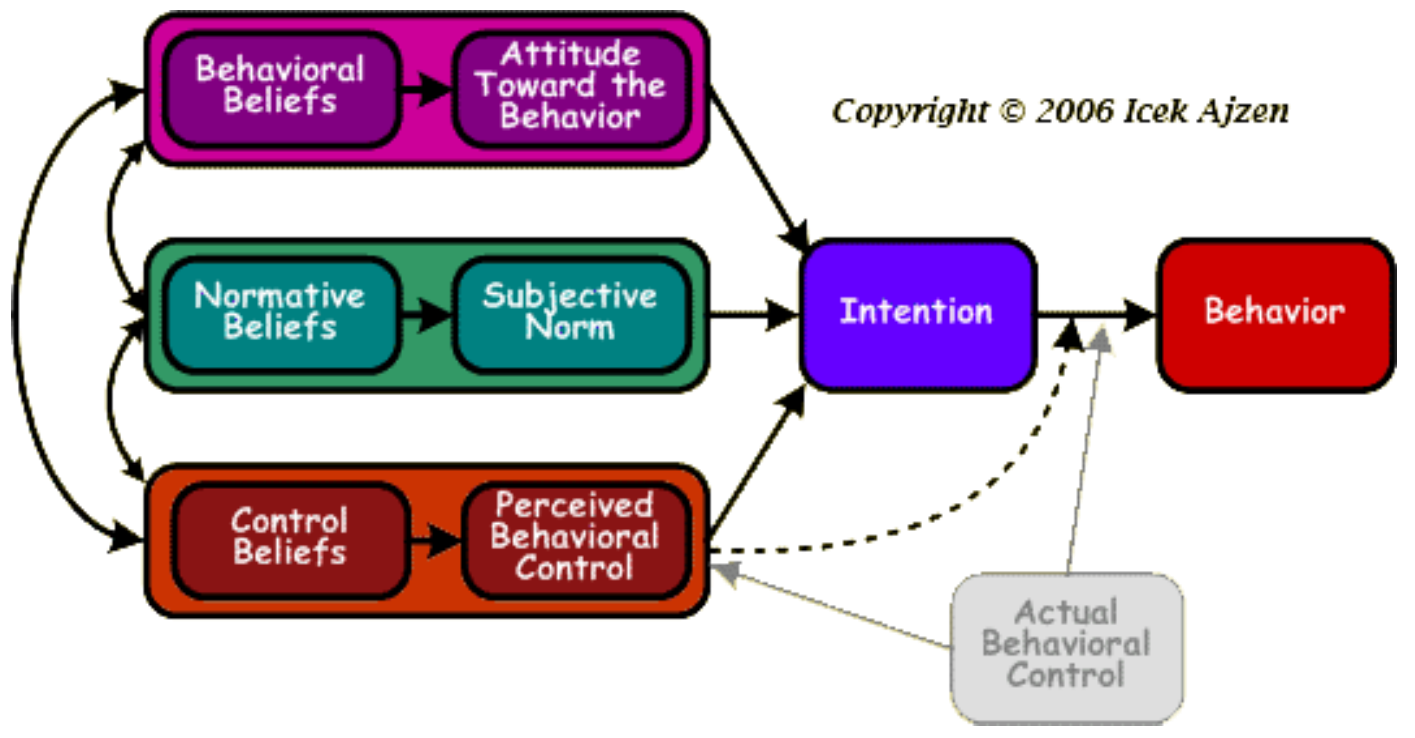

Figure $1 \quad$ Theory of Planned Behavior Diagram. (Ajzen, 2006) 
Table 1

Table showing relationship between theory of planned behavior and study variables

\begin{tabular}{|l|l|}
\hline TPB Construct & Study Variable \\
\hline Control Beliefs & Chance Control \\
\hline Attitude towards Behavior Control & Attitudes to Prevention \\
\hline Normative Beliefs & Perceived Seriousness of Decay \\
\hline Intention & $\begin{array}{l}\text { Importance and Intention to brush child's teeth } \\
\text { Importance and Intention to control sugar snacking }\end{array}$ \\
\hline Actual Behavioral Control & $\begin{array}{l}\text { Parental efficacy to control sugar snacking } \\
\text { Parental efficacy in relation to child toothbrushing }\end{array}$ \\
\hline Behaviors & $\begin{array}{l}\text { Child has visited the dentist, child has received a fluoride treatment, child } \\
\text { uses toothpaste, child eats sweets or candy most days, child eats sugary } \\
\text { foods between meals most days, child drinks soft drinks containing sugar } \\
\text { most days, child eats fruit most days, child eats vegetables most days, child } \\
\text { drinks in bed, child eats in bed, child brushes teeth twice daily, parent } \\
\text { brushes child's teeth twice daily }\end{array}$ \\
\hline
\end{tabular}

For this study control beliefs (external control and chance control), normative beliefs (perceived seriousness of decay), attitude towards behavior (attitude to prevention), intention (importance and intention to brush child's teeth and importance and intention to control sugar snacking) and actual behavioral control (parental efficacy to control sugar snacking and parental efficacy in relation to toothbrushing) were operationalized as the independent variables. Behaviors including child has visited the dentist, child has received a fluoride treatment, child uses toothpaste, reducing foods and drinks high in sugars, maintaining a balanced diet (fruits and vegetables), and child's 
teeth being brushed twice a day were the dependent variables. Behavioral beliefs, subjective norm and perceived behavioral control were not operationalized for the purpose of this study. Constructs used have been highlighted in Figure 2 below; those not used can be identified by the grey color.

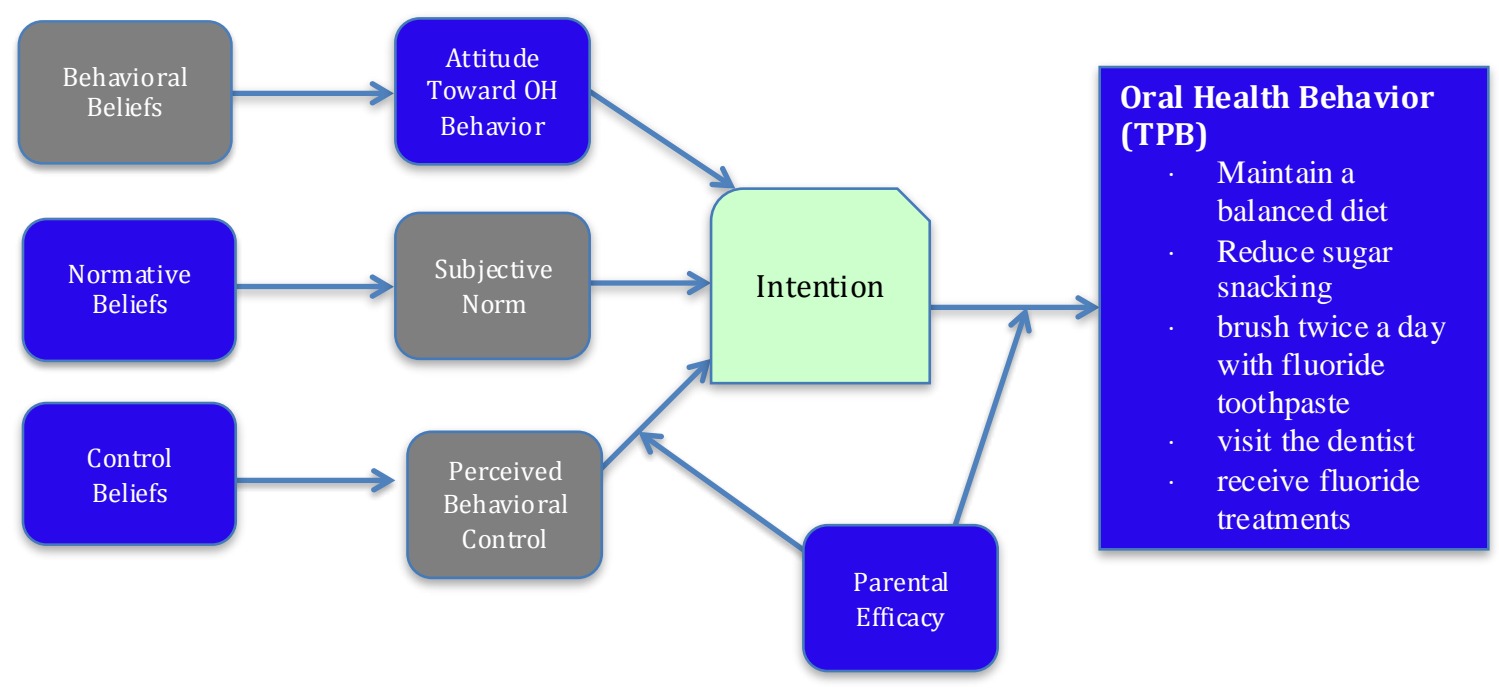

Figure 2 Application of TPB to explore parental perceptions towards caries prevention behaviors for preschool children. (National Cancer Institute (U.S.), 1995)

\section{Research Questions}

The following research questions and hypotheses guided the study:

1. What characterizes the attitudes, beliefs, and behaviors of Black parents about caries preventive behaviors for their preschool children?

2. What are the ethnic group differences in attitudes and beliefs about caries preventive behaviors among Blacks in Miami-Dade? 


\section{Hypotheses}

Ho 1.1 There is no relationship between attitudes and beliefs of Black parents about toothbrushing and toothbrushing behaviors for their preschool children.

Ho 1.2 There is no relationship between attitudes and beliefs of Black parents towards taking their preschool children to the dentist and parents taking their preschool children to the dentist.

Ho 1.3 There is no relationship between attitudes and beliefs of Black parents towards sugar snacking and sugar snacking behaviors for their preschool children.

Ho 2.1 There are no between-group differences in attitudes and beliefs about visiting the dentist among Black parents for their preschool children in the U.S.

Ho 2.2 There are no between-group differences in attitudes and beliefs about toothbrushing among Black parents for their preschool children in the U.S.

Ho 2.3 There are no between-group differences in attitudes and beliefs about sugar snacking among Black parents for their preschool children in the U.S.

\section{Limitations}

The study was limited by the following:

1. Only English-speaking participants were included, therefore the study cannot be generalized to all Haitians in the Miami-Dade area.

2. The small sample sizes limits generalizability to all Blacks.

3. Non-probability purposive sampling may not provide a representative sample of African Americans, Afro Caribbean, and Haitians living in Miami-Dade. 
4. Cross sectional study design may limit study findings to associations.

5. Only African American, Afro-Caribbean, and Haitians were included in the study.

6. Participants may not have accurately recalled some of the information requested.

7. Participants may have selected the response they considered to be correct instead of the one with which they actually agreed.

\section{Delimitations}

The study was delimited by the following:

1. Only schools in selected zip codes were included.

2. Only Black participants who were parents/guardians of preschool children ages $3-5$ years completed the survey.

3. Only African-American, Haitian and Afro-Caribbean Blacks were included in the between group analysis.

4. Only participants over 18 years of age were permitted to complete the survey.

\section{Assumptions}

The study made the following assumptions:

1. Parents/guardians of preschool children ages $3-5$ years had accurate knowledge of the children's oral health behaviors.

2. Parents/guardians of preschool children ages $3-5$ years understood the questions and answered honestly. 
3. Participants completing the survey were knowledgeable about their children's nutrition behaviors. 


\section{Definition of Terms}

Actual behavioral control. This phrase is defined as "the extent to which a person has the skills, resources, and other prerequisites needed to perform a given behavior" (Azjen, 2006).

African American. This phrase is defined as "an American who has African and especially black African ancestors” (Merriam-Webster Dictionary).

Afro-Caribbean. This phrase is defined as "a person of African descent living in or coming from the Caribbean" (Oxford Dictionaries).

Attitude. This term is defined as (a) “a person's beliefs about what will happen if he or she performs the behavior", and (b) “a person's judgment of whether the expected outcome is good or bad" (Edberg, 2015).

Behavior. This term is defined as the manifest, observable response in a given situation with respect to a given target” (Ajzen, 2006).

Behavioral Belief. This phrase is defined as "the subjective probability that the behavior will produce a given outcome" (Azjen, 2006).

Belief. This term is defined as "the subjective probability of a relation between the object of belief and some other object, value, concept, or attribute" (Fishbein \& Ajzen, 1975)

Black. This term is defined as "people of black or dark skinned race of mankind. The term covers a wide range of ethnic and cultural backgrounds" (Agyeman et al., 2005). 
Caries Prevention for Children. This phrase is defined as a balanced diet, limiting foods high in sugar, brushing twice a day with a child size toothbrush and fluoride toothpaste, flossing (if two teeth are touching), fluoride treatment, and visiting the dentist (Mouth Healthy, 2017).

Control Belief. This phrase is defined as "the perceived presence of factors that may facilitate or impede performance of a behavior (Ajzen, 2006).

Dental Caries or cavities (Tooth decay). This phrase is defined as "caries is a chronic, transmissible disease caused by bacteria using sugar to create an acidic environment that erodes teeth. Over time this process leads to holes (cavities) in the tooth's structure" (Silk, 2014).

Disease Prevention. This phrase is defined as "activities designed to protect patients or other members of the public from actual or potential oral health threats and their harmful consequences" (Mosby’s Medical Dictionary, 2009).

Ethnic Groups. This phrase is defined as "subgroups within a larger cultural or social order that are distinguished from the majority and each other by their national, religious, linguistic, cultural, and sometimes racial background" (ERIC Thesaurus).

Haitian. This term is defined as "a native or inhabitant of Haiti" (MerriamWebster Dictionaries).

Health Promotion. This phrase is defined as "the process of enabling people to increase control over, and to improve their health" (WHO).

Intention. This phrase is defined as "an indication of a person's readiness to perform a given behavior and is considered to be the immediate antecedent of behavior" (Azjen, 2006). 
Normative Beliefs. This phrase is defined as "the perceived behavioral expectations of such important referent individuals or groups as the person's spouse, family, friends, and - depanding on the population studied - teacher, doctor, supervisor, and coworkers" (Azjen, 2006).

Perceived Behavioral Control. This phrase is defined as “a person's beliefs about factors that will make it easy or difficult to perform the behavior" (Edberg, 2015).

Subjective norm. This phrase is defined as (a) “a person's beliefs about what other people in his or her social group will think about the behavior, and (b) a person's motivation to conform to these perceived norms" (Edberg, 2015).

Sugar Snacking. This phrase is defined as consuming snacks and beverages high in sugars between meals. 


\section{CHAPTER II}

\section{Literature Review}

This chapter represents a comprehensive literature review about (a) the current state of childhood caries in the U.S.; (b) the importance of caries prevention; and (c) parenting roles for improving oral health, specifically the reduction of caries in children. The review uncovers the need for greater emphasis on reducing the rates of caries among children in the U.S., particularly those from socioeconomically disadvantaged backgrounds.

\section{Literature Review Methodology}

The review of the literature was conducted using PubMed, CINAHL, and Google Scholar. Key words used included: “Oral Health”, "Dental Health”, "Health Education, Dental”, "Fluorides”, “Oral Hygiene”, “Oral Disease”, “Cavities”, “Caries”, “Toothbrush”, “Dentist”, “Parents”, “Knowledge”, “Attitude”, “Belief”, “perception”, "Child, preschool", "African American", and "Black". These key words were searched independently as well as in various combinations, the final combination included all key words together. Specific search terms for different databases were identified before conducting the search and were added to key terms to broaden the search. Relevant research published from 1995 to present was included.

This literature review covers six topic areas: (a) caries in the United States (b) oral health promotion and disease prevention perspectives, (c) oral health disparities, (d) oral health, general health, and quality of life, (e) parental factors influencing children's oral health and (f) oral health interventions. 


\section{Caries Prevalence in the United States}

Despite a reduction in the prevalence of dental caries in permanent teeth for many children since the 1960s, previous findings have shown an increase in caries in primary teeth from 24\% to $28 \%$ between 1988 and 2004 (Dye, Thornton-Evans, Li, \& Iafolla, 2015). Between 2011 and 2012, approximately 37\% of children aged $2-8$ years had experienced dental caries in their primary teeth, and $14 \%$ of these children had untreated tooth decay in their primary teeth (Dye et al., 2015). Caries among those $2-5$ years old were less than half than for those $6-8$ years old, 23\% compared to 56\% (Dye et al., 2015). Ten percent of children $2-5$ years old, and $20 \%$ of children $6-8$ years old had untreated tooth decay (Dye et al., 2015). Between 2011 and 2012, 21\% of 6 - 11 year olds had experienced dental caries in permanent teeth; this prevalence was $14 \%$ for those $6-8$ years old and $29 \%$ for those $9-11$ years old. Approximately $6 \%$ of this population had untreated tooth decay, with $3 \%$ in the $6-8$ age group and $8 \%$ in the $9-11$ age group (Dye et al., 2015). Among adolescents aged $12-19,58 \%$ had experienced dental caries in permanent teeth in 2011 - 2012. Untreated tooth decay was $12 \%$ for adolescents $12-$ 15 years old and 19\% for adolescents $16-19$ years old (Dye et al., 2015). The evidence presented shows that there is a significant oral health problem as it relates to caries experience among children and adolescents, and that something needs to be done to improve the oral health of children in the U.S. Additionally, it is clear that the caries problem becomes more severe as children move into their adolescent years. If children learn how to properly take care of their teeth in their early years they will potentially take those good oral health habits with them throughout life and prevent tooth decay and other oral diseases as they become older (Bahuguna et al., 2011). 


\section{Oral Health Promotion and Disease Prevention Perspectives}

It is important that improvements continue to be made in oral health promotion and prevention measures. The WHO has added a strategy for oral disease prevention and control to its strategy for prevention and control of non-communicable diseases, as it aims to improve oral health globally (Petersen, 2003). The 2013 - 2020 WHO global action plan for the prevention and control of non-communicable diseases continued to recognize the need for improved oral health (British Dental Journal News, 2013).

In the U.S, Surgeon General Benjamin (2010), asserted the importance of oral health and the need for oral health education programs. She emphasized the need for programs to increase awareness about the importance of oral health. The Healthy People 2020 oral health goal is to "prevent and control oral and craniofacial diseases, conditions, and injuries, and improve access to preventive dental services and care" (Healthy People 2020, 2017).

There has been a call for urgent strengthening of public health programs through worldwide improvements in oral health promotion and disease prevention (Petersen et al., 2005). Watt (2005) noted that there is a need for effective, evidence based programs to deal with oral diseases, which are a major public health problem. The importance of the inclusion of community organizations and non-governmental organizations in prevention of oral disease and health promotion has been recognized on a global level and on a national level (Petersen, 2003; USDHHS, 2000; USDHHS, 2003).

Oral health promotion and disease prevention strategies that are of great importance for improving oral health include: tooth brushing, use of fluoride, diet and 
nutrition, tobacco use, health promotion in schools, access to oral health care, oral health information systems and the need for further oral health research (Bagramian et al., 2009; Mouth Healthy, 2017; Institute of Medicine [IOM], 2011; Petersen, 2003).

\section{Oral Health Disparities}

While there have been significant improvements in oral health status, there are disparities that seriously impact socioeconomically disadvantaged groups in both developed and developing countries (Casamassimo, 2001; Petersen et al., 2005; USDHHS, 2003). The rates of caries are more than 5 times higher in developing countries than they are in developed countries (Chu, 2006).

The burden of dental disease is seen most among socioeconomically disadvantaged individuals including those from low-income families, new immigrants, and children with special needs (Rowan-Legg, 2013). This may have its greatest impact on those working without benefits, but unable to qualify for public assistance (RowanLegg, 2013). According to a review conducted by Chu (2006), Early Childhood Caries (ECC) most commonly occurs in poor minority populations, possibly due to caries being associated with familial socio-economic background, parental education and dental knowledge, and access to dental care.

Low-income children in the U. S. experience double the number of dental caries than their counterparts, with approximately $25 \%$ of children from poorer families experiencing $80 \%$ of total tooth decay cases (USDHHS, 2000; ASTDD, 2011). According to Dye, Li, \& Thornton-Evans (2012), percent of poverty level is a significant predictor of whether a child will have untreated dental caries. Furthermore, it has been 
reported that poorer children are three times more likely to have a dental problem for which they have not received care, and the probability that they have visited a dentist is low (Mouradian et al., 2000).

Receiving dental services is particularly important in early childhood since the consequences of poor oral health in this stage of life may have an impact throughout the lifetime (ASTDD, 2011). Unfortunately, this may not always be possible since access to dental healthcare is particularly difficult for poor and minority populations (IOM, 2011). Many children in low-income families are unable to visit a dentist due to the family's limited resources, dentists not accepting public insurance and a shortage of pediatric dentists (Vargas \& Ronzio, 2006). Another study revealed that 78\% of children in 4 states did not receive necessary dental care, despite being covered by Medicaid (Murrin, 2016). The study utilized Medicaid dental claims in 2011 and 2012, Medicaid beneficiary data, and data resulting from interviews with state officials in California, Indiana, Louisiana, and Maryland (Murrin, 2016). Study analyses were focused on required dental services including biannual oral exams, dental cleanings, and fluoride treatments (Murrin, 2016).

The inability of poor children to visit a dentist means that few, if any, children in these populations will be able to receive treatment for caries (Vargas \& Ronzio, 2006). The lack of treatment ultimately results in the children experiencing dental pain (Vargas \& Ronzio, 2006). The pain experienced due to early childhood caries may alter the ability of children to experience a high quality of life (Acharya \& Tandon, 2011; Filstrup et al., 2003; Naidu, Nunn, \& Donnelly-Swift, 2016). Poor children are the ones less likely to 
receive dental treatment and as a result are more likely to experience pain, they are the ones more likely to experience a diminished quality of life due to poor oral health.

\section{Oral Health, General Health, and Quality of Life}

"Oral health is a state of being free from chronic mouth and facial pain, oral and throat cancers, oral sores, birth defects such as cleft lip and palate, periodontal gum disease, tooth decay and tooth loss, and other disorders that affect the oral cavity" (WHO, 2017). Although oral health is often viewed separately from general health, it does have an impact on general health (Sheiham, 2005). Health is defined as "a complete state of physical, mental and social well-being and not merely the absence of disease or infirmity" (WHO, 2006). Maintaining a healthy mouth is important since it is necessary for bodily functions including breathing, biological/physical protection, eating/digestion, verbal communication, and a positive self-image (American Association of Endodontists [AAE], 2000; ASTDD, 2011). Many of these factors may affect an individual's quality of life, which is defined by the world health organization quality of life group (WHOQoL Group) (1998) as “individuals' perception of their position in life in the context of culture, and the value systems in which they live and in relation to their goals, expectations, standards and concerns. Quality of life is ranging concept affected in a complex way by the person's physical health, psychological state, level of independence, social relationships, personal beliefs and their relationship to salient features of the environment" (WHOQoL Group, 1998).

Children with Early Childhood Caries (ECC) are significantly more likely to have a lower oral health related quality of life than children without ECC (Filstrup et al., 
2003). The longitudinal study conducted by Filstrup et al. (2003) included 112 children ranging from $22-70$ months, 69 of them had ECC while 43 of them did not. The Michigan Oral Health Related Quality of Life Scale was utilized, with a version for children (completed by children 3+ years) and one for adults (Filstrup et al., 2003). Results for the impact of ECC on quality of life were consistent for both parents and children (Filstrup et al., 2003).

Alsumait et al. (2015) showed children with missing teeth or carious teeth experienced a decline in their oral health-related quality of life. Four hundred and forty 11 - 12 year old Kuwait school children participated in this study (Alsumait et al., 2015). The study utilized the Child's Perception Questionnaire, which assesses the influence of oral health on function, life-style activities, general sense of well-being, and relationship with others (Alsumait et al., 2015). Students with a greater number of decayed or missing teeth reported a lower quality of life; those with over 4 missing teeth stating that they had experienced emotional stress (Alsumait et al., 2015).

Abanto et al. (2011) conducted a comprehensive study investigating the impact of oral diseases and disorders on oral health-related quality of life of preschool children. The study was conducted among 260 parents and children in Brazil (Abanto et al., 2011). The Early Childhood Oral Health Impact Scale (ECOHIS) was used to collect data about symptoms, function, psychological, self-image/social interaction, parent distress, and family function (Abanto et al., 2011). In each area of data collected, and overall for the ECOHIS, the severity of early childhood caries showed a negative impact on oral health related quality of life (Abanto et al., 2011). 
Dental-related illnesses are responsible for altering individuals' ability to carry out regular activities since they may lead to pain, discomfort, sleepless nights, the need to take time off from school or work, and limitations in the ability to eat (Acs, Shulman, Wai Ng, \& Chussid, 1999; Touger-Decker \& Mobley, 2013). Studies have shown that children lose approximately 51.5 million hours at school annually due to dental-related illness (Abanto et al., 2011; Jackson, Vann, Kotch, Pahel, \& Lee, 2011; Sheiham, 2005, 2006; Watt, 2005). Lack of the ability to eat may further lead to lack of proper nutrition, problems with weight gain, growth and may adversely affect the child's quality of life (Acs et al., 1999; Sheiham, 2006). In addition to affecting quality of life, lack of proper nutrition may lead to, or be indicators of other systemic diseases.

\section{Oral diseases, poor oral health, and chronic diseases}

Oral diseases include dental caries, traumatic dental injury, periodontal disease, tooth loss, oral mucosal legions and oropharyngeal cancers, HIV/AIDS-related oral disease and cleft lip and palate (Abanto et al., 2010; Petersen et al., 2005; USDHHS, 2000). Oral conditions including disease, trauma and developmental defects may impact the mouths of young children (ASTDD, 2011).

Many oral diseases are linked to chronic diseases such as obesity \& diabetes mainly due to both diseases sharing some of the same lifestyle risk factors ( $\mathrm{Li}$, Kolltveit, Tronstad, \& Olsen, 2000; Petersen, 2003; Petersen et al., 2005; USDHHS, 2000). The mouth can reveal signs of nutritional deficiencies, and may provide warning signs for diabetes, cardiovascular disease and obesity, which may present with primary oral symptoms (USDHHS, 2000). 
Dental caries, another largely preventable oral disease, is a common chronic common disease worldwide and in the U. S., impacting $40 \%$ of children $2-11$ years old (CDC, 2014; Edelstein \& Chinn 2009; IOM, 2011). The most common oral disease experienced by preschool aged children is ECC; $25 \%$ of pre-school aged children have experienced tooth decay (ASTDD, 2011), and it is five times more common than asthma (USDHHS, 2000; Benjamin, 2010).

Early childhood caries. According to the American Dental Association (ADA) (2000), ECC is "the presence of one or more decayed, missing or filled tooth surfaces in any primary tooth in a preschool-aged child between birth and 71 months of age." Tooth decay is more common in primary teeth due to their thinner layer of enamel; any child who develops caries before they are six years old may experience serious damage to their teeth and, as a result, their well-being may be compromised (ASTDD, 2011).

ECC is an infectious process, the speed of which may be increased by excessive consumption of foods with a high sugar content (Chu, 2006; Rowan-Legg, 2013). In many instances, the bacteria that causes caries may be passed from mother to child or from child to child (Rowan-Legg, 2013; Kawashita, Kitamura, \& Saito, 2011). Caries may become worse as a child gets older if risk factors are not addressed (ASTDD, 2011).

Prevention of ECC. Preventative measures that may be taken to reduce early childhood caries include community, professional, and individual measures. Behavioral and educational programs that may lead to changes in individual behaviors, as well as early consultation with a dentist, will allow for the provision of oral health education in line with the child's developmental stage (ADA, 2000; Chu, 2006; Rowan-Legg, 2013). 
The guidelines of the ADA (2000) indicate that ideally a child should visit the dentist within 6 months after the eruption of the first tooth and by the very latest 12 months of age.

Caries prevention recommendations include the use of fluoride, proper dental hygiene, and a dental visit within the first year (ADA, 2000; AAPD, 2013). A review of the literature found that the use of fluoride toothpaste and administering of fluoride treatments by a dental professional were the best homecare and professional measures for caries prevention for at risk infants (Twetman, 2008). Fluoride may be obtained via a few sources including drinking water (available only in some communities), and the use of fluoride containing products such as fluoride varnishes, gels, toothpastes, mouth rinses, and supplements (ASTDD, 2011). The caries prevention measures recommended for children aged 3 - 5 years include brushing, better food choices such as maintaining a balanced diet and limiting foods high in sugar, brushing twice a day with a child size toothbrush and fluoride toothpaste, flossing (if two teeth are touching), fluoride treatment, and visiting the dentist (Mouth Healthy, 2017).

In addition to the reduction of dental caries through better food choices, prevention of obesity-related systemic diseases can help to maintain good oral health (Tavares \& Chomitz, 2009). Obesity was shown to have been associated with dental caries in the primary dentition of Mexican children (Vazquez-Nava et al., 2010). Vazquez-Nava et al. (2010) conducted a cross sectional study among 1,160 4 - 5 year old Mexican children. The research team weighed and measured the children to calculate their Body Mass Index (BMI) and each child had an oral examination to determine 
whether they had caries (Vazquez-Nava et al., 2010). The findings indicated that there was a significant relationship between at risk overweight children, overweight children, and caries in primary teeth (Vazquez-Nava et al., 2010).

A study in Brazil corroborated this finding, showing that the prevalence of ECC was associated with infant obesity (dos Santos Junior, Brasilero de Sousa, Oliveira, Franca de Caldas Junior, \& Rosenblatt, 2014). The cross sectional study was conducted among $3204-5$ year old preschool children in southeastern Brazil (dos Santos Junior et al., 2014). The children were measured and weighed, and had an oral examination performed (dos Santos et al., 2014). Obesity as well as ECC can be reduced by healthy lifestyle behaviors such as good nutrition which can have a positive impact on oral and systemic health (Tavares \& Chomitz, 2009).

Nutrition and oral health. The relationship between good nutrition and healthy teeth is one that is widely accepted. The close relationship between diet, nutrition and dental health has been identified, and it has been shown that oral tissues are diet and nutrition dependent (Ndiokwelu \& Ndiokwelu, 2006; Touger-Decker \& Mobley, 2013). The Academy of Dietetics and Nutrition (ADN) maintains the position that nutrition is integral to oral health stating, "the multifaceted interactions between diet, nutrition, and oral health in practice, education, and research in both dietetics and dentistry merit continued, detailed delineation" (Touger-Decker \& Mobley, 2013).

According to the ADA (2000), foods high in sugars should be controlled and a balanced diet is important; children who experience frequent and prolonged exposure to sugared drinks are more likely to experience ECC (Kawashita et al., 2011). A study 
shows that nutritional counseling for low-income families in a child's first year reduces caries incidence and severity at age four (Feldens, Giugliani, Duncan, Drachler, \& Vitolo, 2010), this study is in line with the $\mathrm{ADN}$ position that there is a relationship between nutrition and oral health.

\section{Parental Factors Influencing Children's Oral Health}

The early years of a child's life are their most influential years and, as such, early oral health care is important since this is where the foundation will be laid for a lifetime of preventative education and dental care (Bahuguna et al., 2011). Studies have shown that there is a lack of parental knowledge about children's oral health and many are unaware of the importance of primary dentition (Blinkhorn, Wainwright-Stringer, \& Holloway, 2001; Chhabra \& Chhabra, 2012). Research shows that parents and caregivers play a significant role in ensuring the success of preventative measures and the prevention of ECC (Chu, 2006).

Parental attitudes, beliefs and practices play a significant role in the oral health of children, particularly preschool children (Chhabra \& Chhabra, 2012; Pine et al., 2004; Weyant, Manz, Corby, Rustveld, \& Close, 2007). Studies indicate that parental attitudes are likely to play a role in achieving and maintaining a desired level of oral health in children (Vermaire, Hoogstraten, Van Loveren, Poorterman, \& Van Exel, 2009).

Vermaire et al. (2009) focused on the attitudes towards oral health among parents of 6-year-old children at risk for developing caries. The results showed parents with five types of attitudes. These attitudes were (a) conscious and responsible parents; (b) trivializing and fatalistic parents; (c) appearance-driven and open-minded parents; (d) 
knowledgeable but defensive parents; and (e) conscious and concerned parents. The study indicated that parental attitudes are likely to play a role in achieving and maintaining a desired level of oral health in children.

Attitudes of parents have such a significant impact on the oral health of their children that, in some instances, the attitudes of the parents have been shown to hold greater significance than knowledge, in influencing the oral health behaviors that will ultimately affect the child's dental health (Pine et al., 2004; Saied-Moallemi et al., 2008; Skaret, Espelid, Skeie, \& Haugejordan, 2008; Vermaire et al., 2010). Parental dental attitudes are clearly associated with caries incidence in early childhood (Skeie, Espelid, Riordan, \& Klock, 2008). Parental beliefs and attitudes play a major role in moderating oral health related behaviors in young children and in determining whether they develop caries (Pine et al., 2004). Perceptions of parents have also been shown to be significant in this respect. Poorer perceptions of children's oral health have often resulted in poorer oral health outcomes for the children (Sohn, Taichman, Ismail, \& Reisine, 2008).

Significant differences have been observed in the preventive health behaviors of parents with different racial and ethnic backgrounds (Ronis, Lang, Antonakos, \& Borgnakke, 1998). Attitudes were found to be significantly different in families of varying backgrounds and in families of children with and without caries (Adair et al., 2004). Adair et al. (2004) conducted a study among 2822 children $2-4$ years old and their parents. The research team led by Adair (2004) found significant differences in attitudes between families with a lower SES and those with higher SES. Significant attitudinal differences were also observed between families of children who had caries 
and those who did not (Adair et al., 2004). Differences were also observed in participants and different sites and those of different ethnicities (Adair et al., 2004).

Immigrant background also plays an important role in parental attitudes to children's oral health (Skeie et al., 2008). Skeie et al. (2008) found that 'Attitude to Diet' and 'Parental Indulgence' was related to caries increment. The more exposed children were to negative parental attitudes, the higher the odds ratio (OR). 'Immigrant status' was the greatest predictor of caries increment for this study. The research team concluded that parental dental attitudes are clearly associated with caries increment in early childhood (Skeie et al., 2008).

These differences have also been observed in other studies that show that discrepancies exist in the knowledge and the behaviors related to that knowledge within these groups (Lukes, 2010; Skaret et al., 2008). Skaret et al. (2008) conducted a longitudinal study in which data were collected when the child was 3 years of age and again when the child was 5 years old. Responses were more positive for 17 out of 39 questions for those of western origin compared to those of non-western origin. Parents whose children had no caries at follow up in 2004 reported significantly more positive beliefs and attitudes towards child oral health care in 2002 compared to those whose children had caries in 2004.

Lukes (2010) conducted her study among a sample of Migrant and Seasonal Farm Worker (MSFW) parents/caregivers of preschool children in the Chicago, IL area. In a small sample of 45 parents, most of whom were born in Mexico, there were discrepancies in the age at which parents believed they should discontinue bottle use and the age at 
which bottle use actually stopped (Lukes, 2010). The researcher also found that there were discrepancies in the knowledge about drinks that cause decay and the consumption of those drinks by preschool (Lukes, 2010).

A qualitative study conducted in the island of Trinidad, showed that most parents and caregivers had positive attitudes towards oral health (Naidu, Nunn, \& Forde, 2012). However, there was a discrepancy between the attitudes to care, and the children receiving care due to other culturally based barriers and challenges to achieving ideal preventive care for their child (Naidu et al., 2012).

The influence of culture on the attitudes and behaviors of parents as they relate to their children's oral health is also observed in a study by Chhabra \& Chhabra (2012) among an Indian population in India. The study conducted among 620 Indian parents of preschoolers revealed that there were barriers to children receiving preventive care including fear, lack of knowledge and awareness and importance of primary teeth, and myths related to dental treatment (Chhabra \& Chhabra, 2012). In addition, the elders in the family strongly influence parental decisions for dental treatment (Chhabra \& Chhabra, 2012).

Hilton, Stephen, Barker, \& Weintraub (2007) found that a lack of caregivers' knowledge and beliefs (e.g. beliefs about the cause and prevention of oral disease) about primary teeth created barriers to early preventative care in all racial/ethnic groups. The study included four to six focus groups in each of the African-American, Chinese, Latino, and Filipino communities in San Francisco, California (Hilton et al., 2007). Multiple family care givers (e.g. parents/guardians), especially elders, influenced access to 
preventative care in all racial/ethnic groups (Hilton et al., 2007). The study revealed that there were both similarities and differences between racial/ethnic groups in how cultural beliefs and experiences influence young children's access to dental care (Hilton et al., 2007).

\section{Childhood oral health interventions}

Interventions geared towards reducing ECC need effective approaches in delivering health education and in modifying health behaviors (ASTDD, 2011). Health literacy and culture must be taken into consideration when communicating with parents and caregivers (ASTDD, 2011). The most significant limitation of largely clinical and educational interventions is that they fail to achieve sustainable improvements in oral health due to the palliative nature of the programs and the fact that they ignore the underlying factors that cause poor oral health (Watt, 2005).

Schools provide an important setting for oral health promotion (Kwan, Petersen, Pine, \& Borutta, 2005). There have been oral health interventions geared towards the improvement of oral health in school-aged children, many of which have had favorable

results (Kwan et al., 2005). Additionally, if oral health promotion and disease prevention is involved in school curricula, it provides an opportunity for development and reinforcement of good oral health habits since these are the most influential stages of a child's life (Kwan et al., 2005).

An intervention in Title 1 schools in a Midwestern suburb was conducted to determine the effectiveness of an alternative workforce model on the oral health of lowincome children (Simmer-Beck et al., 2015). The study included 295 low-income, Title 1 
elementary school students who participated in a school oral health based program where preventative dental care was provided by dental hygienists with an extended care permit (ECP). Children in this study ranged from under 5 years of age to 11 years, with 69 of the children being less than 5 years when the study began. The number of visits with the ECP program dental hygienist showed that tooth decay decreased, restorations increased and treatment urgency decreased significantly (Simmer-Beck et al., 2015). Overall, the use of an alternative workforce proved to be effective in improving oral health among lowincome elementary school children (Simmer-Beck et al., 2015).

Petersen et al. (2015) improved the oral health of some children in southern Thailand by implementing a school-based intervention. All participating children were between $4-6$ years at the beginning of the intervention (Petersen et al., 2015). The intervention included teacher supervised brushing after lunch, oral health education twice a year, and regular communication from teacher to parent/caretaker about improving children's oral health (Petersen et al., 2015). Petersen et al. (2015) found that there was a significant reduction in caries in schools that cooperated most; plaque scores were also significantly lower.

An oral health intervention, based in Grenada, aimed to reduce childhood caries by using the existing education and early childhood health care systems (Wolff, Hill, Wilson-Genderson, Hirsch, \& Dasanayake, 2016). The study by Wolff et al. (2016) included children ages $7-8$, and $14-15$ years of age. The intervention included teams delivering 3 components of dental care; the first being a daily toothbrushing routine in the classroom using fluoride toothpaste for 2 minutes, second was a fluoride varnish $3-4$ 
times per year for each child, and finally application of glass ionomer sealants (Wolff et al., 2016). Teachers were trained on proper toothbrushing techniques and varnish application as well as oral health and nutrition education lessons (Wolff et al., 2016).

Community based interventions geared towards improving toothbrushing, improving diets, and increasing fluoride use proved to be effective (Huebner \& Milgrom, 2015; Pine et al., 2000; Wenhall et al., 2005). A school and home-based randomized controlled trial conducted by Pine et al. (2000) in deprived communities in the north east of Scotland showed that twice daily, supervised brushing with a fluoride toothpaste will decrease the caries experience of 5 year olds. This two-year intervention study utilized toothbrushing charts, six monthly dental examinations and parental questionnaires (Pine et al., 2000). The two main parts of the intervention included supervised brushing on school days and a school and home based incentive to encourage twice daily brushing (Pine et al., 2000).

Wennhall et al. (2005) utilized a community setting for their intervention, which also proved to be effective. The research team utilized an outreach facility in Sweden in order to carry out their intervention (Wennhall et al., 2005). The success of this intervention was seen in the greater number of children in the intervention group who were caries free upon its completion. The intervention provided parent education, including dietary recommendations and toothbrush instruction as well as fluoride tablets (Wennhall et al., 2005). It allowed for improvement in the use of fluoride and increased parental assistance with daily tooth brushing (Wennhall et al., 2005). After three years, 
Wennhall, Matsson, Schroder, and Twetman (2008) showed that the intervention continued to have a positive impact on its participants.

A toothbrushing intervention was used to improve toothbrushing of infants and young children (Huebner \& Milgrom, 2015). Huebner \& Milgrom (2015) utilized community based participatory research where parents helped to design a toothbrushing intervention, which comprised of a series of four educational sessions (Huebner \& Milgrom, 2015). At each of the sessions parents were allowed time to socialize and to choose free supplies (Huebner \& Milgrom, 2015). Each parent was given a children's book encouraging toothbrushing (Huebner \& Milgrom, 2015). The researchers saw that improved confidence in brushing twice a day, improved attitudes towards brushing and improved self-efficacy toothbrushing (Huebner \& Milgrom, 2015).

Community based oral health interventions have also been used to improve a wider range of oral health behaviors. A community-based program conducted in British Columbia proved to be effective in reducing childhood caries (Harrison \& Wong, 2003). The study included 41 children under the age of 5 , most of whom were immigrants (Harrison \& Wong, 2003). The program utilized one-on-one counseling for mothers by lay health counselors, supported by community-wide activities (Harrison \& Wong, 2003). Mothers who had multiple counseling sessions showed improved bottle habits and their children showed reduced prevalence of caries compared to similarly aged children at baseline (Harrison \& Wong, 2003).

In the U. S., Watson, Horowitz, Garcia, \& Canto (2001) carried out an oral health intervention in a Latino community in Washington, DC. Watson et al. (2001) found that a 
community participatory approach was feasible and useful for building upon existing local resources and addressing oral health issues in this community, which lacked access to traditional dental care and health promotion initiatives. These researchers used the PRECEDE-PROCEED model (Green \& Kreuter, 1999) to guide the intervention (Watson et al., 2001). The themes addressed in the intervention were the prevention of dental caries and early childhood caries (Watson et al., 2001). Culturally appropriate health education and promotion activities were utilized in collaboration with local community organizations, volunteers and local practitioners (Watson et al., 2001). These included health fairs, school dental checkups for children entering kindergarten, age appropriate oral health presentations, and reinforcement messages along with other activities (Watson et al., 2001).

\section{Chapter Summary}

The literature review presented in this section documents a high prevalence of dental caries in the U.S. and provides evidence of the need for improved oral health promotion and disease prevention initiatives. The importance of oral health promotion and disease prevention has been recognized both globally and nationally, and health agencies such as the WHO and USDHHS have begun to put measures in place to improve oral health promotion. Oral health goals have been mentioned as a part of Healthy People 2020 and within the WHO action plan for non-communicable diseases. Oral health disparities have a significant impact on socioeconomically disadvantaged groups, with the rates of oral diseases being significantly higher among poor, minority populations. The relationship between oral health and general health is gaining increased 
recognition as researchers take note of the fact that the mouth is a part of the body as whole, and therefore the health of the mouth is, therefore, also important to the health of the body.

The significant role that parents play in the oral health of a child is clearly stated in the literature, specifically their attitudes, culture and behaviors. Based on the literature, school-based and community interventions seem to be most common. School-based programs have been observed to be more effective if parents are also included. 


\section{CHAPTER III}

\section{Methodology}

This exploratory study utilized a cross-sectional survey design. One hundred and ninety-two parents from 4 predominantly Black municipalities in Miami-Dade County participated in the study. The study used an oral health questionnaire to collect data about parental attitudes and beliefs, and children's oral health behaviors. These data were used to examine the relationship between attitudes, beliefs, and behaviors, and to assess whether between group differences exist among Black ethnic groups.

\section{Population and Sample}

One hundred and ninety-two parents/guardians of Black, preschool children (ages $3-5)$ participated in the study. Participants were recruited through 12 preschools in Miami-Dade, in 4 zip codes where larger percentages of Blacks live and attend school, i.e. 33056, 33161, 33168, and 33169 (Table 2, Figure 2). African American and Afro Caribbean recruitment occurred primarily at preschools in zip codes 33054, 33056, and 33169. Haitian recruitment occurred primarily at preschools in zip code 33161.

Directors at schools in the aforementioned zip codes were contacted by phone and/or email, and the researcher provided them with a brief overview and researcherdesigned flyer to inform them about the proposed study, and invited them to participate if they were interested. Preschool Directors or office personnel at participating schools distributed researcher-designed flyers to parents of $3-5$ year old children at the preschool, inviting them to participate in the study 3 days to 1 week prior to the 
researcher going to the school to begin data collection. Preschools distributed parental flyers either by email or by hard copy depending on their preference.

Table 2

Preschools for Recruitment

\begin{tabular}{lcc}
\hline \multicolumn{1}{c}{ Name } & Zip Code & $\begin{array}{c}\text { No. of } \\
\text { Surveys }\end{array}$ \\
\hline Preschool 1 & 33169 & $15(8)$ \\
Preschool 2 & 33169 & 17 \\
Preschool 3 & 33169 & 8 \\
Preschool 4 & 33169 & 8 \\
Preschool 5 & 33056 & 6 \\
Preschool 6 & 33056 & $25(9)$ \\
Preschool 9 & 33169 & 2 \\
Preschool 10 & 33056 & 16 \\
Preschool 11 & 33161 & 15 \\
Preschool 12 & 33161 & 17 \\
Preschool 7 & 33168 & $18(7)$ \\
Preschool 8 & 33056 & $17(4)$ \\
\hline
\end{tabular}

Note. ()$=$ the number or surveys completed by referrals at that site.

Inclusion and exclusion criteria. Black parents/guardians of preschool children $3-5$ years old were included. Participants had to be over the age of 18 years, and had to be able to speak and read English.

\section{Protection of Human Participants}

IRB. The study protocol was approved by the Florida International University Institutional Research Board (Protocol \#104350) on 3/15/16 (See Appendix A). 
Consent process. Parents were consented in a private area at each preschool.

Parents were provided with information about the study, the total number of participants, long term potential benefits, and compensation. They were also informed that their participation was voluntary. Parents who agreed to participate at the end of the consent process were provided with two copies of the consent form to sign. Parents kept one copy and the other copy was kept for the researcher's records.

Confidentiality and Privacy. All participants were provided with brown, selfsealing envelopes, in which they placed their completed surveys. All completed surveys and consent folders were kept in a locked drawer in AHC 5, Room 411. Only authorized researchers entered data provided on the surveys. No identifying information was collected on the surveys.

\section{Data Collection Procedures}

On the dates advertised on the recruitment flyer, a table was set up at the preschool in the afternoon between 3pm and 6pm for the parents to be consented when they collected their child. Consented participants were directed to a private area where trained researchers provided them with the survey to be completed, as well as a brown, self-sealing envelope. Participants were asked to return their completed questionnaires in the envelopes provided, and seal them to protect their identity. It took participants between 20 minutes and 45 minutes to complete the 114-item questionnaire.

Data collection began on April $25^{\text {th }}, 2016$ and continued until September $23^{\text {rd }}$, 2016. There were periods during the summer months where recruitment was slow at some preschools due to many children being out for the summer. Two trained researchers 
facilitated data collection at each school for $1-3$ days until the desired number of participants was obtained. Refreshments were provided for all participants. Each parent who agreed to participate, and who completed the survey received a Bright Smiles Bright Future kit, and a $\$ 10$ Walmart gift card; and each participating school received a gift card totaling $\$ 30$.

Instrumentation. The oral health questionnaire contained 114 questions, and included The International Collaborative Study on Child Dental Health Questionnaire to Parents (CDHQ) containing 100 questions, and The Child Nutrition Questionnaire (CNQ) containing 14 questions. The $C D H Q$ was used to collect demographic information, as well as data on the attitudes, beliefs, and behaviors of Black parents of preschool children 3 - 5 years old. Pine et al. (2004) developed the questionnaire as part of a multi-disciplinary study to develop two standardized measures. The CDHQ is comprised of five sections, A through E, laid out as follows:

- $\underline{\text { Section } \mathrm{A}}$ - of 37 questions and focuses on visiting the dentist, toothache experience and treatment, and general questions about attitudes and beliefs towards the child's baby teeth and dental health.

- $\underline{\text { Section B }}-17$ questions and focuses on the child's oral hygiene behaviors, including toothbrushing practices.

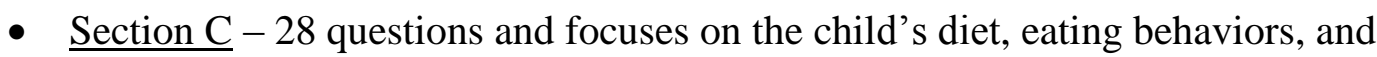
attitudes and beliefs about controlling the child's diet and snacking habits.

- Section $\mathrm{D}-6$ questions and focuses on the parent's oral health behaviors. 
- Section E, the final section, has 12 questions and focuses on the child's routine and parent's background information including gender, marital status, education, income, and ethnicity.

The test-retest reliability was determined to $b e(r=0.93, p \leq 0.001)$, the internal reliability (alpha $=0.89)$, and the construct validity (alpha $=0.52-0.82)$. Four items were added to Section A of the questionnaire to include questions about visiting the dentist to provide a more comprehensive idea of what was done at the dentist, and how recently they had gone. Two items were also added to Section $\mathrm{C}$ of the questionnaire so that it included specific questions about fruit and vegetable consumption of the children.

The Child Nutrition Questionnaire was used to collect diet and nutrition data about the children. This instrument was developed by National Maternal and Child Oral Health Resource Center (OHRC) by health and nutrition experts who contributed to the first edition of "Bright Futures in Practice: Nutrition", and was validated by over 100 representatives for federal agencies and national organizations, who are experts in the field. The two-part instrument (CDHQ \& CNQ) was pilot tested by a panel of experts, including parents of $3-5$ year olds African American, Afro Caribbean, and Haitian ethnic groups. These parents provided feedback on the length of time the survey took to complete, the structure and wording of the questions, and clarity of the questionnaire.

\section{Data Analysis}

The study looked at 8 categories of attitudes and beliefs:

1. Intention to control sugar snacking

2. Parental efficacy to control sugar snacking 
3. Intention to brush child's teeth

4. Parental efficacy to brush child's teeth

5. Attitude to prevention

6. Perceived seriousness of decay

7. Chance control

8. External control

The categories were determined as follows:

The following questions were reverse scored and the average of these responses made up parental efficacy in relation to child tooth brushing $(\alpha=0.73)$ (Adair et al., 2004):

Section A

- 12. If our child does not want to brush his/her teeth every day we don't feel we should make them

- 23. I don't know how to brush my child's teeth properly

- 30. It would not make any difference to our child getting tooth decay, if we helped him/her brush every day

- 32. We don't have time to brush our child's teeth twice a day

- 33. We cannot make our child brush his/her teeth twice a day

Section C

- 26. It is not worth it to battle with our child to brush his/her teeth twice a day. 
The average of the following questions in Section A made up importance and intention to brush child's teeth ( $\alpha=0.81)$ (Adair et al., 2004):

- 18. As a family we intend to brush our child's teeth for him/her

- 19. We intend to brush our child's teeth for him/her twice a day

- 20. The people in my family would feel it was important to help brush our child's teeth twice a day

- 21. The people we know well would feel it was important to brush our child's teeth twice a day

- 22. We feel able to brush our child's teeth for him/her.

Attitudes to prevention were determined by the average of the following questions in Section A $(\alpha=0.52)$ (Adair et al., 2004).

- 13. It is important to clean my child's teeth everyday so my child has a nice smile

- 24. If we brush our child's teeth twice a day, we can prevent our child getting tooth decay in the future

- 25. If our child uses a fluoride toothpaste, it will prevent tooth decay.

Importance and intention to control sugar snacking was determined by the average of the following questions ( $\alpha=0.64)$ (Adair et al., 2004): 


\section{Section A}

- $\quad$ 16. We can prevent tooth decay in our child by reducing sugary foods and drinks between meals

\section{Section C}

- 14. As a family, we intend controlling how often our child has sugary foods or drinks between meals

- 15 . The people in my family would feel it was important to control how often our child has sugary foods and drinks between meals

- 20. Our child eating sugary foods and drinks in between meals would cause tooth decay

- 21. The people we know well would feel it was important to control how often our child has sugary foods and drinks.

Parental efficacy to determine sugar snacking was determined by reverse coding the following questions in Section $\mathrm{C}$ and then calculating their average $(\alpha=0.64)$ (Adair et al., 2004):

- 16. As a family, we feel it is difficult for us to stop our child having sugary foods and drinks between meals

- 19. It is worthwhile to give our child sweets/biscuits to behave well.

- 22. In our family it would be unfair not to give sweets to our child every day 
- 23. It is often too stressful to say no to my child when they want sweets.

Seriousness of decay was calculated by determining the average of the following questions in Section A $(\alpha=0.72)$ (Adair et al., 2004):

- 4. As a family, we are confident that we can reduce the chances of our child getting tooth decay

- 5 . Tooth decay will not get better by itself

- 7. Tooth decay would have major consequences on our child's general health

- 8 . Tooth decay is a serious problem in baby teeth

- 9. As parents, it is our responsibility to prevent our child from getting tooth decay

- 10. Our child losing baby teeth due to tooth decay would be upsetting

- 11. We feel it is important that we check our child's teeth for decay.

Chance control (decay occurs by chance) was determined by reverse coding the following questions in Section A and calculating the average $(\alpha=0.61)$ (Adair et al., 2004).

- 15. No matter what we do, our child is likely to get tooth decay

- 17. It is just bad luck if our child gets tooth decay

- 29. If our child gets tooth decay, it is by chance

- 36. Tooth decay runs in families. 
- 37. Some people have naturally soft teeth.

External control (preventing decay is the dentist's responsibility) was determined by reverse coding the following questions and calculating the average ( $\alpha=0.55$ ) (Adair et al., 2004):

\section{Section A}

- 14. It is the responsibility of the dentist to prevent our child getting tooth decay

\section{Section C}

- 25. Bringing our child to the dentist on a regular basis is the best way to prevent tooth decay

- 28. The dentist is the best person to prevent tooth decay in our child.

Responses for attitude and belief items were separated into 2 categories: scores of $0-3.49$ were coded as negative, and scores of $3.5-5$ were coded as positive. Toothbrushing behaviors were determined by the sum of reported times when teeth were brushes and then no if they didn't brush twice a day, yes if they did. Sugar snacking behaviors were determined by combining "every day" and "most days" as "yes" and all other response as "no". Child drinking eating in bed was the sum of what parents reported they drink and eat in bed no = nothing, and yes $=$ the parent had selected one or more drink or food options. Descriptive analysis including frequencies was conducted for the demographics of the participants using IBM SPSS 20.0 (IBM Corp, 2011). These variables were used to separate the Black ethnic groups included in the study. It was also 
used to determine the socio-economic status of the individuals and their ages, which were used as covariates in the Logistic regression models.

Research question 1. What characterizes the attitudes, beliefs, and behaviors of Black parents about caries preventive behaviors for their preschool children?

Logistic regression was used to answer research question 1, and hypotheses 1, 2, and 3, which focus on the relationship between attitudes beliefs, and caries preventive behaviors. Logistic regression was used to determine whether the parents' attitudes and beliefs predicted their children's preventive oral health behaviors.

Research question 2. What are the ethnic group differences in attitudes and beliefs about caries preventive behaviors of Blacks in Miami-Dade County?

Chi-square was used to test research question 2, and hypotheses 4, 5, and 6 to determine whether there were differences in attitudes and beliefs about caries preventive behaviors between the different Black ethnic groups. IBM SPSS 20.0 (IBM Corp, 2011) was used for all statistical analyses.

\section{Chapter Summary}

The study utilized a cross sectional design to explore the relationship between parental attitudes and beliefs and caries preventive behaviors among 192 Blacks in Miami-Dade. The oral health questionnaire comprised of the CDHQ and the CNQ was used to collect data about attitudes and beliefs about caries preventive behaviors, as well caries preventive behaviors. Logistic regression was used to examine the relationship between parental attitudes and children's oral health behaviors. Chi-square analysis was 
used to determine whether differences existed between Black ethic groups. Data analyses were performed using SPSS 20.0. 


\section{CHAPTER IV}

\section{Results}

This chapter presents a comprehensive report of data analysis results to answer the research study questions. The two-fold purpose of the study was to (a) examine the attitudes, beliefs, and behaviors of Black parents about preventative measures against caries for their preschool children ( $3-5$ years) and (b) determine whether the attitudes and beliefs about caries preventive behaviors vary between different ethnic groups of Blacks in Miami-Dade. The chapter is organized into the following sections (a) sample description, (b) research question 1 and hypotheses tested (c) research question 2 and hypotheses tested, and (d) chapter summary.

\section{Sample Description}

The final sample consisted of 192 participants recruited from 12 preschools. Participants who did not identify as African American, Afro Caribbean, or Haitian (3.1\%) were excluded from between group analyses, but were included for all other analyses.

There were mostly females in the final sample. Most of the participants were between 31 - 40 years of age, or 21 - 30 years of age. Most of the participants were either single or married. Participants who identified as African American accounted for most of the final sample. Table 3 shows detailed demographics of the sample population. 
Table 3

Detailed Demographics of Sample Population $(n=192)$

\begin{tabular}{|c|c|}
\hline Variable & No. $(\%)$ \\
\hline \multicolumn{2}{|l|}{ Age $(\text { Years })^{\mathrm{a}}$} \\
\hline $18-20$ & $7(3.6)$ \\
\hline $21-30$ & $70(36.5)$ \\
\hline $31-40$ & $77(40.1)$ \\
\hline over 40 & $23(12.0)$ \\
\hline \multicolumn{2}{|l|}{ Ethnicity } \\
\hline African American & $116(60.4)$ \\
\hline Afro-Caribbean & $35(18.2)$ \\
\hline Haitian & $35(18.2)$ \\
\hline Other & $6(3.1)$ \\
\hline \multicolumn{2}{|l|}{ Gender $^{\mathrm{b}}$} \\
\hline Male & $55(28.6)$ \\
\hline Female & $134(69.8)$ \\
\hline \multicolumn{2}{|l|}{ Marital Status ${ }^{\mathrm{c}}$} \\
\hline Married & $77(40.1)$ \\
\hline Single & $100(52.1)$ \\
\hline Divorced/Separated & $7(3.6)$ \\
\hline Widowed & $1(0.5)$ \\
\hline \multicolumn{2}{|c|}{ Mother's Education Level ${ }^{\mathrm{d}}$} \\
\hline$<$ High School & $18(9.4)$ \\
\hline High School & $61(31.8)$ \\
\hline Some College & $63(32.8)$ \\
\hline Bachelors & $15(7.8)$ \\
\hline Graduate Degree & $29(15.1)$ \\
\hline Other & $5(2.6)$ \\
\hline \multicolumn{2}{|l|}{ Father's Education Level ${ }^{\mathrm{e}}$} \\
\hline$<$ High School & $16(8.3)$ \\
\hline High School & $84(43.8)$ \\
\hline Some College & $50(26.0)$ \\
\hline Bachelors & $13(6.8)$ \\
\hline Graduate Degree & $15(7.8)$ \\
\hline Other & $2(1.0)$ \\
\hline \multicolumn{2}{|l|}{ Income $^{f}$} \\
\hline$<20,000$ & $71(37.0)$ \\
\hline $20,000-39,000$ & $47(24.5)$ \\
\hline $40,000-69,000$ & $35(18.2)$ \\
\hline $70,000+$ & $14(7.3)$ \\
\hline
\end{tabular}

Note "No." = number

$\mathrm{a}=15$ missing

$\mathrm{b}=3$ missing

$\mathrm{c}=7$ missing

$\mathrm{d}=1$ missing

$\mathrm{e}=12$ missing

$\mathrm{f}=25$ missing 
Research question 1: What characterize the attitudes, beliefs, and behaviors of Black parents about caries preventive behaviors for their preschool children?

Hypotheses:

Ho 1.1 There is no relationship between attitudes and beliefs of Black parents about toothbrushing and toothbrushing behaviors for their preschool children.

Ho 1.2 There is no relationship between attitudes and beliefs of Black parents towards taking their preschool children to the dentist and parents taking their preschool children to the dentist.

Ho 1.3 There is no relationship between attitudes and beliefs of Black parents towards sugar snacking and sugar snacking behaviors for their preschool children.

Table 4

Parental Oral Health Attitudes and Beliefs ( $n=192)$

\begin{tabular}{lc}
\hline \multicolumn{1}{c}{ Positive Oral Health Attitude } & No. (\%) \\
\hline Intention & $156(81.3)$ \\
Intention to control sugar snacking & $169(88.0)$ \\
Intention to brush child's teeth & $103(53.6)$ \\
Actual Behavioral Control & $128(66.7)$ \\
$\quad$ Parental efficacy to control sugar snacking & \\
Parental efficacy to brush child's teeth & $163(84.9)$ \\
Attitude to Behavior & $175(91.1)$ \\
$\quad$ Attitude to prevention & $101(52.6)$ \\
Normative Belief & $35(18.2)$ \\
Perceived seriousness of decay & \\
Control Beliefs & \\
Chance control & \\
External control & \\
\hline Note "No." = number &
\end{tabular}


A majority of the parents reported positive attitudes with regards to intention to control sugar snacking, intention to brush child's teeth, attitude to prevention, and perceived seriousness of decay. Only slightly more than half of the parents reported that they had the efficacy to control sugar snacking and to brush child's teeth, and chance control. Less than $20 \%$ of the parents reported a positive attitude towards external control (18.2\%) (Table 4).

Table 5

Reported Oral Health Behaviors ( $n=192)$

\begin{tabular}{lr}
\hline \multicolumn{1}{c}{ Behavior } & No. $(\%)$ \\
\hline Child has visited the dentist & $162(84.4)$ \\
Child has had fluoride treatment & $85(46.7)$ \\
Child uses toothpaste & $176(91.7)$ \\
Child eats sweets or candy most days & $39(20.9)$ \\
Child eats sugary foods between meals most days & $39(20.7)$ \\
Child drinks soft drinks containing sugar most days & $46(24.0)$ \\
Child eats fruit most days & $101(52.6)$ \\
Child eats vegetables most days & $119(62.0)$ \\
Child drinks in bed & $162(84.4)$ \\
Child eats in bed & $103(53.6)$ \\
Child brushes teeth twice daily & $118(61.5)$ \\
Parent brushes child's teeth twice daily & $145(75.5)$ \\
\hline
\end{tabular}

Note "No." = number 
Most parents have reported that their child has: visited the dentist, uses toothpaste, drinks in bed, and that they brush their child's teeth twice daily. Only slightly more than half of the parents reported that their child eats fruit and vegetables most days, that their child eats in bed, and that the child brushes their own teeth. Few of the parents reported that their child consumed sweets or sweet drinks most days (20.9\% and $24.0 \%$ respectively), and slightly less than half of the children had received a fluoride treatment (see Table 5).

Chi square analysis was conducted to determine whether there were significant associations between oral health attitudes and beliefs, and oral health behaviors. For variables that had significant associations logistic regression was conducted to examine the relationships between the variables. There were no significant associations between attitudes about visiting the dentist and children actually visiting the dentist therefore no further analysis was conducted $\mathrm{X}^{2}(1, \mathrm{~N}=192)=.198, p=.657$.

1.1 Logistic regression was completed to examine the relationship between oral health attitudes and beliefs and toothbrushing behaviors. Significant predictors of toothbrushing behaviors are reported in Table 6. 
Table 6

Logistic regression examining relationships between oral health attitudes and beliefs and toothbrushing behaviors $(n=192)$

\begin{tabular}{|c|c|c|c|c|c|}
\hline Independent Variable & Dependent Variable & $\mathrm{B}$ & Sig & OR & $\begin{array}{c}\% \\
\text { correct }\end{array}$ \\
\hline Perceived seriousness of decay & Child uses toothpaste & 3.222 & $<0.001^{*}$ & 25.08 & 96.7 \\
\hline $\begin{array}{l}\text { Constant } \\
(\text { model } \mathrm{p}<0.001)^{*}\end{array}$ & & 1.179 & 0.039 & 3.25 & \\
\hline Parental efficacy to brush child's teeth & $\begin{array}{l}\text { Parent brushes child's } \\
\text { teeth twice a day }\end{array}$ & 1.128 & $0.001 *$ & 3.09 & $75.5^{* *}$ \\
\hline $\begin{array}{l}\text { Constant } \\
(\text { model } \mathrm{p}<0.001)^{*}\end{array}$ & & 0.445 & 0.083 & 1.56 & \\
\hline Chance control & & 0.888 & $0.011^{*}$ & 2.43 & $75.5^{* *}$ \\
\hline $\begin{array}{l}\text { Constant } \\
(\text { model } \mathrm{p}=0.009)^{*}\end{array}$ & & 0.710 & 0.001 & 2.03 & \\
\hline
\end{tabular}

Note $. \mathrm{B}=$ beta $. \mathrm{Sig}=$ significance $. \mathrm{OR}=$ Odds Ratio. $\%$ correct $=$ percentage of correctly predicted values $* p<0.05$

**model used based on best contingency table with the least number of variables 


\subsection{Logistic regression was completed to examine the relationship between oral}

health attitudes and beliefs and toothbrushing behaviors after controlling for gender, age, and ethnicity. Table 7 shows oral health attitude and belief predictors.

Table 7

Logistic regression examining the relationship between oral health attitudes and beliefs and toothbrushing behaviors, controlling for gender, ethnicity and age $(n=192)$

\begin{tabular}{|c|c|c|c|c|c|}
\hline Independent Variable & Dependent Variable & B & Sig & OR & $\begin{array}{c}\% \\
\text { correct }\end{array}$ \\
\hline Perceived seriousness of decay & Child uses toothpaste & 3.667 & $0.001^{*}$ & 39.122 & 97 \\
\hline Gender & & 1.752 & 0.112 & 5.765 & \\
\hline Ethnicity & & -0.015 & 0.973 & 0.985 & \\
\hline Age & & -0.176 & 0.793 & 0.836 & \\
\hline $\begin{array}{l}\text { Constant } \\
(\text { model } \mathrm{p}=0.004)^{*}\end{array}$ & & -1.476 & 0.587 & 0.229 & \\
\hline $\begin{array}{l}\text { Parental efficacy to brush } \\
\text { child's teeth }\end{array}$ & $\begin{array}{l}\text { Parent brushes child's teeth } \\
\text { twice a day }\end{array}$ & 1.348 & $0.001 *$ & 3.851 & 76 \\
\hline Gender & & -0.450 & 0.312 & 0.637 & \\
\hline Ethnicity & & -0.052 & 0.796 & 0.949 & \\
\hline Age & & 0.028 & 0.911 & 1.028 & \\
\hline $\begin{array}{l}\text { Constant } \\
(\text { model } \mathrm{p}=0.011)^{*}\end{array}$ & & 1.128 & 0.320 & 3.090 & \\
\hline Chance control & & 1.08 & $0.005^{*}$ & 2.945 & 76 \\
\hline Gender & & -0.253 & 0.551 & 0.776 & \\
\hline Ethnicity & & 0.037 & 0.849 & 1.038 & \\
\hline Age & & 0.110 & 0.658 & 1.117 & \\
\hline $\begin{array}{l}\text { Constant } \\
(\text { model } \mathrm{p}=0.049)^{*}\end{array}$ & & 0.742 & 0.5 & 2.1 & \\
\hline
\end{tabular}

Note $\mathrm{B}=$ beta. $\mathrm{Sig}=$ significance. $\mathrm{OR}=$ Odds Ratio. $\%$ correct $=$ percentage of correctly predicted values. $* p<0.05$ 


\subsection{Logistic regression was completed to examine the relationship between oral}

health attitudes and beliefs and toothbrushing behaviors. Table 8 shows oral health attitude and belief predictors after controlling for income, mother's education level, and father's education level.

Table 8

Logistic regression examining the relationship between oral health attitudes and beliefs and toothbrushing behaviors, controlling for income, mother's education level, father's education level ( $n=192)$

\begin{tabular}{|c|c|c|c|c|c|}
\hline Independent Variable & Dependent Variable & $\mathrm{B}$ & Sig & OR & $\begin{array}{c}\% \\
\text { correct }\end{array}$ \\
\hline Perceived seriousness of decay & \multirow{5}{*}{$\begin{array}{l}\text { Child uses } \\
\text { toothpaste }\end{array}$} & 3.033 & $0.001 *$ & 20.749 & \multirow[t]{5}{*}{$96.0 * *$} \\
\hline Income & & 0.515 & 0.345 & 1.673 & \\
\hline Mother's education level & & -0.011 & 0.980 & 0.989 & \\
\hline Father's education level & & 0.880 & 0.293 & 2.410 & \\
\hline $\begin{array}{l}\text { Constant } \\
(\text { model } \mathrm{p}=0.005)^{*}\end{array}$ & & -1.718 & 0.449 & 0.179 & \\
\hline Parental efficacy to brush child's teeth & \multirow{5}{*}{$\begin{array}{l}\text { Parent brushes } \\
\text { child's teeth twice } \\
\text { a day }\end{array}$} & 1.089 & $0.010^{*}$ & 2.970 & \multirow[t]{5}{*}{76.1} \\
\hline Income & & 0.329 & 0.147 & 1.390 & \\
\hline Mother's education level & & 0.165 & 0.392 & 1.180 & \\
\hline Father's education level & & -0.289 & 0.143 & 0.749 & \\
\hline $\begin{array}{l}\text { Constant } \\
(\text { model } \mathrm{p}=0.008)^{*}\end{array}$ & & 0.098 & 0.882 & 1.103 & \\
\hline Chance control & & 0.798 & $0.042 *$ & 2.221 & \multirow[t]{5}{*}{76.1} \\
\hline Income & & 0.351 & 0.125 & 1.420 & \\
\hline Mother's education level & & 0.213 & 0.271 & 1.237 & \\
\hline Father's education level & & -0.265 & 0.175 & 0.767 & \\
\hline $\begin{array}{l}\text { Constant } \\
(\text { model } \mathrm{p}=0.021)^{*}\end{array}$ & & 0.178 & 0.790 & 1.194 & \\
\hline
\end{tabular}

Note. $\mathrm{B}=$ beta. $\mathrm{Sig}=$ significance. $\mathrm{OR}=$ Odds Ratio. $\%$ correct $=$ percentage of correctly predicted values. $* p<0.05$

**model used based on best contingency table with the least number of variables 


\subsection{Logistic regression was completed to examine the relationship between oral}

health attitudes and beliefs and toothbrushing behaviors. Table 9 shows oral health

attitude and belief predictors after controlling for gender, age, ethnicity, income, mother's

education level, and father's education level.

Table 9

Logistic regression examining the relationship between oral health attitudes and beliefs and toothbrushing behaviors, controlling for gender, ethnicity, age, income, mother's education level, father's education level $(n=192)$

\begin{tabular}{|c|c|c|c|c|c|}
\hline Independent Variable/Covariates & Dependent Variable & $\mathrm{B}$ & Sig & OR & $\begin{array}{c}\% \\
\text { correct }\end{array}$ \\
\hline Perceived seriousness of decay & \multirow{8}{*}{$\begin{array}{l}\text { Child uses } \\
\text { toothpaste }\end{array}$} & 3.229 & $0.003^{*}$ & 25.260 & \multirow[t]{8}{*}{96.3} \\
\hline Gender & & 1.802 & 0.161 & 6.064 & \\
\hline Ethnicity & & -0.546 & 0.389 & 0.579 & \\
\hline Age & & -0.662 & 0.445 & 0.516 & \\
\hline Income & & 0.748 & 0.214 & 2.112 & \\
\hline Mother's education level & & -0.114 & 0.808 & 0.892 & \\
\hline Father's education level & & 1.173 & 0.163 & 3.23 & \\
\hline $\begin{array}{l}\text { Constant } \\
(\text { model } \mathrm{p}=0.010)^{*}\end{array}$ & & -2.903 & 0.371 & 0.055 & \\
\hline Parental efficacy to brush child's teeth & \multirow{16}{*}{$\begin{array}{l}\text { Parent brushes } \\
\text { child's teeth twice } \\
\text { a day }\end{array}$} & 1.229 & 0.011 & 3.418 & \multirow[t]{8}{*}{76.4} \\
\hline Gender & & -0.054 & 0.918 & 0.948 & \\
\hline Ethnicity & & 0.155 & 0.529 & 1.168 & \\
\hline Age & & -0.197 & 0.531 & 0.821 & \\
\hline Income & & 0.430 & 0.091 & 1.537 & \\
\hline Mother's education level & & 0.046 & 0.838 & 1.047 & \\
\hline Father's education level & & -0.214 & 0.380 & 0.807 & \\
\hline $\begin{array}{l}\text { Constant } \\
(\text { model } p=0.067)\end{array}$ & & 0.369 & 0.789 & 1.446 & \\
\hline Chance control & & 1.014 & 0.019 & 2.757 & \multirow[t]{8}{*}{77.8} \\
\hline Gender & & 0.166 & 0.739 & 1.181 & \\
\hline Ethnicity & & 0.238 & 0.323 & 1.268 & \\
\hline Age & & -0.194 & 0.541 & 0.824 & \\
\hline Income & & 0.480 & 0.064 & 1.616 & \\
\hline Mother's education level & & 0.067 & 0.767 & 1.069 & \\
\hline Father's education level & & -0.191 & 0.433 & 0.826 & \\
\hline $\begin{array}{l}\text { Constant } \\
(\text { model } \mathrm{p}=0.090)\end{array}$ & & -0.057 & 0.967 & 0.945 & \\
\hline
\end{tabular}

Note. $\mathrm{B}=$ beta $. \mathrm{Sig}=$ significance. $\mathrm{OR}=$ Odds Ratio. $\%$ correct $=$ percentage of correctly predicted values. $* p<0.05$ 
Logistic regression was conducted to determine whether parental attitudes about toothbrushing predicted children's actual toothbrushing behaviors. The dependent variables for this analysis were "child uses toothpaste" and "parent brushes child's teeth twice a day". The independent variables for this analysis were "perceived seriousness of decay", "parental efficacy to brush child's teeth", "chance control”, "age", "gender", "ethnicity", "income", "mother's education level" and "father's education level".

Perceived seriousness of decay, parental efficacy to brush child's teeth, and chance control are significant predictors of children using toothpaste and parents brushing children's teeth twice a day $(p<.005)$. These predictors remain significant even when controlling for demographics (age, gender, ethnicity), and when controlling for socio economic factors (SES) (income, mother's education level, father's education level) $(p<.05)$. Only perceived seriousness of decay remained a significant predictor when controlling for age, gender, ethnicity, income, mother's education, and father's education. Parental efficacy to brush child's teeth and chance control were no longer significant when controlling for these 6 variables. The child was 20.7 times as likely to use toothpaste if the parent perceived decay to be serious, the parent was 3.1 times as likely to brush the child's teeth twice a day if their parental efficacy to brush the child's teeth was positive, and 2.5 times as likely to brush the child's teeth twice a day if they had a positive attitude towards chance control.

1.3 Logistic regression was completed to examine the relationship between oral health attitudes and sugar snacking/diet behaviors Table 10 shows oral health attitude and 


\section{belief predictors. Table 11 reports shows attitude and belief predictors for sugar}

snacking/diet behaviors while controlling for gender, ethnicity, and age.

Table 10

Table showing logistic regression for oral health attitudes and beliefs and predicting sugar snacking/diet behaviors ( $n=192)$

\begin{tabular}{|c|c|c|c|c|c|}
\hline Independent Variable & Dependent Variable & B & Sig & OR & $\begin{array}{c}\% \\
\text { correct }\end{array}$ \\
\hline $\begin{array}{l}\text { Chance control } \\
\text { Constant } \\
(\text { model } \mathrm{p}=0.012)\end{array}$ & Child drinks in bed & $\begin{array}{r}-1.061 \\
2.339\end{array}$ & $\begin{array}{l}0.016^{*} \\
<0.001\end{array}$ & $\begin{array}{r}0.346 \\
10.375\end{array}$ & $84.4 * *$ \\
\hline $\begin{array}{l}\text { Parental efficacy to control sugar snacking } \\
\text { Constant } \\
(\text { model } \mathrm{p}=0.007)^{*}\end{array}$ & Eat in bed & $\begin{array}{r}-0.792 \\
0.577\end{array}$ & $\begin{array}{r}0.008^{*} \\
0.009\end{array}$ & $\begin{array}{l}0.453 \\
1.781\end{array}$ & $59.4 * *$ \\
\hline $\begin{array}{l}\text { Chance control } \\
\text { Constant } \\
(\text { model } \mathrm{p}=0.017)^{*}\end{array}$ & & $\begin{array}{r}-0.695 \\
0.517\end{array}$ & $\begin{array}{r}0.018^{*} \\
0.017\end{array}$ & $\begin{array}{l}0.499 \\
1.676\end{array}$ & $58.3^{* *}$ \\
\hline $\begin{array}{l}\text { Attitude to prevention } \\
\text { Constant } \\
\text { (model } \mathrm{p}=0.062 \text { ) }\end{array}$ & Child eats candy most days & $\begin{array}{l}-0.851 \\
-0.642\end{array}$ & $\begin{array}{r}0.054 \\
0.1\end{array}$ & $\begin{array}{l}0.427 \\
0.526\end{array}$ & $79.1 * *$ \\
\hline $\begin{array}{l}\text { Attitude to prevention } \\
\text { Constant } \\
(\text { model } \mathrm{p}=0.001)^{*}\end{array}$ & $\begin{array}{l}\text { Child drinks soft drinks } \\
\text { containing sugar most days }\end{array}$ & $\begin{array}{r}-1.378 \\
0\end{array}$ & $\begin{array}{r}0.001 * \\
1\end{array}$ & $\begin{array}{r}0.252 \\
1\end{array}$ & 75.4 \\
\hline $\begin{array}{l}\text { Intention to control sugar snacking } \\
\text { Constant } \\
(\text { model } \mathrm{p}=0.001)^{*}\end{array}$ & Child eats fruit most days & $\begin{array}{r}1.226 \\
-0.821\end{array}$ & $\begin{array}{r}0.002 * \\
0.023\end{array}$ & $\begin{array}{l}3.409 \\
0.440\end{array}$ & $61.8^{* *}$ \\
\hline $\begin{array}{l}\text { Chance control } \\
\text { Constant } \\
(\text { model } \mathrm{p}<0.001)^{*}\end{array}$ & & $\begin{array}{r}1.053 \\
-0.359\end{array}$ & $\begin{array}{r}0.001 * \\
0.093\end{array}$ & $\begin{array}{l}2.865 \\
0.698\end{array}$ & $62.9 * *$ \\
\hline $\begin{array}{l}\text { Parental efficacy to control sugar snacking } \\
\text { Constant model } \\
(\mathrm{p}=0.053)\end{array}$ & $\begin{array}{l}\text { Child eats vegetables most } \\
\text { days }\end{array}$ & $\begin{array}{l}0.586 \\
0.228\end{array}$ & $\begin{array}{l}0.054 \\
0.287\end{array}$ & $\begin{array}{l}1.797 \\
1.256\end{array}$ & $63.0 * *$ \\
\hline
\end{tabular}

Note $. \mathrm{B}=$ beta. $\mathrm{Sig}=$ significance. $\mathrm{OR}=$ Odds Ratio. $\%$ correct $=$ percentage of correctly predicted values. $* p<0.05$

**model used based on best contingency table with the least number of variables 


\section{Table 11}

Table showing logistic regression for oral health attitudes and beliefs and predicting sugar snacking/diet behaviors, controlling for gender and ethnicity and age $(n=192)$

\begin{tabular}{|c|c|c|c|c|c|}
\hline Independent Variable & Dependent Variable & $\mathrm{B}$ & Sig & OR & $\begin{array}{c}\% \\
\text { correct }\end{array}$ \\
\hline Chance control & \multirow[t]{5}{*}{ Child drinks in bed } & -0.844 & 0.068 & 0.43 & \multirow[t]{5}{*}{84.6} \\
\hline Gender & & 0.049 & 0.922 & 1.05 & \\
\hline Ethnicity & & 0.163 & 0.527 & 1.177 & \\
\hline Age & & -0.119 & 0.679 & 0.888 & \\
\hline $\begin{array}{l}\text { Constant } \\
(\text { model } \mathrm{p}=0.342)\end{array}$ & & 2.184 & 0.105 & 8.885 & \\
\hline Parental efficacy to control sugar snacking & \multirow[t]{10}{*}{ Child eats in bed } & -0.850 & $0.009^{*}$ & 0.427 & \multirow[t]{5}{*}{60.6} \\
\hline Gender & & -0.637 & 0.085 & 0.529 & \\
\hline Ethnicity & & -0.044 & 0.799 & 0.957 & \\
\hline Age & & -0.157 & 0.473 & 0.855 & \\
\hline $\begin{array}{l}\text { Constant } \\
(\text { model } \mathrm{p}=0.013)^{*}\end{array}$ & & 2.218 & 0.025 & 9.191 & \\
\hline Chance control & & -0.588 & 0.065 & 0.556 & \multirow[t]{5}{*}{59.4} \\
\hline Gender & & -0.636 & 0.085 & 0.53 & \\
\hline Ethnicity & & -0.078 & 0.644 & 0.925 & \\
\hline Age & & -0.233 & 0.275 & 0.792 & \\
\hline $\begin{array}{l}\text { Constant } \\
(\text { model } \mathrm{p}=0.058)\end{array}$ & & 2.337 & 0.018 & 10.354 & \\
\hline Attitude to prevention & \multirow{5}{*}{$\begin{array}{l}\text { Child eats candy } \\
\text { most days }\end{array}$} & -0.942 & 0.039 & 0.39 & \multirow[t]{5}{*}{77.3} \\
\hline Gender & & -0.019 & 0.965 & 0.981 & \\
\hline Ethnicity & & -0.023 & 0.908 & 0.977 & \\
\hline Age & & -0.108 & 0.663 & 0.897 & \\
\hline $\begin{array}{l}\text { Constant } \\
(\text { model } \mathrm{p}=0.387)\end{array}$ & & -0.1 & 0.934 & 0.904 & \\
\hline Attitude to prevention & \multirow{5}{*}{$\begin{array}{l}\text { Child drinks soft } \\
\text { drinks containing } \\
\text { sugar most days }\end{array}$} & -1.518 & $0.001 *$ & 0.219 & \multirow[t]{5}{*}{$76.4 * *$} \\
\hline Gender & & 0.050 & 0.907 & 1.051 & \\
\hline Ethnicity & & 0.665 & $0.001 *$ & 1.944 & \\
\hline Age & & -0.228 & 0.375 & 0.796 & \\
\hline $\begin{array}{l}\text { Constant } \\
(\text { model } \mathrm{p}<0.001)^{*}\end{array}$ & & -0.501 & 0.675 & 0.606 & \\
\hline Intention to control sugar snacking & \multirow{10}{*}{$\begin{array}{l}\text { Child eats fruit most } \\
\text { days }\end{array}$} & 1.076 & $0.012 *$ & 2.933 & \multirow[t]{5}{*}{64.2} \\
\hline Gender & & -0.464 & 0.214 & 0.629 & \\
\hline Ethnicity & & 0.172 & 0.340 & 1.188 & \\
\hline Age & & 0.217 & 0.306 & 1.242 & \\
\hline $\begin{array}{l}\text { Constant } \\
(\text { model } \mathrm{p}=0.020)^{*}\end{array}$ & & -0.710 & 0.473 & 0.492 & \\
\hline Chance control & & 1.246 & $<0.001 *$ & 3.478 & \multirow[t]{5}{*}{65.9} \\
\hline Gender & & -0.555 & 0.145 & 0.574 & \\
\hline Ethnicity & & 0.267 & 0.133 & 1.307 & \\
\hline Age & & 0.075 & 0.734 & 1.078 & \\
\hline $\begin{array}{l}\text { Constant } \\
(\text { model } \mathrm{p}=0.020)^{*}\end{array}$ & & -0.106 & 0.914 & 0.899 & \\
\hline Parental efficacy to control sugar snacking & Child eats vegetables & 0.755 & $0.026^{*}$ & 2.127 & \multirow[t]{5}{*}{64.0} \\
\hline Gender & \multirow[t]{4}{*}{ most days } & -0.504 & 0.193 & 0.604 & \\
\hline Ethnicity & & -0.345 & 0.050 & 0.708 & \\
\hline Age & & 0.090 & 0.686 & 1.094 & \\
\hline $\begin{array}{l}\text { Constant } \\
(\text { model } \mathrm{p}=0.044)^{*}\end{array}$ & & 1.334 & 0.189 & 3.796 & \\
\hline
\end{tabular}

Note $\mathrm{B}=$ beta. $\mathrm{Sig}=$ significance. $\mathrm{OR}=$ Odds Ratio. $\%$ correct $=$ percentage of correctly predicted values. $* p<0.05$

**model used based on best contingency table with the least number of variables 


\subsection{Logistic regression was completed to examine the relationship between oral}

health attitudes and sugar snacking/diet behaviors. Table 12 shows predictors while

controlling for gender, age, ethnicity, income, mother's education and father's education.

Table 12

Table showing logistic regression for oral health attitudes and beliefs predicting sugar snacking/diet behaviors, controlling for gender and ethnicity and age and income and mother and father education level $(n=192)$

\begin{tabular}{|c|c|c|c|c|c|}
\hline Independent Variable & Dependent Variable & $\mathrm{B}$ & Sig & OR & $\begin{array}{c}\% \\
\text { correct }\end{array}$ \\
\hline Chance control & \multirow[t]{8}{*}{ Child drinks in bed } & -0.744 & 0.155 & 0.475 & \multirow[t]{8}{*}{84.6} \\
\hline Gender & & 0.365 & 0.525 & 1.44 & \\
\hline Ethnicity & & 0.360 & 0.236 & 1.433 & \\
\hline Age & & 0.040 & 0.907 & 1.041 & \\
\hline Income & & 0.536 & 0.055 & 1.709 & \\
\hline Mother's education level & & -0.135 & 0.547 & 0.874 & \\
\hline Father's education level & & 0.234 & 0.371 & 1.264 & \\
\hline $\begin{array}{l}\text { Constant } \\
(\text { model } \mathrm{p}=0.342)\end{array}$ & & -0.404 & 0.801 & 0.667 & \\
\hline Parental efficacy to control sugar snacking & \multirow[t]{16}{*}{ Child eats in bed } & -0.412 & 0.289 & 0.662 & \multirow[t]{8}{*}{63.2} \\
\hline Gender & & -0.752 & 0.082 & 0.471 & \\
\hline Ethnicity & & 0.139 & 0.499 & 1.149 & \\
\hline Age & & 0.090 & 0.740 & 1.094 & \\
\hline Income & & 0.397 & 0.048 & 1.488 & \\
\hline Mother's education level & & -0.173 & 0.347 & 0.841 & \\
\hline Father's education level & & -0.292 & 0.140 & 0.747 & \\
\hline $\begin{array}{l}\text { Constant } \\
(\text { model } \mathrm{p}=0.052)\end{array}$ & & 1.625 & 0.175 & 5.079 & \\
\hline Chance control & & 0.035 & 0.926 & 1.036 & \multirow[t]{8}{*}{62.5} \\
\hline Gender & & -0.766 & 0.076 & 0.465 & \\
\hline Ethnicity & & 0.127 & 0.535 & 1.135 & \\
\hline Age & & 0.038 & 0.887 & 1.038 & \\
\hline Income & & 0.373 & 0.061 & 1.451 & \\
\hline Mother's education level & & -0.215 & 0.243 & 0.807 & \\
\hline Father's education level & & -0.294 & 0.133 & 0.745 & \\
\hline $\begin{array}{l}\text { Constant } \\
(\text { model } \mathrm{p}=0.076)\end{array}$ & & 1.725 & 0.148 & 5.611 & \\
\hline Attitude to prevention & \multirow{8}{*}{$\begin{array}{l}\text { Child eats candy } \\
\text { most days }\end{array}$} & -0.678 & 0.188 & 0.508 & \multirow[t]{8}{*}{74.5} \\
\hline Gender & & -0.204 & 0.668 & 0.815 & \\
\hline Ethnicity & & 0.066 & 0.771 & 1.068 & \\
\hline Age & & 0.029 & 0.923 & 1.029 & \\
\hline Income & & -0.093 & 0.671 & 0.911 & \\
\hline Mother's education level & & 0.006 & 0.974 & 1.006 & \\
\hline Father's education level & & -0.31 & 0.175 & 0.733 & \\
\hline $\begin{array}{l}\text { Constant } \\
(\text { model } \mathrm{p}=0.629)\end{array}$ & & 0.651 & 0.636 & 1.917 & \\
\hline
\end{tabular}

Note $\mathrm{B}=$ beta. $\mathrm{Sig}=$ significance. $\mathrm{OR}=$ Odds Ratio. $\%$ correct $=$ percentage of correctly predicted values. ${ }^{*} p<0.05$ 
Table 12 contd.

\begin{tabular}{|c|c|c|c|c|c|}
\hline Independent Variable & Dependent Variable & B & Sig & OR & $\begin{array}{c}\% \\
\text { correct }\end{array}$ \\
\hline Attitude to prevention & \multirow{8}{*}{$\begin{array}{l}\text { Child drinks soft } \\
\text { drinks containing } \\
\text { sugar most days }\end{array}$} & -1.413 & $0.011^{*}$ & 0.244 & \multirow[t]{8}{*}{76.2} \\
\hline Gender & & 0.132 & 0.804 & 1.141 & \\
\hline Ethnicity & & 1.111 & $<0.001 *$ & 3.037 & \\
\hline Age & & -0.109 & 0.738 & 0.897 & \\
\hline Income & & 0.434 & 0.072 & 1.543 & \\
\hline Mother's education level & & -0.144 & 0.519 & 0.866 & \\
\hline Father's education level & & -0.579 & $0.029 *$ & 0.561 & \\
\hline $\begin{array}{l}\text { Constant } \\
(\operatorname{model} \mathrm{p}<0.001)^{*}\end{array}$ & & -0.585 & 0.691 & 0.557 & \\
\hline Intention to control sugar snacking & \multirow{16}{*}{$\begin{array}{l}\text { Child eats fruit most } \\
\text { days }\end{array}$} & 1.298 & $0.006^{*}$ & 3.663 & \multirow[t]{8}{*}{69.7} \\
\hline Gender & & -0.137 & 0.772 & 0.872 & \\
\hline Ethnicity & & 0.298 & 0.199 & 1.347 & \\
\hline Age & & -0.077 & 0.786 & 0.926 & \\
\hline Income & & 0.462 & $0.039 *$ & 1.588 & \\
\hline Mother's education level & & -0.368 & 0.078 & 0.692 & \\
\hline Father's education level & & 0.383 & 0.090 & 1.467 & \\
\hline $\begin{array}{l}\text { Constant } \\
(\text { model } \mathrm{p}=0.003)^{*}\end{array}$ & & -1.426 & 0.273 & 0.240 & \\
\hline Chance control & & 1.103 & $0.006^{*}$ & 3.014 & \multirow[t]{8}{*}{70.4} \\
\hline Gender & & -0.002 & 0.996 & 0.998 & \\
\hline Ethnicity & & 0.442 & 0.051 & 1.556 & \\
\hline Age & & -0.120 & 0.671 & 0.887 & \\
\hline Income & & 0.486 & $0.030 *$ & 1.626 & \\
\hline Mother's education level & & -0.494 & $0.019 *$ & 0.61 & \\
\hline Father's education level & & 0.443 & 0.053 & 1.557 & \\
\hline $\begin{array}{l}\text { Constant } \\
(\text { model } \mathrm{p}=0.003)^{*}\end{array}$ & & -1.213 & 0.350 & 0.297 & \\
\hline Parental efficacy to control sugar snacking & \multirow{8}{*}{$\begin{array}{l}\text { Child eats } \\
\text { vegetables most } \\
\text { days }\end{array}$} & 0.849 & $0.036^{*}$ & 2.336 & \multirow[t]{8}{*}{69} \\
\hline Gender & & 0.018 & 0.969 & 1.018 & \\
\hline Ethnicity & & -0.342 & 0.101 & 0.710 & \\
\hline Age & & -0.113 & 0.688 & 0.893 & \\
\hline Income & & 0.451 & 0.036 & 1.571 & \\
\hline Mother's education level & & -0.431 & $0.029 *$ & 0.650 & \\
\hline Father's education level & & 0.445 & 0.043 & 1.561 & \\
\hline $\begin{array}{l}\text { Constant } \\
(\text { model } \mathrm{p}=0.044)^{*}\end{array}$ & & 0.148 & 0.906 & 1.159 & \\
\hline
\end{tabular}

Note $\mathrm{B}=$ beta $. \mathrm{Sig}=$ significance. $\mathrm{OR}=$ Odds Ratio. $\%$ correct $=$ percentage of correctly predicted values . $*_{p}<0.05$

1.3 Logistic regression was completed to examine the relationship between oral health attitudes and sugar snacking/diet behaviors. Table 13 shows predictors while controlling for income, mother's education, and father's education. 


\section{Table 13}

Table showing logistic regression for oral health attitudes and beliefs predicting sugar snacking/diet behaviors, controlling for income and mother and father education level ( $n=192)$

\begin{tabular}{|c|c|c|c|c|c|}
\hline Independent Variable & Dependent Variable & B & Sig & OR & $\begin{array}{c}\% \\
\text { correct }\end{array}$ \\
\hline Chance control & \multirow[t]{5}{*}{ Child drinks in bed } & -0.929 & 0.057 & 0.395 & \multirow[t]{5}{*}{83.0} \\
\hline Income & & 0.491 & 0.056 & 1.633 & \\
\hline Mother's education level & & 0.042 & 0.835 & 1.043 & \\
\hline Father's education level & & 0.083 & 0.707 & 1.087 & \\
\hline $\begin{array}{l}\text { Constant } \\
(\text { model } \mathrm{p}=0.077)\end{array}$ & & 0.968 & 0.218 & 2.632 & \\
\hline Parental efficacy to control sugar snacking & \multirow[t]{10}{*}{ Eat in bed } & -0.378 & 0.294 & 0.686 & \multirow[t]{5}{*}{62.3} \\
\hline Income & & 0.519 & $0.006^{*}$ & 1.68 & \\
\hline Mother's education level & & -0.224 & 0.167 & 0.800 & \\
\hline Father's education level & & -0.257 & 0.125 & 0.773 & \\
\hline $\begin{array}{l}\text { Constant } \\
(\operatorname{model} \mathrm{p}=0.008)^{*}\end{array}$ & & 0.620 & 0.270 & 1.859 & \\
\hline Chance control & & -0.215 & 0.534 & 0.807 & 62.3 \\
\hline Income & & 0.496 & $0.007 *$ & 1.642 & \\
\hline Mother's education level & & -0.235 & 0.144 & 0.790 & \\
\hline Father's education level & & -0.276 & 0.096 & 0.759 & \\
\hline $\begin{array}{l}\text { Constant } \\
(\text { model } \mathrm{p}=0.011)^{*}\end{array}$ & & 0.649 & 0.257 & 1.914 & \\
\hline Attitude to prevention & \multirow{5}{*}{$\begin{array}{l}\text { Child eats candy most } \\
\text { days }\end{array}$} & -0.567 & 0.247 & 0.567 & \multirow[t]{5}{*}{76.0} \\
\hline Income & & -0.061 & 0.763 & 0.940 & \\
\hline Mother's education level & & -0.002 & 0.991 & 0.998 & \\
\hline Father's education level & & -0.246 & 0.231 & 0.782 & \\
\hline $\begin{array}{l}\text { Constant } \\
(\text { model } \mathrm{p}=0.404)\end{array}$ & & 0.072 & 0.919 & 1.075 & \\
\hline Attitude to prevention & \multirow{5}{*}{$\begin{array}{l}\text { Child drinks soft drinks } \\
\text { containing sugar most days }\end{array}$} & -1.158 & $0.015^{*}$ & 0.314 & \multirow[t]{5}{*}{72.7} \\
\hline Income & & 0.143 & 0.461 & 1.154 & \\
\hline Mother's education level & & -0.099 & 0.578 & 0.906 & \\
\hline Father's education level & & -0.195 & 0.326 & 0.823 & \\
\hline $\begin{array}{l}\text { Constant } \\
(\text { model } \mathrm{p}<0.033)^{*}\end{array}$ & & 0.556 & 0.423 & 1.744 & \\
\hline Intention to control sugar snacking & \multirow[t]{10}{*}{ Child eats fruit most days } & 1.541 & $<0.001^{*}$ & 4.668 & \multirow[t]{5}{*}{67.3} \\
\hline Income & & 0.321 & 0.098 & 1.379 & \\
\hline Mother's education level & & -0.305 & 0.082 & 0.737 & \\
\hline Father's education level & & 0.355 & 0.062 & 1.426 & \\
\hline $\begin{array}{l}\text { Constant } \\
(\text { model } \mathrm{p}<0.001)^{*}\end{array}$ & & -1.509 & 0.030 & 0.221 & \\
\hline Chance control & & 1.007 & $0.006^{*}$ & 2.738 & \multirow[t]{5}{*}{66.0} \\
\hline Income & & 0.297 & 0.113 & 1.346 & \\
\hline Mother's education level & & -0.384 & 0.029 & 0.681 & \\
\hline Father's education level & & 0.411 & $0.033 *$ & 1.508 & \\
\hline $\begin{array}{l}\text { Constant } \\
(\text { model } \mathrm{p}=0.005)^{*}\end{array}$ & & -0.736 & 0.233 & 0.479 & \\
\hline Parental efficacy to control sugar snacking & \multirow{5}{*}{$\begin{array}{l}\text { Child eats vegetables most } \\
\text { days }\end{array}$} & 0.634 & 0.083 & 1.885 & \multirow[t]{5}{*}{66.2} \\
\hline Income & & 0.408 & 0.033 & 1.504 & \\
\hline Mother's education level & & -0.354 & 0.036 & 0.702 & \\
\hline Father's education level & & 0.289 & 0.117 & 1.335 & \\
\hline $\begin{array}{l}\text { Constant } \\
(\operatorname{model} \mathrm{p}=0.019)\end{array}$ & & -0.315 & 0.592 & 0.730 & \\
\hline
\end{tabular}

Note. $\mathrm{B}=$ beta. Sig $=$ significance. $\mathrm{OR}=$ Odds Ratio. $\%$ correct $=$ percentage of correctly predicted values. ${ }^{*} p<0.05$ 
Logistic regression was conducted to determine whether parental attitudes about sugar snacking predicted children's actual diet/sugar snacking behaviors. The dependent variables for this analysis were "child drinks in bed", "eats in bed", "child eats candy most days", "child drinks soft drinks containing sugar most days", "child eats fruit most days" and "child eats vegetables most days". The independent variables for this analysis were "intention to control sugar snacking", "parental efficacy to control sugar snacking", "attitude to prevention", "chance control", "age", "gender", "ethnicity", "income", “mother's education level” and "father's education level".

Chance control, parental efficacy to control sugar snacking, attitude to prevention and intention to control sugar snacking were all significant predictors of sugar snacking behaviors $(p<.05)$. A child was $65 \%$ less likely to eat in bed if the parent had a chance control attitude. Chance control however was no longer a significant predictor of whether a child drinks in bed when controlling for demographic and SES variables.

Children are 55\% less likely to eat in bed if parents have positive parental efficacy to control sugar snacking. Parental efficacy to control sugar snacking remains a significant predictor when controlling for demographics. In the model controlling for SES variables however, income is the significant predictor. The model is no longer significant when controlling for SES and demographic variables. Chance control is only significant as a predictor for the child eating in bed when there are no covariates. A child is $50 \%$ less likely to eat in bed if parents have a positive chance control attitude. The model controlling for SES variable is significant, however income is the significant predictor in that model. 
Attitude to prevention is not a significant predictor for whether a child eats candy most days. It is however a significant predictor for whether a child drinks soda containing sugar most days. A child is $75 \%$ less likely to consume soda containing sugar most days if the parent has a positive attitude to prevention. Attitude to prevention remains a significant predictor of consumption of soda even when controlling for demographic and SES variables.

Intention to control sugar snacking and chance control are significant predictors of whether a child eats fruit most days. Children are 3.41 times and 2.87 times more likely to eat fruit most days if parents have positive intentions to control sugar snacking and positive chance control respectively. This relationship remains significant even when controlling for SES and demographic variables.

Parental efficacy to control sugar snacking is only a significant predictor of children eating vegetables most days when controlling for demographic variables. Children are twice as likely to eat vegetables most days if parental efficacy to control sugar snacking is positive. The model controlling for SES is also significant, however income and mother's education level are the significant predictors in this model.

Research question 2: What are the ethnic group differences in attitudes and beliefs about caries preventive behaviors of Black parents of preschoolers in Miami-Dade?

2.1 There are no between-group differences in attitudes and beliefs about visiting the dentist among Black parents for their preschool children in the U.S.

2.2 There are no between-group differences in attitudes and beliefs about toothbrushing among Black parents for their preschool children in the U.S. 
2.3 There are no between-group differences in attitudes and beliefs about sugar snacking among Black parents for their preschool children in the U.S.

Chi square analysis was conducted to determine whether there were between group differences in oral health attitudes and beliefs. The results are presented in table 14 .

Table 14

Chi Square showing between group differences in attitudes $(n=186)$

\begin{tabular}{lll}
\multicolumn{1}{c}{ Attitude } & Chi square & Sig \\
\hline Intention & & \\
$\quad$ Intention to control sugar snacking & 8.728 & $0.013^{*}$ \\
$\quad$ Intention to brush child's teeth & 3.211 & 0.201 \\
Actual Behavior Control & & \\
$\quad$ Parental efficacy to control sugar snacking & 7.412 & $0.025^{*}$ \\
$\quad$ Parental efficacy to brush child's teeth & 7.737 & $0.021^{*}$ \\
Attitude towards Behavior & & \\
Attitude to prevention & 1.596 & 0.450 \\
$\quad$ Perceived seriousness of decay & 4.295 & 0.117 \\
Control Beliefs & & \\
Chance control & 9.920 & $0.007^{*}$ \\
External control & 2.839 & 0.242 \\
\hline
\end{tabular}

Note. Sig = significance.

$* p<0.05$

Between group differences were observed for intention to control sugar snacking $X^{2}(2, \mathrm{~N}=186)=8.728, p=.013$, parental efficacy to control sugar snacking $X^{2}(2, \mathrm{~N}=$ $186)=7.412, p=.025$, parental efficacy to brush child's teeth $X^{2}(2, \mathrm{~N}=186)=7.737, p$ $=.021$, and chance control $X^{2}(2, \mathrm{~N}=186)=9.920, p=.007$.

Post-hoc chi square analyses were conducted to determine between which groups the parental oral health attitude and belief differences existed. The results are presented in table 15 . 
Table 15

Chi Square Post Hoc Analyses for between group differences ( $n=186)$

\begin{tabular}{llll}
\hline \multicolumn{1}{c}{ Attitude } & \multicolumn{1}{c}{ Groups } & Chi square & sig \\
\hline Parental efficacy to control sugar snacking & Afro Caribbean*African American & 7.330 & $0.007 *$ \\
& African American*Haitian & 0.107 & 0.744 \\
& Afro Caribbean *Haitian & 3.916 & $0.048^{*}$ \\
Parental efficacy to brush child's teeth & African American*Afro Caribbean & 6.449 & $0.011^{*}$ \\
& African American*Haitian & 2.525 & 0.112 \\
& Afro Caribbean*Haitian & 0.764 & 0.382 \\
Chance control & & 9.576 & $0.002 *$ \\
& African American*Afro Caribbean & 0.014 & 0.904 \\
& African American*Haitian & 6.119 & $0.013 *$ \\
Intention to control sugar snacking & Afro Caribbean *Haitian & 6.535 & $0.011^{*}$ \\
& African American * Afro Caribbean & 3.211 & 0.073 \\
& African American *Haitian & 0.729 & 0.673 \\
\hline
\end{tabular}

Note. Sig = significance.

$* p<0.05$

Post hoc chi square analyses show that differences in parental efficacy to control sugar snacking existed between Afro-Caribbean and African American parents, and between Afro-Caribbean and Haitian parents. Parental efficacy to brush child's teeth differed between Afro-Caribbean and Haitian parents. There were significant differences between Afro-Caribbean parents, and between Afro-Caribbean and Haitian parents regarding chance control. Intention to control sugar snacking was significantly different between Afro-Caribbean and African American parents.

\section{Test of Hypotheses}

Ho 1.1 There is no relationship between attitudes and beliefs of Black parents about toothbrushing and toothbrushing behaviors for their preschool children.

Logistic regression showed that perceived seriousness of decay predicted children using toothpaste $(p<.001)$, parental efficacy to brush teeth predicted parent brushing 
child's teeth twice a day $(p=.001)$, and chance control predicted parent brushing child's teeth twice a day $(p=.009)$. This null hypothesis is rejected.

Ho 1.2 There is no relationship between attitudes and beliefs of Black parents towards taking their preschool children to the dentist and parents taking their preschool children to the dentist.

Chi-square analysis showed that there was no significant association between attitudes about visiting the dentist and parents taking their preschool children to the dentist. This null hypothesis is not rejected.

Ho 1.3 There is no relationship between attitudes and beliefs of Black parents towards sugar snacking and sugar snacking behaviors for their preschool children.

Logistic regression analysis showed that chance control $(p=.016, p=.018, p=$ $.001)$, parental efficacy to control sugar snacking $(p=.008)$, attitude to prevention ( $p=$ $.001)$ and intention to control sugar snacking $(p=.002)$ were all significant predictors of sugar snacking behaviors. Therefore, the null hypothesis is rejected.

Ho 2.1 There are no between-group differences in attitudes and beliefs about visiting the dentist among Black parents for their preschool children in the U.S.

Chi square analysis showed that there were no significant associations between groups for external control (it is the responsibility of the dentist to prevent decay). This null hypothesis is not rejected.

Ho 2.2 There are no between-group differences in attitudes and beliefs about tooth brushing among Black parents for their preschool children in the U.S. 
Chi square analysis showed significant between group differences in parental efficacy to control sugar snacking $\mathrm{X}^{2}(2, \mathrm{~N}=186)=7.412, p=.025$ and chance control $\mathrm{X}^{2}(2, \mathrm{~N}=186)=9.920, p=.007$. Consequently, this null hypothesis is rejected.

Ho 2.3 There are no between-group differences in attitudes and beliefs about sugar snacking among Black parents for their preschool children in the U.S.

Chi square analysis showed that there were significant between group differences in parental efficacy to brush child's teeth $\mathrm{X}^{2}(2, \mathrm{~N}=186)=7.737, p=.021$ and chance control $\mathrm{X}^{2}(2, \mathrm{~N}=186)=9.920, p=.007$. Consequently, this null hypothesis is rejected.

\section{Chapter Summary}

One hundred and ninety-two surveys were completed in total. A majority of parents were positive about 4 attitude/belief items, and the most of the children practiced 7 favorable oral health behaviors. Oral health attitudes were significant predictors of toothbrushing and sugar snacking behaviors. However, oral health attitudes did not have any significant associations with visiting the dentist. Significant between-group differences were observed for 4 of the attitudes examined. 


\section{CHAPTER V}

\section{Discussion, Conclusion, Recommendations}

This chapter brings closure to the research study, discusses the results of the study and provides a conclusion and recommendations for future research. The chapter is organized into the following sections (a) discussion and limitations, (b) conclusion and (d) recommendations.

Dental caries is one of the most common chronic conditions that affect children in the U.S. even though it is largely preventable (CDC, 2014). In the U. S., non-Hispanic Black children are among those who carry a disproportionate burden of oral health disparities when compared to other racial/ethnic groups (CDC, 2015).

Improving the oral health of Black children is in line with two of the oral health goals of Healthy People 2020: a) to reduce the proportion of young children aged $3-5$ with dental caries experience in their primary teeth; and b) to reduce the proportion of young children aged $3-5$ with untreated tooth decay in their primary teeth (Healthy People 2020, 2017). Early oral health care is important since this is where the foundation will be laid for a lifetime of preventative education and dental care (Bahuguna, et al., 2011). Since the oral health of pre-school children is dependent upon the attitudes and behaviors of their parents towards oral health (Chhabra \& Chhabra, 2012), it is important to understand what characterizes the attitudes and beliefs about caries prevention behaviors, and actual caries prevention behaviors among ethnically diverse, Black parents of preschool children ( $3-5$ years). The existing literature fails to adequately explain the attitudes, beliefs and behaviors about caries preventative behaviors of Black parents of 
preschool children ( $3-5$ years). This study seeks to bridge the knowledge gap allowing for the advancement of public health efforts to improve the oral health of preschool children.

\section{Discussion}

\section{Visiting the Dentist}

Most parents had negative external control (preventing decay is the dentist's responsibility), which means that they accept that they, the parents, are primarily responsible for preventing their children's tooth decay. This finding is contrary to Adair et al. (2004), who found a positive average for external control among African Americans in their sample. Despite this, many parents reported that their child had visited the dentist. Less than half of the participants, however, had reported having a fluoride treatment at the dentist and since fluoride treatments help to reduce tooth decay (AAPD, 2013) and professional fluoride varnish treatments are among the best measures for preventing caries (Twetman, 2008), it is important to increase the number of children receiving such treatments. Even though parents have accepted primary responsibility for preventing their children's tooth decay, visiting the dentist twice annually is still recommended by the AAPD (2013). Given the acknowledged benefits of biannual dentists visits, practitioners and researchers need to be innovative in developing interventions that encourage dental visits. Nevertheless this should be done without changing the view that parents, and not dentists, are primarily responsible for preventing tooth decay in their children. 


\section{Toothbrushing}

Most parents reported that their children use toothpaste, which is a favorable oral health behavior according to Mouth Healthy, 2017. Even though most parents (75\%) reported brushing their teeth twice daily, another favorable behavior (AAPD, 2013; Mouth Healthy, 2017), there is definitely room for improvement. Furthermore, even though a majority of parents in this study have positive intentions to brush their child's teeth, only $66 \%$ of them reported parental efficacy to brush child's teeth. Whilst this finding is also in agreement with Saied-Moallemi et al. (2008) that positive oral health attitudes predict good oral health behaviors, it also indicates the need for culturally tailored interventions geared towards improving parental efficacy to brush children's teeth. The data show that the intention is present, which is favorable, but parents are unable to turn this intention into action unless they are able to improve their efficacy to do so. Effective intervention should be able to accomplish this.

\section{Diet/Sugar Snacking}

As supported by the literature, positive oral health attitudes predicted good oral health behaviors (Saied-Moallemi et al., 2008). Few parents reported that their children eat sugary foods most days or consume soft drinks containing sugar most days. At the same time, only a little over $50 \%$ of parents reported that their children consumed fruits or vegetables most days.

Whilst the data show that a large majority of parents had positive intentions to control sugar snacking only slightly more than $50 \%$ of them had the efficacy necessary to accomplish this goal. It can, therefore, be inferred that interventions should be geared 
toward improving parental efficacy to control sugar snacking rather than towards modifying beliefs on the subject. Since these behaviors are also associated with childhood obesity (Tavares \& Chomitz, 2009), it may, therefore, be beneficial to incorporate and/or use adapted components of proven childhood obesity intervention strategies to address these issues. If childhood obesity interventions are implemented correctly, sugar snacking may be reduced and consumption of fruits and vegetables may be increased simultaneously (Tavares \& Chomitz, 2009).

Results of the study show that oral health attitudes and beliefs differ between Black ethnic groups. These findings are in agreement with Agyemang et al. (2005). These attitudinal and belief differences should, therefore, be taken into consideration when planning oral health interventions. Failure to recognize these differences when developing interventions aimed specifically at improving the oral health of Blacks is likely to make it more difficult to reduce/eliminate oral health disparities that currently exist.

Since, as studies show, there are different attitudes and beliefs between ethnic groups within the Black community, an intervention or approach that is not specifically tailored to a specific group may be ineffective on many of the people it is intended to target. It is, therefore, necessary for researchers to involve members of the target group in the planning stages of any intervention to ensure that it has been customized for the specific group, before implementation.

The broad interventions, targeting all Blacks, may miss some ethnic groups due to differences in culture (Agyemang et al., 2005). The resulting racial and ethnic disparities 
in oral health (CDC, 2015) may continue for many years to come if individual ethnic groups are not addressed from their level of culturally sensitive understanding. The need for different interventions to address the oral health needs of the various Black ethnic groups, means that it may take more thought and collaboration if oral health disparities as mentioned by the surgeon general and in Healthy People 2020 (USDHHS, 2000; Healthy People 2020, 2017) are to be reduced. If this approach is taken, it is plausible that eventually, the noted disparities will be reduced since each group will get the attention it needs.

\section{Limitations}

Only English-speaking participants were included. Therefore, the study cannot be generalized to all Haitians in Miami-Dade County. Despite this, only some of the more recent Haitian immigrants may have been excluded. In some instances, participants were able to speak English better than they could read it, and in those cases, they asked for assistance understanding the questions and were still able to complete the survey. The small sample size and convenience sampling also limited the generalizability of the study, but still allowed for valuable knowledge to be gained.

Participants may not have accurately recalled some of the information requested. However, many of the behavioral questions were routine so the responses should have provided a general idea of their oral health related habits. Participants may also have selected the response they considered to be desirable instead of the one with which they actually agreed. This notwithstanding, the instrument was designed to ask the same 
question in many different ways, a technique which is used to elicit the most reliable response.

Despite unequal numbers of African American, Afro-Caribbean, and Haitian parents significant between-group differences were observed. The survey document, based on its size, gave the impression that it was longer that it actually was. It appeared to intimidate some of the participants. However, most participants still completed the survey in its entirety and, therefore, valuable information was still collected.

\section{Conclusions}

Many parents reported positive attitudes, beliefs and behaviors in line with preventing caries among Black children. Oral health attitudes and beliefs were significant predictors of children's sugar snacking/diet behaviors, and children's tooth brushing behaviors. However, there was no significant relationship observed between parents' oral health attitudes and beliefs, and their children visiting the dentist or receiving professional fluoride treatments.

Between-group differences for African Americans, Afro-Caribbeans and Haitians exist for 4 out of the 8 oral health attitudes and beliefs examined. There were differences between the groups in intention to control sugar snacking, parental efficacy to control sugar snacking, parental efficacy to brush child's teeth and chance control. Afro Caribbean beliefs were significantly different from both African American and Haitian participants in parental efficacy to control sugar snacking and chance control. Significant differences only existed between African American and Afro Caribbean participants for intention to control sugar snacking, and parental efficacy to brush child's teeth. 
The results of this study are conclusive in three areas, a) there is a clear, observable need for oral health interventions that incorporate activities that can improve parental efficacy to practice good oral health behaviors with their children, b) interventions should be culturally relevant and (c) interventions may need to be customized to target specific ethnic groups, even within a race, that suffer a disproportionate burden of oral health disparities.

\section{Recommendations}

Consideration of cultural differences between Black ethnic groups is essential if the effectiveness of oral health interventions is to be maximized. In many areas, where cultural differences exist, different racial/ethnic groups need to be targeted specifically. Therefore, instead of grouping all Black ethnic groups together under an all encompassing racial classification such as "Black", it may be more helpful to identify country of origin in addition to race/ethnicity.

While the survey captured important information and took a maximum of 40 minutes to complete, it was a long survey instrument and appeared to intimidate some of the participants. In future studies, it may be more effective to use a shorter survey instrument that asks fewer questions about each category of attitudes, beliefs, and behaviors.

Future research should further examine parental attitudes and beliefs regarding the role of the dentist in improving/maintaining children's oral health. A more comprehensive understanding of parental attitudes and beliefs regarding the role of the 
dentist will support development and implementation of interventions to address the specific needs of parents.

Future studies should include a clinical examination of participants' children to provide useful data for assessing a child's oral health status and making the necessary referrals for dental health services and oral health education.

Health educators should play a major role in designing and delivering quality oral health and disease prevention interventions for parents of preschoolers. Parental education should be included in interventions geared towards improving children's oral health. Finally, public health professionals must include a culturally appropriate parental component to oral health education in coordinated school health programs.

\section{Summary}

The purpose of this exploratory, cross sectional study was to (a) examine the attitudes, beliefs and behaviors of Black parents about preventative measures against caries for their preschool children (3 - 5 years) and (b) determine whether the attitudes and beliefs about caries preventive behaviors vary between different ethnic groups of Blacks in Miami-Dade.

The final sample of 192 Black parents recruited from predominantly Black preschools in Miami-Dade County completed a 114-item oral health survey. The instrument collected information about oral health attitudes and beliefs of parents and information about the children's oral health behaviors. Data were analyzed using IBM SPSS 20.0 (IBM Corp, 2011). 
Clearly there are opportunities to complement school-based health education for preschool children with a culturally appropriate parental component. Health educators can play a major role in designing and delivering quality oral health and disease prevention interventions for parents of preschoolers. The between-group differences indicate that interventions need to be more specifically tailored to the racial/ethnic group intended to receive the intervention, in order to have greater effectiveness. 


\section{REFERENCES}

Abanto, J., Carvalho, T.S., Mendes, F.M., Wanderley, M.T., Bonecker, M., \& Raggio, D.P. (2011). Impact of oral diseases and disorders on oral health-related quality of life of preschool children. Community Dentistry and Oral Epidemiology, 39, 105114.

Acharya, S., \& Tandon, S. (2011). The effect of early childhood caries on the quality of life of children and their parents. Contemporary Clinical Dentistry, 2(2), 98.

Acs, G., Shulman, R., Wai Ng, M., \& Chussid, S. (1999). The effect of dental rehabilitation on the body weight of children with early childhood caries. Pediatric Dentistry, 21(2), 109-113.

Adair, P. M., Pine, C. M., Burnside, G., Nicoll, A., Gillett, A., Anwar, S., ... Young, D.W. (2004). Familial and cultural perceptions and beliefs of oral hygiene and dietary practices among ethically and socio-economically diverse groups. Community Dental Health, 21(S) 102-111.

Agyemang, C., Bhopal, R., \& Bruijnzeels, M. (2005). Negro, Black, Black African, African American, African Caribbean, African American, or what? Labelling African origin populations in the health arena in the $21^{\text {st }}$ century. Journal of Epidemiology and Community Health, 59, 1014-1018.

Ajzen, I. (1991). The theory of planned behavior. Organizational Behavior and Human Decision Processes, 50(2), 179-211.

Ajzen, I. (2006). TPB diagram. Retrieved from: http://people.umass.edu/aizen/tpb.diag.html\#null-link

Alsumait, A., ElSalhy, M., Raine, K., Cor, K., Gokiert, R., Al-Mutawa, S., \& Amin, M. (2015). Impact of dental health on children's oral health-related quality of life: a cross-sectional study. Health and Quality of Life Outcomes, 13(1), 98.

American Academy of Pediatric Dentistry. (2013). Guideline on fluoride therapy. Pediatric Dentistry, 35(5), E165.

American Academy of Pediatric Dentistry. (2013). Guideline on periodicity of examination, preventive dental services, anticipatory guidance/counseling, and oral treatment for infants, children, and adolescents. Pediatric Dentistry, 35(5), E148.

American Dental Association. (2000). Statement on early childhood caries. Retrieved from: http://www.ada.org/2057.aspx 
American Association of Endodontists. (2000). Oral disease and systemic health: what's the connection. Endodontics. Retrieved from:

http://www.aae.org/uploadedfiles/publications_and_research/endodontics_colleagu es_for_excellence_newsletter/ss00ecfe.pdf

Association of State and Territorial Dental Directors. (2011). Best practice approach: prevention and control of early childhood tooth decay. Retrieved from: http://www.astdd.org/prevention-and-control-of-early-childhood-tooth-decay/

Bagramian, R. A., Garcia-Godoy, F., \& Volpe, A. R. (2009). The global increase in dental caries. A pending public health crisis. American Journal of Dentistry, 21(1), 3-8.

Bahuguna, R., Jain, A., \& Khan, A.K. (2011). Early dental visit-an overview. Asian Journal of Oral Health \& Allied Sciences, 1(1), 58-60.

Benjamin, R. M. (2010). Oral health: the silent epidemic. Public Health Reports, 125(2), 158-159.

Blinkhorn, A. S., Wainwright-Stringer, Y. M., \& Holloway, P. J. (2001). Dental health knowledge and attitudes of regularly attending mothers of high-risk, pre-school children. International Dental Journal, 51(6), 435-438.

British Dental Journal News. (2013). Oral diseases included in global action plan. British Dental Journal, 214(12), 609.

Casamassimo, P. S. (2001). Dental disease prevalence, prevention, and health promotion: the implications on pediatric oral health of a more diverse population. Pediatric Dentistry, 25(1), 16-18.

CDC (2014). Children's oral health. Retrieved from: http://www.cdc.gov/OralHealth/children_adults/child.htm

CDC (2015). Disparities in oral health. Retrieved from: http://www.cdc.gov/oralhealth/oral_health_disparities/index.htm

Chhabra, N., \& Chhabra, A. (2012). Parental knowledge, attitudes and cultural beliefs regarding oral health and dental care of pre-school children in an Indian population: a quantitative study. European Archives of Paediatric Dentistry, 13(2), 76-82.

Chu, S. (2006). Early childhood caries: risk and prevention in underserved populations. Journal of Young Investigators. Retrieved from: http://www.jyi.org/issue/reviewearly-childhood-caries-risk-and-prevention-in-underserved-populations/ 
dos Santos Junior, V. E., de Sousa, R. M. B., Oliveira, M. C., de Caldas Junior, A. F., \& Rosenblatt, A. (2014). Early childhood caries and its relationship with perinatal, socioeconomic and nutritional risks: a cross-sectional study. BMC Oral Health, 14(1), 47.

Dye, B. A., Li, X., \& Thornton-Evans, G. (2012). Oral health disparities as determined by selected Healthy People 2020 oral health objectives for the United States, 2009-2010. Hyattsville (MD): National Center for Health Statistics.

Dye, B. A., Thornton-Evans, G., Li, X., \& Iafolla, T. J. (2015). Dental caries and sealant prevalence in children and adolescents in the United States, 2011-2012. US Department of Health and Human Services, Centers for Disease Control and Prevention, National Center for Health Statistics.

Edberg, M. (2015). Essentials of health behavior. Burlington, MA: Jones \& Bartlett Publishers.

Edelstein. B. L., \& Chinn, C. H. (2009). Update on disparities in oral health and access to dental care for America's children. Academic Pediatrics, 9(6), 415-419.

ERIC Thesaurus. Ethnic groups. Retrieved from: http://eric.ed.gov/?ti=Ethnic+Groups

Feldens, C. A., Giugliani, E. R. J., Duncan, B. B., Drachler, M., \& Vitolo, M. R. (2010). Long-term effectiveness of a nutritional program in reducing early childhood caries: a randomized trial. Community Dentistry and Oral Epidemiology, 38(4), 324-332.

Filstrup, S. I., Briskie, D., Da Fonseca, M., Lawrence, L., Wandera, A., Inglehart, M. R. (2003). Early childhood caries and quality of life: child and parent perspectives. Pediatric Dentistry, 25(5), 431-440.

Fishbein, M., \& Ajzen, I. (1975). Belief, Attitude, Intention, and Behavior: An Introduction to Theory and Research.Reading, MA: Addison-Wesley.

Green, L. J., \& Kreuter, M. W. (1999). The precede-proceed model. Health promotion planning: an educational approach. 3rd ed. Mountain View (CA): Mayfield Publishing Company, 32-43.

Harrison, R. L., \& Wong, T. (2003). An oral health promotion program for an urban minority population of preschool children. Community Dentistry and Oral Epidemiology, 31(5), 392-399. 
Healthy People 2020 (2017). Oral health. Washington, DC: U.S. Department of Health and Human Services, Office of Disease Prevention and Health Promotion Retrieved from: http://www.healthypeople.gov/2020/topics-objectives/topic/oralhealth

Hilton, I. V., Stephen, S., Barker, J. C., \& Weintraub, J. A. (2007). Cultural factors and children's oral health care: a qualitative study of carers of young children. Community Dentistry and Oral Epidemiology, 35(6), 429-438.

Huebner, C. E. \& Milgrom, P. (2015). Evaluation of a parent-designed programme to support tooth brushing of infants and young children. International Journal of Dental Hygeine, 13, 65-73.

IBM Corp. (2011). IBM SPSS Statistics for Windows, Version 20.0 [computer software]. Armonk, NY.

Institute of Medicine (2011). Advancing oral health in America. Report Brief.

Jackson, S. L., Vann, Jr. W. F., Kotch, J. B., Pahel, B. T., \& Lee, J. Y. (2011). Impact of poor oral health on children's school attendance and performance. American Journal of Public Health, 101(10), 1900-1906.

Kawashita, Y., Kitamura, M., \& Saito, T. (2011). Early childhood caries. International Journal of Dentistry, 2011.

Kwan, S. Y. L., Petersen, P. E., Pine, C. M., \& Borutta, A. (2005). Health-promoting schools: an opportunity for oral health promotion. Bulletin of the World Health Organization, 83(9), 677-685.

Li, X., Kolltveit, K. M., Tronstad, L., \& Olsen, I. (2000). Systemic diseases caused by oral infection. Clinical microbiology reviews, 13(4), 547-558.

Lukes, S. M. (2010). Oral health knowledge attitudes and behaviors of migrant preschooler parents. Journal of Dental Hygiene, 84(2), 87-93.

Merriam-Webster, Incorporated. (2017). African-American. Retrieved from: https://www.merriam-webster.com/dictionary/African-American

Merriam-Webster, Incorporated. (2017). Haitian. Retrieved from: https://www.merriamwebster.com/dictionary/Haitian

Mosby's Medical Dictionary (2009). Disease Prevention. Retrieved from: http://medicaldictionary.thefreedictionary.com/disease+prevention 
Mouth Healthy (2017). Babies and kids healthy habits. Retrieved from: http://www.mouthhealthy.org/en/babies-and-kids/healthy-habits/

Mouth Healthy (2017). Babies and kids nutrition. Retrieved from: http://www.mouthhealthy.org/en/babies-and-kids/nutrition/

Mouradian, W. E., Wehr, E., \& Crall, J. J. (2000). Disparities in childrens oral health and access to dental care. The Journal of the American Medical Association, 284(20), 2625-2631.

Murrin, S. (2016). Most Children with Medicaid in four States are not receiving required dental services. Washington, DC: U.S. Department of Health and Human Services, Office of Inspector General.

Naidu, R., Nunn, J., \& Donnelly-Swift, E. (2016). Oral health-related quality of life and early childhood caries among preschool children in Trinidad. BMC Oral Health, 16(1), 128.

Naidu, R., Nunn, J., \& Forde, M. (2012). Oral healthcare of preschool children in Trinidad: a qualitative study of parents and caregivers. BMC Oral Health, 12(1), 27-40.

National Cancer Institute (U.S.). (1995). Theory at a glance: A guide for health promotion practice. Bethesda, MD: U.S. Dept. of Health and Human Services, Public Health Service, National Institutes of Health, National Cancer Institute.

National Maternal and Child Oral Health Resource Center. Infant, children and adolescent nutrition questionnaires. Retrieved from: https://www.brightfutures.org/nutrition/pdf/pocket.pdf

Ndiokwelu, E., \& Ndiokwelu, C. (2006). Dietary counseling in the prevention and control of oral diseases-a review. African Journal of oral Health, 3(1-2).

Oxford University Press. (2017). Afro-Caribbean. Retrieved from: https://en.oxforddictionaries.com/definition/us/afro-caribbean

Petersen, P. E. (2003). The world oral health report 2003: continuous improvement of oral health in the 21st century - the approach of the WHO global oral health programme. Community Dentistry and Oral Epidemiology, 31 (supple. 1), 3-24.

Petersen, P. E., Bourgeois, D., Ogawa, H., Estupinan-Day, S., \& Ndiaye, C. (2005). The global burden of oral diseases and risks to oral health. Policy and Practice. Theme Papers. 
Petersen, P. E., Hunsrisakhun, J., Thearmontree, A., Pithpornchaiyakul, S., Hintao, J., Jurgensen, N., \& Ellwood, R. P. (2015). School-based intervention for improving the oral health of children in southern Thailand. Community Dental Health, 32, 4450 .

Pine, C. M., McGoldrick, P. M., Burnside, G., Curnow, M. M., Chesters, R. K., Nicholson, J., \& Huntington, E. (2000). An intervention programme to establish regular toothbrushing: understanding parents' beliefs and motivating children. International Dental Journal, 50(S6_Part1), 312-323.

Pine, C., Adair, P., Nicoll, A., Burnside, G., Petersen, P.E., Beighton, D., ...Whelton, H. (2004). International comparisons of health inequalities in childhood dental caries. Community Dental Health, 21(S), 121-130.

Pine, C., Adair, P., Petersen, P.E., Douglas, C., Burnside, G., Nicoll, A.,...Williams, S. (2004). Developing explanatory models of health inequalities in childhood dental caries. Community Dental Health, 21(S), 86-95.

Ronis, D. L., Lang, P., Antonakos, C. L., \& Borgnakke, W. S. (1998). Preventative oral health behaviors among African Americans and Whites in Detroit. Journal of Public Health Dentistry, 58(3), 234-240.

Rowan-Legg, A. (2013). Oral health care for children: a call for action. Paediatric Child Health, 18(1), 37-43.

Saied-Moallemi, Z., Virtanen, J.I., Ghofranipour, F., \& Murtomaa, H. (2008). Influence of mothers' oral health knowledge and attitudes on their children's dental health. European Archives of Paediatric Dentistry, 9(2), 79-83.

Schwartz, S. J., Unger, J. B., Zamboanga, B. L., \& Szapocznik, J. (2010). Rethinking the concept of acculturation: implications for theory and research. American Psychologist, 65(4), 237.

Sheiham, A. (2005). Oral health, general health, and quality of life. Bulletin of the World Health Organization, 83(9), 644-645.

Sheiham, A. (2006). Dental caries affects weight, growth, and quality of life in pre-school children. British Dental Journal, 201, 625-626.

Silk, H. (2014). Diseases of the mouth. Primary Care: Clinics in Office Practice, 41(1), 75-90. 
Simmer-Beck, M., Walker, M., Gadbury-Amyot, C., Liu, Y., Kelly, P., \& Branson, B. (2015). Effectiveness of an alternative dental workforce model on the oral health of low-income children in a school-based setting. American Journal of Public Health, 105(9), 1763-1769.

Skaret, E., Espelid, I., Skeie, M. S., \& Haugejordan, O. (2008). Parental beliefs and attitudes towards child caries prevention: assessing consistency and validity in a longitudinal design. BMC Oral Health, 8, 1-8.

Skeie, M. S., Espelid, I., Riordan, P. J., \& Klock, K. S. (2008). Caries increment in children aged 3-5 years in relation to parents' dental attitudes: Oslo, Norway 2002 to 2004. Community dentistry and oral epidemiology, 36(5), 441-450.

Sohn, W., Taichman, S. L., Ismail, A. I., \& Reisine, S. (2008). Caregiver's perception of child's oral health status among low-income African Americans. Pediatric Dentistry, 30(6), 480-487.

Tavares, M., \& Chomitz, V. (2009). A healthy weight intervention for children in a dental setting: a pilot study. The Journal of the American Dental Association, 140(3), 313-316.

Touger-Decker, R., \& Mobley, C. (2013). Position of the Academy of Nutrition and Dietetics: oral health and nutrition. Journal of the Academy of Nutrition and Dietetics, 113(5), 693-701.

Twetman, S. (2008). Prevention of Early Childhood Caries (ECC) Review of literature published 1998-2007. European Archives of Paediatric Dentistry, 9(1), 12-18.

U.S. Department of Health and Human Services. (2000). Oral health in America: A report of the surgeon general. Rockville MD: U. S. Department of Health and Human Services, National Institute of Dental and Craniofacial Research, National Institutes of Health.

U.S. Department of Health and Human Services. (2003). A National Call to Action to Promote Oral Health. Retrieved from: http://www.nidcr.nih.gov/datastatistics/surgeongeneral/nationalcalltoaction/nation alcalltoaction.htm

Vargas, C. M., \& Ronzio, C. R. (2006). Disparities in early childhood caries. BMC oral health, 6(1), S3. 
Vázquez-Nava, F., Vázquez-Rodríguez, E. M., Saldívar-González, A. H., Lin-Ochoa, D., Martínez-Perales, G. M., \& Joffre-Velázquez, V. M. (2010). Association between obesity and dental caries in a group of preschool children in Mexico. Journal of Public Health Dentistry, 70(2), 124-130.

Vermaire, J. H., Hoogstraten, J., Van Loveren, C., Poorterman, J. H. G., \& Van Exel, N. J. A. (2009). Attitudes towards oral health among parents of 6-year-old children at risk of developing caries. Community Dentistry and Oral Epidemiology, 38, 507520 .

Watson, M. R., Horowitz, A. M., Garcia, I., \& Canto, M. T. (2001). A Community Participatory Oral Health Promotion Program in an Inner-city Latino Community. Journal of Public Health Dentistry, 61(1), 34-41.

Watt, R. G. (2005). Strategies and approaches in oral disease prevention and health promotion. Bulletin of the World Health Organization, 83(9), 711-718.

Wennhall, I., Mårtensson, E. M., Sjunnesson, I., Matsson, L., Schröder, U., \& Twetman, S. (2005). Caries-preventive effect of an oral health program for preschool children in a low socio-economic, multicultural area in Sweden: results after one year. Acta Odontologica Scandinavica, 63(3), 163-167.

Wennhall, I., Matsson, L., Schröder, U., \& Twetman, S. (2008). Outcome of an oral health outreach programme for preschool children in a low socioeconomic multicultural area. International Journal of Paediatric Dentistry, 18(2), 84-90.

Weyant, R. J., Manz, M., Corby, P., Rustveld, L., \& Close, J. (2007). Factors associated with parents' and adolescents' perceptions of oral health and need for dental treatment. Community Dentistry and Oral Epidemiology, 35, 321-330.

Wolff, M. S., Hill, R., Wilson-Genderson, M., Hirsch, S., Dasanayake, A. P. (2016). Nationwide 2.5-year school-based public health intervention program designed to reduce the incidence of caries in children of Grenada. Caries Research, 50(suppl 1), 68-77.

World Health Organization. Health promotion. Retrieved from: http://www.who.int/topics/health_promotion/en/

World Health Organization. (2006). Constitution of the world health organization. Retrieved from: http://www.who.int/governance/eb/who_constitution_en.pdf

World Health Organization. (2012). Oral health fact sheet No.318. Retrieved from: http://www.who.int/mediacentre/factsheets/fs318/en/ 
World Health Organization. (2017). Oral health. Retrieved from: http://www.who.int/topics/oral_health/en/

World Health Organization Quality of Life Group. (1998). The World Health Organization quality of life assessment (WHOQOL): development and general psychometric properties. Social Science \& Medicine, 46(12), 1569-1585.

Zong, J., \& Batalova, J. (2016). Caribbean immigrants in the United States. Retrieved from: http://www.migrationpolicy.org/article/caribbean-immigrants-united-states 


\section{APPENDICES}

\section{Appendix A}

\section{Figures}

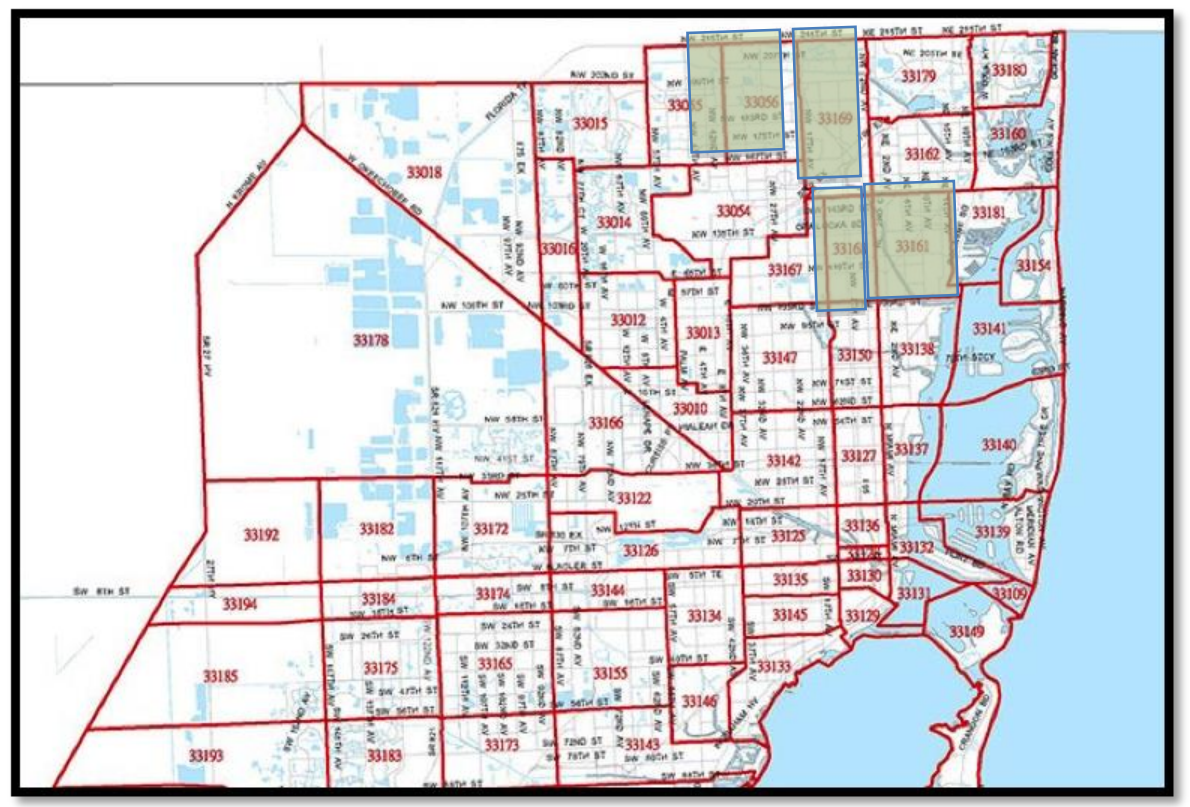

Figure 3 Map of Miami highlighting Zip codes where data was collected.

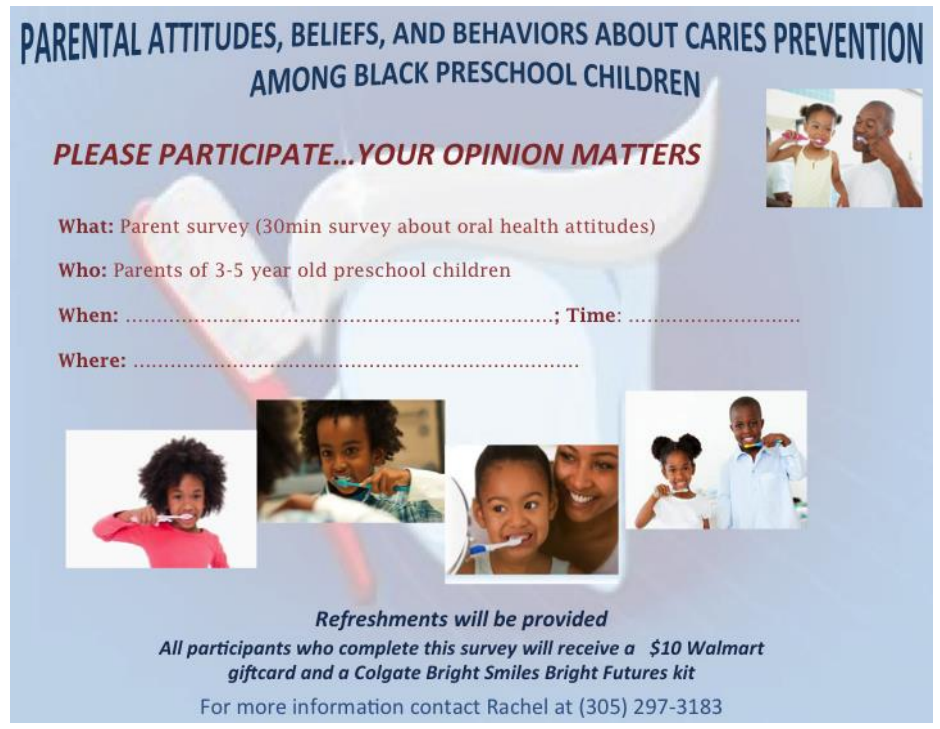

Figure $4 \quad$ Recruitment Flyer 


\section{Appendix B}

\section{Oral Health Questionnaire}

ORAL HEALTH QUESTIONNAIRE

ID No:

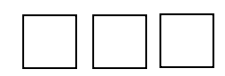

\section{Preschool Children Oral Health Study \\ Parent Questionnaire}

Thank you for agreeing to take part in a survey on preschool children's dental health to help give us an understanding of parental attitudes towards preschool children's caries preventative behaviors. We are trying to understand the wide range of dental attitudes, beliefs and behaviors that parents of preschool children have about their children's teeth. In this questionnaire there are no right or wrong answers - we are just trying to understand what is usual for your family.

All information provided in this questionnaire will be treated confidentially.

Participation in this study is optional and you may discontinue at any time if you wish to do so.

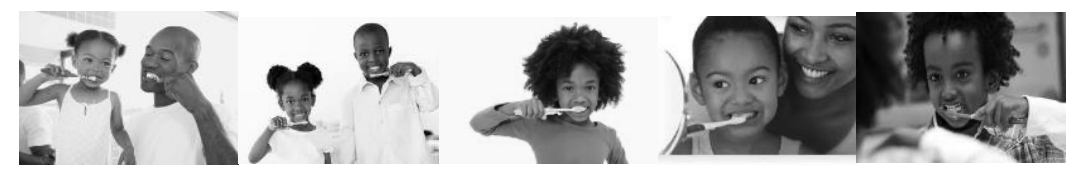

The following questions are about your preschool child.

Section A (About Me And My Child)

The first set of questions is about visiting the dentist, toothache, and general questions about your child's baby teeth and dental health.

1. Have you ever taken your child to a dentist?

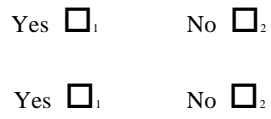

If yes, did the dentist examine your child's teeth?

If yes, when was the last visit?

Within the last 3 months $\square_{1} \quad$ Within the last 12 months $\square_{3}$

Within the last 6 months $\square_{2} \quad$ Within the last 2 years $\quad \square_{4}$

Has your child ever had a fluoride treatment during a visit to the dentist?

Yes $\square$. No $\square_{2} \quad$ I do not know $\square_{3}$ 


\section{ORAL HEALTH QUESTIONNAIRE}

2. Has your child ever had toothache in the last year?

Yes $\square$. No $\square$

If yes, how often? $\quad$ once $\square_{1} \quad$ twice $\square_{2}$ three times $\square_{3}$ more $\square$

3. If your child gets toothache would you (Check all that apply):

$\begin{array}{llll}\text { give your child painkillers } & \square_{1} & \text { obtain antibiotics } & \square_{2} \\ \text { go to the dentist } & \square_{3} & \text { go to the doctor } & \square_{4} \\ \text { use a herbal remedy } & \square_{5} & \text { ask for the tooth to be taken out } & \square_{6} \\ \text { do nothing, it will get better on its own } & \square_{7} & \text { consult family } & \square_{8} \\ \text { go to pharmacist } & \square_{9} & \text { seek other medical care } & \square_{10}\end{array}$

The next set of questions are about feelings and attitudes towards tooth decay and toothbrushing. Please tick one box on each line.

\begin{tabular}{|c|c|c|c|c|c|}
\hline & $\begin{array}{l}\text { strongly } \\
\text { disagree }\end{array}$ & disagree & $\begin{array}{l}\text { neither } \\
\text { agree or } \\
\text { disagree }\end{array}$ & agree & $\begin{array}{l}\text { strongly } \\
\text { agree }\end{array}$ \\
\hline $\begin{array}{l}\text { 4. As a family, we are confident that we can reduce } \\
\text { the chances of our child getting tooth decay }\end{array}$ & 1 & 2 & 3 & 4 & \\
\hline 5. Tooth decay will not get better by itself & 1 & 2 & 3 & 4 & 5 \\
\hline $\begin{array}{l}\text { 6. Regular visits to the dentist would be effective in } \\
\text { stopping our child from having tooth decay }\end{array}$ & 1 & 2 & 3 & 4 & 5 \\
\hline $\begin{array}{l}\text { 7. Tooth decay would have major consequences on } \\
\text { our child's general health }\end{array}$ & 1 & 2 & 3 & 4 & 5 \\
\hline 8. Tooth decay is a serious problem in baby teeth & 1 & 2 & 3 & 4 & 5 \\
\hline $\begin{array}{l}\text { 9. As parents, it is our responsibility to prevent our } \\
\text { child from getting tooth decay. }\end{array}$ & 1 & 2 & 3 & 4 & 5 \\
\hline $\begin{array}{l}\text { 10. Our child losing a baby tooth due to tooth decay } \\
\text { would be upsetting }\end{array}$ & 1 & 2 & 3 & 4 & 5 \\
\hline $\begin{array}{l}\text { 11. We feel it is important that we check our child's } \\
\text { teeth for decay }\end{array}$ & 1 & 2 & 3 & 4 & 5 \\
\hline $\begin{array}{l}\text { 12. If our child does not want to brush his/her teeth } \\
\text { every day we don't feel we should make them }\end{array}$ & 1 & 2 & 3 & 4 & 5 \\
\hline $\begin{array}{l}\text { 13. It is important to clean my child's teeth every day } \\
\text { so my child has a nice smile }\end{array}$ & 1 & 2 & 3 & 4 & 5 \\
\hline $\begin{array}{l}\text { 14. It is the responsibility of the dentist to prevent our } \\
\text { child getting tooth decay }\end{array}$ & 1 & 2 & 3 & 4 & \\
\hline
\end{tabular}


ORAL HEALTH QUESTIONNAIRE

\begin{tabular}{|l|r|r|r|r|r|}
\hline & $\begin{array}{r}\text { strongly } \\
\text { disagree }\end{array}$ & $\begin{array}{r}\text { neither } \\
\text { agree or } \\
\text { disagree }\end{array}$ & $\begin{array}{r}\text { sisagree } \\
\text { agree }\end{array}$ & $\begin{array}{r}\text { strongly } \\
\text { agree }\end{array}$ \\
\hline $\begin{array}{l}\text { 34. My child's teeth are brushed as part of my child's } \\
\text { daily washing routine (washing hands and face) }\end{array}$ & 1 & 2 & 5 \\
\hline $\begin{array}{l}\text { 35. Buying toothbrushes and toothpaste for the whole } \\
\text { family is expensive. }\end{array}$ & 1 & 2 & 3 & 4 & 5 \\
\hline 36. Tooth decay runs in families. & 1 & 2 & 3 & & 4 \\
\hline 37. Some people just naturally have soft teeth. & 1 & 2 & 3 & & 4 \\
\hline
\end{tabular}

\section{Section B (Oral Hygiene Behaviors)}

The next set of questions are about toothbrushing / tooth cleaning.

1. What is used to clean your child's teeth? (Please tick as many boxes as necessary)

Toothbrush $\quad \square_{1} \quad$ Chewing sticks $\square$.

Cloth $\quad \square_{3} \quad$ Finger $\quad \square_{4}$

Other $\square$ (please specify)

Nothing used

$\square 6$

What else do you use?

Toothpaste

$\square$ - Salt

Powder

$\square$ Other $\square_{4}$ (please specify)

Nothing

$\square_{5}$

2. Who brushes/cleans your child's teeth? (Please tick as many boxes as necessary)

child

$\square$. parent

someone else

$\square$ teeth are not brushed / cleaned

$\square$

$\square$

3. How often are your child's teeth brushed/cleaned? (Please tick one box)

$\begin{array}{llll}\text { Never } & \square_{1} & \text { Not every day } & \square_{2} \\ \text { Once a day } & \square_{3} & \text { Twice a day } & \square_{4} \\ \text { Three times a day } & \square_{5} & \text { Every other day } & \square_{6}\end{array}$


ORAL HEALTH QUESTIONNAIRE

4. How old was your child when he/she first started having his/her teeth brushed/cleaned?

$\begin{array}{llll}\text { Under 1 year } & \square_{1} & \text { 1 year - under 2 years } & \square_{2} \\ \text { 2 years - under 3 years } & \square_{3} & \text { 3 years or over } & \square_{4} \\ \text { Cannot remember } & \square_{5} & \text { Teeth are not brushed/cleaned } & \square_{6}\end{array}$

5. How old was your child when he/she started brushing/cleaning his/her teeth on his/her own?
Under 2 years
$\square .2$ years - under 3 years
3 years or over
$\square$ Cannot remember
Does not brush / clean their teeth
$\square$

6. Has your child always brushed/cleaned his/her own teeth?

Yes

No, someone used to help

Does not brush / clean their teeth

Please tick one box on each line.

\begin{tabular}{|c|c|c|c|c|}
\hline & Every day & Most days & Occasionally & Never \\
\hline $\begin{array}{l}\text { 7. Do you remind your child to } \\
\text { brush/clean their teeth? }\end{array}$ & 1 & 2 & 3 & 4 \\
\hline $\begin{array}{l}\text { 8. Do you check if they have } \\
\text { brushed/cleaned their teeth? }\end{array}$ & 1 & 2 & 3 & 4 \\
\hline $\begin{array}{l}\text { 9. Do you watch them while they } \\
\text { brush/clean their teeth? }\end{array}$ & 1 & 2 & 3 & 4 \\
\hline $\begin{array}{l}\text { 10. Do you help them to brush/clean } \\
\text { their teeth? }\end{array}$ & 1 & 2 & 3 & 4 \\
\hline $\begin{array}{l}\text { 11. Do you brush/clean their teeth } \\
\text { for them? }\end{array}$ & 1 & 2 & 3 & 4 \\
\hline
\end{tabular}


ORAL HEALTH QUESTIONNAIRE

4. How old was your child when he/she first started having his/her teeth brushed/cleaned?

$\begin{array}{llll}\text { Under 1 year } & \square_{1} & \text { 1 year - under 2 years } & \square_{2} \\ \text { 2 years - under 3 years } & \square_{3} & \text { 3 years or over } & \square_{4} \\ \text { Cannot remember } & \square_{5} & \text { Teeth are not brushed/cleaned } & \square_{6}\end{array}$

5. How old was your child when he/she started brushing/cleaning his/her teeth on his/her own?
Under 2 years
$\square .2$ years - under 3 years
3 years or over
$\square$ Cannot remember
Does not brush / clean their teeth
$\square$

6. Has your child always brushed/cleaned his/her own teeth?

Yes

No, someone used to help

Does not brush / clean their teeth

Please tick one box on each line.

\begin{tabular}{|c|c|c|c|c|}
\hline & Every day & Most days & Occasionally & Never \\
\hline $\begin{array}{l}\text { 7. Do you remind your child to } \\
\text { brush/clean their teeth? }\end{array}$ & 1 & 2 & 3 & 4 \\
\hline $\begin{array}{l}\text { 8. Do you check if they have } \\
\text { brushed/cleaned their teeth? }\end{array}$ & 1 & 2 & 3 & 4 \\
\hline $\begin{array}{l}\text { 9. Do you watch them while they } \\
\text { brush/clean their teeth? }\end{array}$ & 1 & 2 & 3 & 4 \\
\hline $\begin{array}{l}\text { 10. Do you help them to brush/clean } \\
\text { their teeth? }\end{array}$ & 1 & 2 & 3 & 4 \\
\hline $\begin{array}{l}\text { 11. Do you brush/clean their teeth } \\
\text { for them? }\end{array}$ & 1 & 2 & 3 & 4 \\
\hline
\end{tabular}




\section{ORAL HEALTH QUESTIONNAIRE}

12. When do you brush/clean your child's teeth? (Please tick as many boxes as necessary)

When they first get up in the morning

Before lunch

$\square$ After breakfast

$\square$

$\square$ After lunch

Before dinner

$\square$ After dinner

$\square$.

Before going to sleep at night

$\square \quad$ Teeth are not brushed

口。

Other occasions $\square$, please specify.

13. When does your child brush/clean his/her teeth by themselves? (Please tick as many boxes as necessary)

When they first get up in the morning

$\square . \quad$ After breakfast

$\square$

Before lunch

$\square$ After lunch

$\square$

Before dinner

$\square$ After dinner

Before going to sleep at night

Child does not brush their own teeth

$\square$ 。

$\square_{8}$

Other occasions $\square$, please specify ...

14. People start using toothpaste at different ages. Has your child started using toothpaste?

Yes, always

Yes, sometimes

No

If yes, which brand of toothpaste do you usually buy for your child to use?

Brand name

At what age did your child begin using toothpaste?

$\begin{array}{lll}\square_{1} & \text { 1 year - under 2 years } & \square_{2} \\ \square_{3} & \text { 3 years or over } & \square_{4} \\ \square_{5} & \text { Does not use toothpaste } & \square_{6}\end{array}$

2 years - under 3 years

Cannot remember

Does not use toothpaste

$\square$.

Cannot remember

15. When your child's teeth are brushed, do you use toothpaste?

Never use toothpaste

Sometimes use toothpaste

Always use toothpaste 
ORAL HEALTH QUESTIONNAIRE

16. Does your child use a toothbrush?

Yes $\square$. No $\square_{2}$

If yes, does your child:

have his/her own toothbrush? $\square_{1} \quad$ OR $\quad$ do they share a toothbrush with someone else? $\square_{2}$

17. If your child uses toothpaste, how much toothpaste does your child usually use on his/her toothbrush? Please tick the picture which most closely resembles the amount of toothpaste you use.

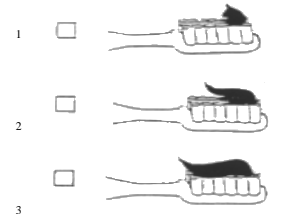

Section C (Dietary Practices)

The following questions are related to eating and drinking.

1. Have you ever had advice about what your child should or should not be eating or drinking to look after his/her teeth?

Yes $\square$. No $\square 2$

If yes, who has advised you?

family $\square_{1} \quad$ friends $\square_{2} \quad$ dentist $\square_{3} \quad$ doctor $\square_{4} \quad$ baby clinic $\square$

other $\square_{6}$ please specify

Please tick one box on each line.

\begin{tabular}{|c|c|c|c|c|c|}
\hline & Every day & Most days & Once a week & Occasionally & Never \\
\hline $\begin{array}{l}\text { 2. How often does your child eat } \\
\text { sweets/ candy (including } \\
\text { chocolates)? }\end{array}$ & 1 & 2 & 3 & 4 & 5 \\
\hline $\begin{array}{l}\text { 3. How often does your child eat } \\
\text { sugary foods between meals (for } \\
\text { example, cookies/biscuits, cake, } \\
\text { jam)? }\end{array}$ & 1 & 2 & 3 & 4 & 5 \\
\hline $\begin{array}{l}\text { 4. How often does your child drink } \\
\text { soft drinks containing sugar? } \\
\text { (including soda, fizzy drinks, etc; } \\
\text { not "diet" type drinks) }\end{array}$ & 1 & 2 & 3 & 4 & 5 \\
\hline $\begin{array}{l}\text { 5. How often does your child eat } \\
\text { fresh, canned, or frozen fruit? }\end{array}$ & 1 & 2 & 3 & 4 & \\
\hline
\end{tabular}




\section{ORAL HEALTH QUESTIONNAIRE}

\begin{tabular}{|c|c|c|c|c|c|}
\hline & Every day & Most days & Once a week & Occasionally & Never \\
\hline $\begin{array}{l}\text { 6. How often does your child eat } \\
\text { fresh, canned, or frozen } \\
\text { vegetables? }\end{array}$ & 1 & 2 & 3 & 4 & 5 \\
\hline
\end{tabular}

7. What does your child usually eat/drink within an hour before going to bed to sleep at night?

Eats $_{1}$

Drinks $_{2}$

Does not eat/drink before going to bed

8. Many children take a drink to bed with them either to have before they go to sleep, or during the night. How often does your child have something to drink in bed or during the night? (Please tick one box)

$\begin{array}{llll}\text { Every day } & \square_{1} & \text { Most days } & \square_{2} \\ \text { Occasionally } & \square_{3} & \text { Never } & \square\end{array}$

9. When your child has a drink in bed or during the night, what does he/she usually have? (Please tick as many boxes as necessary)

$\square$ Milk drinks (eg. chocolate milk)

Milk with sugar or honey

$\square$ Fruit juices

$\square$

Fruit squashes

$\square$. Fizzy drinks

Tea/coffee

$\square$ Water

$\square$

Herbal drinks/tea

$\square$ 口 Other $\square_{10}$ (please specify)....

Never has a drink in bed

$\square_{11}$

10. Thinking about food, how often does your child eat in bed or during the night? (Please tick one box) Every day

$\square$. Most days

$\square 2 \quad$ Occasionally

$\square 3 \quad$ Never 


\section{ORAL HEALTH QUESTIONNAIRE}

11. When your child has something to eat when going to sleep or during the night, what does he/she usually have?

Sweet biscuits/cookies (including chocolate biscuits/cookies) $\square$ Fruit $\square$ Savory and plain biscuits/crackers (including cheese biscuits) $\square$ Sandwiches (sweet)

Cakes

$\square$ Sweets or chocolate

Crisps or savory snacks

$\square \quad$ Never eats in bed

Other

$\square$, please specify

12. When you sweeten your child's drinks, what do you add?

Sugar

$\square$. Honey

Condensed milk

$\square$ ever sweeten child's drinks

Other

$\square$ s please specify

13. Which drinks do you sweeten?
Milk
$\square$ Water
Tea
$\square$ Other
$\square$ please specify

The next set of questions are about feelings and attitudes towards sugary foods and drinks.

Please tick one box on each line

\begin{tabular}{|c|c|c|c|c|c|}
\hline & $\begin{array}{l}\text { strongly } \\
\text { disagree }\end{array}$ & disagree & $\begin{array}{l}\text { neither } \\
\text { agree or } \\
\text { disagree }\end{array}$ & agree & $\begin{array}{l}\text { strongly } \\
\text { agree }\end{array}$ \\
\hline $\begin{array}{l}\text { 14. As a family, we intend controlling how often our } \\
\text { child has sugary foods or drinks between meals }\end{array}$ & 1 & 2 & 3 & 4 & 5 \\
\hline $\begin{array}{l}\text { 15. The people in my family would feel it was } \\
\text { important to control how often our child has } \\
\text { sugary foods and drinks between meals }\end{array}$ & 1 & 2 & 3 & 4 & 5 \\
\hline $\begin{array}{l}\text { 16. As a family, we feel it is difficult for us to stop } \\
\text { our child having sugary foods and drinks between } \\
\text { meals }\end{array}$ & 1 & 2 & 3 & 4 & 5 \\
\hline $\begin{array}{l}\text { 17. We feel able to give our child healthy alternatives } \\
\text { to sugary foods between meals (e.g. like apples } \\
\text { instead of sweets). }\end{array}$ & 1 & 2 & 3 & 4 & 5 \\
\hline $\begin{array}{l}\text { 18. We feel able to give our child healthy alternatives } \\
\text { to sugary drinks between meals (e.g. like water } \\
\text { instead of a fizzy drink) }\end{array}$ & 1 & 2 & 3 & 4 & 5 \\
\hline
\end{tabular}


ORAL HEALTH QUESTIONNAIRE

\begin{tabular}{|c|c|c|c|c|c|}
\hline & $\begin{array}{l}\text { strongly } \\
\text { disagree }\end{array}$ & disagree & $\begin{array}{l}\text { neither } \\
\text { agree or } \\
\text { disagree }\end{array}$ & agree & $\begin{array}{r}\text { strongly } \\
\text { agree }\end{array}$ \\
\hline $\begin{array}{l}\text { 19. It is worthwhile to give our child } \\
\text { sweets/biscuits/cookies to behave well. }\end{array}$ & 1 & 2 & 3 & 4 & 5 \\
\hline $\begin{array}{l}\text { 20. Our child eating sugary foods and drinks in } \\
\text { between meals would cause tooth decay }\end{array}$ & 1 & 2 & 3 & 4 & 5 \\
\hline $\begin{array}{l}\text { 21. The people we know well would feel it was } \\
\text { important to control how often our child has } \\
\text { sugary foods and drinks }\end{array}$ & 1 & 2 & 3 & 4 & 5 \\
\hline $\begin{array}{l}\text { 22. In our family, it would be unfair not to give } \\
\text { sweets to our child every day }\end{array}$ & 1 & 2 & 3 & 4 & 5 \\
\hline $\begin{array}{l}\text { 23. It is often too stressful to say no to my child when } \\
\text { they want sweets }\end{array}$ & 1 & 2 & 3 & 4 & 5 \\
\hline $\begin{array}{l}\text { 24. When our child is tired, it can be a struggle to } \\
\text { brush his/her teeth }\end{array}$ & 1 & 2 & 3 & 4 & 5 \\
\hline $\begin{array}{l}\text { 25. Bringing our child to the dentist on a regular basis } \\
\text { is the best way to prevent tooth decay }\end{array}$ & 1 & 2 & 3 & 4 & 5 \\
\hline $\begin{array}{l}\text { 26. It is not worth it to battle with our child to brush } \\
\text { his/her teeth twice a day }\end{array}$ & 1 & 2 & 3 & 4 & 5 \\
\hline 27. It is just bad luck if our child gets tooth decay & 1 & 2 & 3 & 4 & 5 \\
\hline $\begin{array}{l}\text { 28. The dentist is the best person to prevent tooth } \\
\text { decay in our child }\end{array}$ & 1 & 2 & 3 & 4 & 5 \\
\hline
\end{tabular}

\section{Section D (Parent's Oral Health Behaviors)}

The following questions are related to your experiences of visiting the dentist and oral care

1. What is your usual reason for going to see a dentist? (Please tick one box)

Regularly for a check up

Regularly for treatment

Only if I have problems with my teeth or gums

I do not visit a dentist

$\square$

$\square$

$\square$
$\square$

2. What brand of toothpaste do you usually use? 


\section{ORAL HEALTH QUESTIONNAIRE}

3. When do you brush your teeth? (Please tick as many boxes as necessary)

When you first get up in the morning

$\square$. After breakfast

Before mid-day meal

$\square$ After mid-day meal

Before evening meal

$\square$. After evening meal

Before going to bed

$\square \quad$ Do not brush every day

$\square$

$\square_{4}$

$\square 6$

Other occasions $\square$, please specify

Please tick one box on each line.

\begin{tabular}{|c|c|c|c|c|}
\hline & Every day & Most days & Occasionally & Never \\
\hline How often do you use the fol & & & & \\
\hline 4. Dental floss & 1 & 2 & 3 & 4 \\
\hline 5. Mouthrinses & 1 & 2 & 3 & 4 \\
\hline 6. Sugar-free chewing gum & 1 & 2 & 3 & 4 \\
\hline
\end{tabular}

Section E (My Household)

Now to the final questions. People have different care arrangements for their children. The following questions help us understand childcare routines, and the section ends with a few routine questions on background information.

1. Who does your child live with? (Tick as many boxes that apply)

Mother

Mother and father

Father and stepmother

Other relatives

Other $\square$ Father

$\square$ Mother and stepfather

$\square$ - Grandparents

$\square$ please specify

$\square$ s please specify

2. How many children are living in your house now?

3. Is this your first child, second child etc.?

4. What is your gender? Male $\square \cdot \quad$ Female 
ORAL HEALTH QUESTIONNAIRE

5. What is your age? $\quad 18-20 \quad \square_{1} \quad 21-30 \quad \square_{2} \quad 31-40 \quad \square_{3} \quad$ over $40 \quad \square_{4}$

6. What is the age of your child?
What is your marital status?
Married
口. Single
Divorced / separated?
$\square$ Widowed
$\square$

8. What is your occupation?

9. What is your annual household income?

$\begin{array}{llll}<\$ 20,000 & \square_{1} & \$ 20,000-\$ 39,000 & \square_{2} \\ \$ 40,000-\$ 69,000 & \square_{3} & \$ 70,000+ & \square_{4}\end{array}$

10. What ethnic group do you identify with?

African American

$\square$

Afro Caribbean (not Haitian)

Haitian

$\square_{3}$

African

$\square$ please specify

Other

$\square$ s please specify

11. What is the highest level of education completed by the child's mother?

Less than High School

$\square$ High school

Some College

$\square$ Bachelors

$\square_{4}$

Graduate Degree

$\square$

Other

$\square$ 6 please specify

12. What is the highest level of education completed by the child's father?

Less than High School

$\square$ High school

$\square_{2}$

Some College

$\square$ Bachelors

Graduate Degree

$\square$

Other

$\square$ 6 please specify

12 
ORAL HEALTH QUESTIONNAIRE

Part II of this questionnaire will help to give us a more in depth understanding of your child's diet and nutrition, which is one of the behaviors that can help to prevent caries.

1. How would you describe your child's appetite?

Good $\square$

Fair $\square_{2}$

Poor $\square$

2. How many days does your family eat meals together per week?

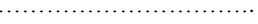

3. How would you describe mealtimes with your child?

Always pleasant

Usually pleasant

Sometimes pleasant $\square$

Never pleasant

$\square$

4. How many meals does your child eat per day?

..........................

How many snacks?

.............................

5. Which of these foods did your child eat or drink last week? (Check all that apply.)

Grains

Bread $\square_{1} \quad$ Noodles/pasta/rice $\square$ s

Rolls $\square_{2} \quad$ Tortillas

Bagels $\square_{3} \quad$ Crackers

Muffins $\square_{4} \quad$ Cereal/grits

Other grains: 
ORAL HEALTH QUESTIONNAIRE

\begin{tabular}{|c|c|c|}
\hline Fruits & & \\
\hline Apples/juice & $\square$ & Bananas \\
\hline Oranges/juice & $\square_{2}$ & Pears \\
\hline Grapefruit/juice & $\square_{3}$ & Melon \\
\hline Grapes/juice & $\square_{4}$ & Peaches \\
\hline
\end{tabular}

Other fruits/juice: ............................

Milk and Other Dairy Products

Whole milk $\square$. $\quad$ Yogurt $\square$.

Reduced-fat (2\%) milk $\square_{2} \quad$ Cheese $\quad \square 6$

Low-fat (1\%) milk $\square_{3} \quad$ Ice cream $\quad \square$ 7

Fat-free (skim) milk $\quad \square_{4} \quad$ Flavored milk $\square_{8}$

Other milk and dairy products: ........................

Meat and Meat Alternatives

$\begin{array}{llll}\text { Beef/hamburger } & \square_{1} & \text { Sausage/bacon } & \square_{7} \\ \text { Pork } & \square_{2} & \text { Peanut butter/nuts } & \square_{8} \\ \text { Chicken } & \square_{3} & \text { Eggs } & \square_{9} \\ \text { Turkey } & \square_{4} & \text { Dried beans } & \square_{10} \\ \text { Fish } & \square_{5} & \text { Tofu } & \square_{11} \\ \text { Cold cuts } & \square_{6} & & \end{array}$

Cold cuts

Other meat and meat alternatives: .....................

Vegetables

Corn $\quad \square_{1} \quad$ Greens (collard, spinach) $\square_{6}$

Peas $\square_{2} \quad$ Green salad $\quad \square 7$

Potatoes $\square_{3} \quad$ Broccoli $\quad \square_{8}$

French fries $\square_{4} \quad$ Green beans $\square$ 9

Tomatoes $\square 5 \quad$ Carrots $\quad \square_{10}$

Other vegetables: ........................ 
ORAL HEALTH QUESTIONNAIRE

\begin{tabular}{llll}
\multicolumn{2}{l}{ Fats and Sweets } & & \\
Cake/cupcakes & $\square_{1}$ & Doughnuts & $\square_{5}$ \\
Pie & $\square_{2}$ & Candy & $\square_{6}$ \\
Cookies & $\square_{3}$ & Fruit-flavored drinks & $\square_{7}$ \\
Chips & $\square_{4}$ & Soft drinks & $\square_{8}$
\end{tabular}

Other fats and sweets: .........................

6. If your child is 5 years old or younger, does he or she eat any of these foods? (Check all that apply.)

$\begin{array}{llll}\text { Hot dogs } & \square_{1} & \text { Popcorn } & \square_{6} \\ \text { Pretzels and chips } & \square_{2} & \text { Marshmallows } & \square_{7} \\ \text { Raw celery or carrots } & \square_{3} & \text { Round or hard candy } & \square_{8} \\ \text { Nuts and seeds } & \square_{4} & \text { Raisins } & \square_{9} \\ \text { Peanut butter } & \square & \text { Whole grapes } & \square_{10}\end{array}$

7. How much juice does your child drink per day? How much sweetened beverage (for example, fruit punch, and soft drinks) does your child drink per day?

8. Does your child take a bottle to bed at night or carry a bottle around during the day?

Yes $\square$. No

9. What is the source of the water your child drinks? Sources include public, well, commercially bottled, and home system-processed water.

10. Do you have a working stove, oven, and refrigerator where you live?

Yes $\square$. No $\square$

11. Were there any days last month when your family didn't have enough food to eat or enough money to buy food?

Yes $\square$. No $\square$ 
ORAL HEALTH QUESTIONNAIRE

12. Did you participate in physical activity (for example, walking or riding a bike) in the past week? If yes, on how many days and for how long?

Yes $\square_{1} \quad$ No $\square_{2}$

13. Does your child spend more than 2 hours per day watching television and videotapes or playing computer games? If yes, how many hours per day?

Yes $\square_{1} \quad$ No $\square_{2}$

14. What concerns or questions do you have about feeding your child?

Thank you very much for your help. 


\section{Appendix C}

\section{Correspondences}

\section{단묘 FLORIDA \\ INTERNATIONAL UNIVERSITY}

Dr. Mary Shaw

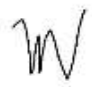

March 15, 2016

"Parental Attitudes, Beliefs, and Behaviors About Caries Prevention

Among Their Black Preschool Children"

The

Institutional Review Board of Florida International University has your study for the use of human subjects via the

process. Your

study was found to be in compliance with this institution's Federal Wide Assurance (00000060).
IRB-16-0082
$03 / 08 / 16$
104350
IRB Expiration Date: $03 / 08 / 17$

As a requirement of IRB Approval you are required to:

Submit an IRB Amendment Form for all proposed

Receive annual review and re-approval of your study prior to your IRB expiration date.

Submit the IRB Renewal Form at least 30 days in advance of the study's expiration date. or discontinued.

Special Conditions: N/A

For further information, you may visit the IRB website at http://research.fiu.edu/irb.

MMV/em 


\title{
FIU FIU
}

\author{
ROBERT STBMPEL CoLLEGE OF PUSLIC HEATH AND SocLAL WorK \\ DEPARTMENT OF HEALTH PROMOTION \& DISEASE PREVENTION \\ 11200 S.W. 8« Street, AHC $2579 B$, Miami, FL 33199 Tel: 305.348.7789 Fax: 305.348 .4901 cphsw.fiu.edu \\ Florida Intemational University is an Equal Opportunity/Access Emplojer and Institution TDD via PRS 1-800-955-8771
}

May 8, 2015

Copyright Officer

National Maternal and Child Oral Health Resource Center

2115 Wisconsin Avenue NW, Suite 601

Washington, DC 20057

Mailing Address: Box

571272 Washington, DC

20057-1272

1 Attention Copyright Officer:

I am requesting permission to reprint/reproduce The Nutrition Questionnaire for Children from pages 2 and 3 of the brightfutures.org Infant, Children, and Adolescent Nutrition Questionnaires. I would like to include it in my dissertation proposal tentatively titled, "Parental Attitudes, Beliefs, and Behaviors about Caries Prevention among Black Preschool Children".

I will include in my dissertation to be published by Florida International University a credit line specified by the National Maternal and Child Oral Health Resource Center (OHRC). I will state in my dissertation proposal that readers are to receive permission for duplication of any cited materials from OHRC. FIU is a minority-serving nonprofit organization.

The approximate print run will be 350 , and the publication will be distributed free of charge by myself, primary researcher, and research assistants to participating parents of preschool children for dissertation research. I am enclosing copies of the original item which will be the version used in my dissertation proposal. If you could respond by May, $31^{\text {st }}, 2015$, that would help us stay on schedule. If you have any questions, please contact me at 305-297-3183 or rclar057@fiu.edu, or my advisor, Dr. Mary Shaw at 305-348-7512 or at marshaw@fiu.edu.

Thank you.

Sincerely,

Rachel Clarke 
Please sign or stamp here to indicate approval/permission to use material(s) mentioned above:

Permission is granted for use of The Nutrition Questionnaire for Children from pages 2 and 3 of the brightfutures.org Infant, Children, and Adolescent Nutrition Questionnaires as described above.

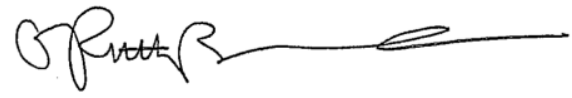

* Be sure to mention if your organization is a nonprofit, since publishers often waive or reduce permission fees for materials used for nonprofit purposes. Also be sure to mention any plans to put the publication on the Web or on CD-ROM, because this kind of use (i.e., electronic or multimedia use) requires an additionalor separate granting of permission. 


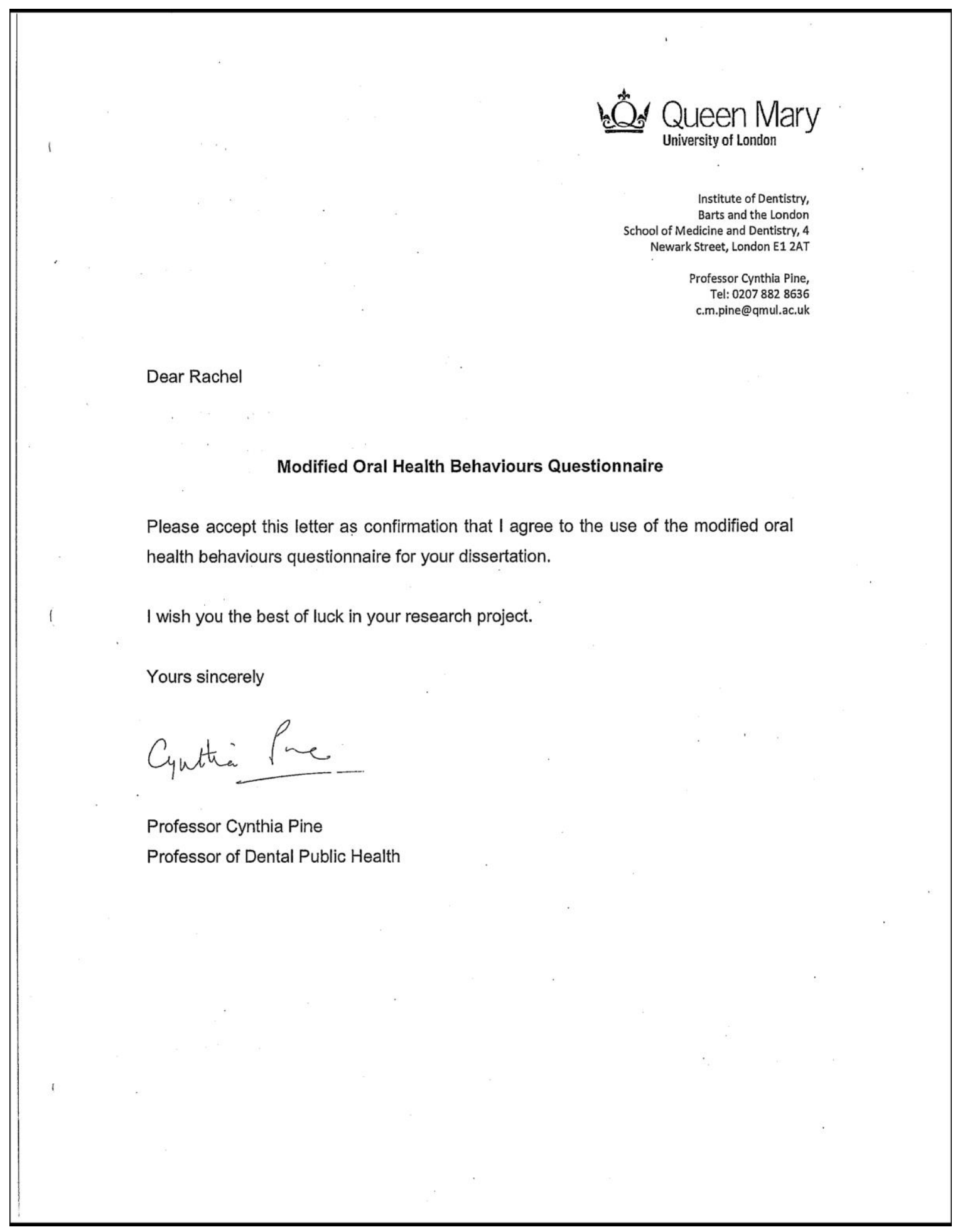


9/15/2015

Dear Dr. Pine,

I am a doctoral student at Florida Intermational University Robert Stempel College of Public Health and Social Work (RSCPHSW) in the Public Health program. I am developing my dissertation proposal te

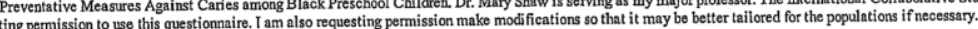

I have attached a one page abstract draft of my dissertation proposal. A copy of the final instrument will be sent to you for approval before use. A copy of the study findings and/or publications resulting will I

Rachei Clarke

Doctoral Student

Health Promotion \& Disease Preventio

-

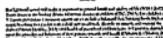

prop onc page.docx

Rachel Clarke <rclar057@fiu.edu>

to c.m.pine, p.m.adair

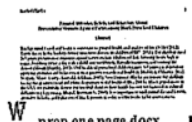

W prop one pagedocx

Cynthia Pine <c.m.pine@qmul.ac.uk>

to Pauline, Girvan, me

Dear Rachel

I am dellghted that our Instrument will assist your research in this way. I am copying in both $\mathrm{Dr}$ Adair and $\mathrm{Dr}$ Burnside for their information.

We continue to use thls instrument and will be interested in seeing developments/modifications. By copy, I will ask Dr Burnside to send you the original one that we developed.

With best wishes for your research,

Cynthia

Professor Cynthla PIne CBE

Sent from my iPhone 
Permission to use Theory of Planned Behavior

Inbox $x$

Rachel Clarke <rclar057@fiu.edu>

Feb 3

to aizen

Dear Dr. Aizen,

My name is Rachel Clarke, and I am a PhD Candidate in the Department of Health Promotion and Disease Prevention at Florida International University. I am in the process of doing my dissertation research under the guidance of Dr. Mary Shaw.

I am requesting permission to use the Theory of Planned Behavior for my dissertation entitled "Parental Attitudes, Beliefs, and Behaviors about Caries Prevention among Black Preschool Children." I look forward to hearing from you soon.

Thank you.

Respectfully,

Rachel Clarke, CHES

$\mathrm{PhD}$ Candidate

Florida International University

Dept. of Health Promotion \& Disease Prevention

aizen

Feb 19

to me

Dear Ms. Clarke,

The theory of planned behavior is in the public domain. No permission is needed to use the theory in research, to construct a TPB questionnaire, or to include an ORIGINAL drawing of the model in a thesis, dissertation, presentation, poster, article, or book. If you would like to reproduce a published drawing of the model, you need to get permission from the publisher who holds the copyright. You may use the drawing on my website (http://people.umass.edu/aizen/tpb.diag.html) for non-commercial purposes, including publication in a journal article, so long as you retain the copyright notice.

Best regards,

Icek Ajzen

Professor Emeritus

University of Massachusetts - Amherst

http://www.people.umass.edu/aizen 


\section{RACHEL CLARKE, CHES}

2015-2017

2016-Present

2015-Present

2013-2015

2010
Doctoral Candidate

Florida International University

Miami, Florida

Researcher, Oral Health Research Section

FIU Neighborhood Help

Florida International University

Miami, FL

Graduate Assistant

Dept. Health Promotion and Disease Prevention

Robert Stempel College of Public Health \& Social

Work

Florida International University

Miami, FL

Starr Scholarship Recipient

Florida International University

Miami, FL

B.S., Chemistry

Howard University

Washington, DC

PUBLICATIONS AND PRESENTATIONS

Clarke, R. \& Shaw, M. (2017). Parental oral health perceptions about Black preschool children's oral health behaviors. Poster submitted to the $145^{\text {th }}$ Annual Meeting of the American Public Health Association, Atlanta, GA.

Clarke, R. \& Shaw, M. (2017). Oral health attitudes and beliefs among Black preschool parents: Implications for children's oral health behaviors. Pediatric Dentistry. (Manuscript in progress)

Clarke, R. \& Shaw, M. (2017). Parental attitudes, beliefs and behaviors about caries prevention among Black preschool children. Roundtable presentation to be made at the SOPHE $68^{\text {th }}$ Annual Conference, Denver, CO.

Clarke, R., Bhatt, C., Bastida, E. (2016). Oral health of older Mexican Americans: A longitudinal study. Paper presented at the $144^{\text {th }}$ Annual Meeting of American Public Health Association, Denver, CO. 
Madhivanan, P., Pierre-Victor, D., Soumyadeem, M., Prasad, B., Powell, B., JeanBaptiste, N., Clarke, R., Avent, T., Krupp, K. (2016). Human Papillomavirus Vaccination and sexual disinhibition in females. A systematic review. American Journal of Preventive Medicine, 51(3), 373-383.

Madhivanan, P., Pierre Victor, D., Clarke, R., Jean Baptiste, N., Bahelah, R., Mukherjee, S., Anderson, C., Avent, T., Stephens, D. (2015). Does HPV vaccination lead to risky sexual behaviors? A systematic review. Paper presented at $30^{\text {th }}$ International Papillomavirus Conference, Lisbon, Portugal.

Pierre-Victor, D., Clarke, R., Antoine, R., \& Madhivanan, P. (2014). Human Papillomavirus vaccine perception and factors influencing vaccine decision among Haitian female college students. Poster presented at the $142^{\text {nd }}$ Annual Meeting of the American Public Health Association, New Orleans, LA.

Trevino, R., Shaw-Ridley, M., \& Baez, R. (2014). Bienestar/NEEMA health program: Health curriculum teacher's guide. San Antonio, Texas: Social and Health Research Center. (Clarke, R., Oral Health Contributing author).

Bachmann, B. O., McNees, R., Melancon, B. J., Ghidu, V. P., Clarke, R., Crews, B., ...Sulikwoski, G. A. (2010). Light- induced isomerization of Apoptolidin A leads to inversion of C2-C3 double bond geometry. Organic Letters, 12(13), 29442947.

Clarke, R., McNees, R., Romaine, I., Wang, J., Bachmann, B., \& Sulikowski, G. (2009). New Apoptolidin derivatives: possible new apoptosis inducers. Poster presented at Vanderbilt NSF Summer internship closing seminar, Nashville, TN. 